Psychoactive substance use and other driver-related risk factors of road traffic injury: An epidemiological study of associations, trends, and crash characteristics

Thesis for the degree of Philosophiae Doctor (PhD)

Anja Valen

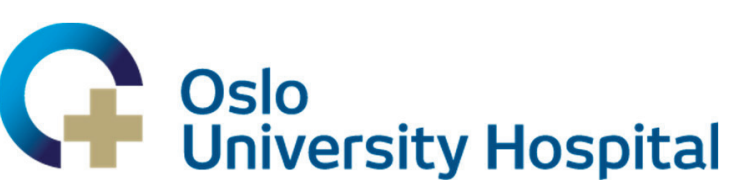

Department of Forensic Sciences

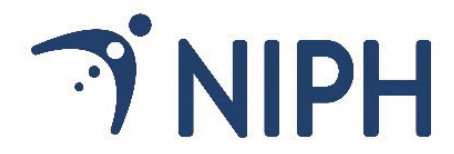

Norwegian Institute of Public Health

Division of Forensic Sciences

\title{
$\mathrm{UiO}$ : University of Oslo
}

Faculty of Medicine 
(C) Anja Valen, 2021

Series of dissertations submitted to the Faculty of Medicine, University of Oslo

\section{ISBN 978-82-8377-819-9}

All rights reserved. No part of this publication may be reproduced or transmitted, in any form or by any means, without permission.

Cover: Hanne Baadsgaard Utigard.

Print production: Reprosentralen, University of Oslo. 


\section{Table of contents}

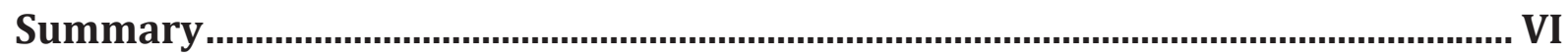

Acknowledgements............................................................................................. VII

Acronyms, abbreviations, and terminology …..........................................................

List of papers ..................................................................................................

Overview of this thesis............................................................................................ XIII

1 Introduction .......................................................................................................... 1

1.1 Risk factors of road traffic injury …....................................................................... 2

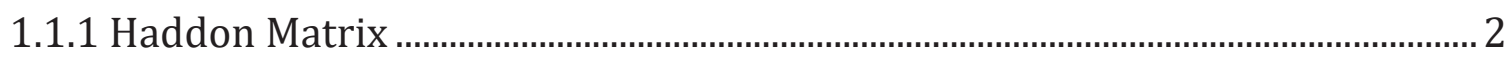

1.1.2 Human risk factors .......................................................................................... 4

1.1.3 Vehicle-related risk factors................................................................................. 8

1.1.4 Environmental risk factors ................................................................................

1.1.5 Aspects regarding traffic injury prevention ………………………………….... 11

1.2. Substances that may increase the risk of a road traffic crash................................ 13

1.2.1 Alcohol...................................................................................................................... 14

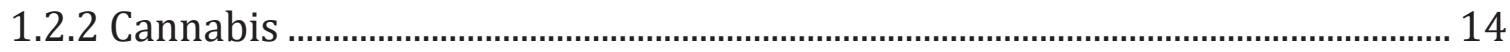

1.2.3 Stimulants .............................................................................................................. 15

1.2.4 Medicinal drugs ....................................................................................................... 17

1.2.5 Combined substance use .......................................................................................... 19

1.3 Global trends in fatal road traffic crashes .................................................................. 21

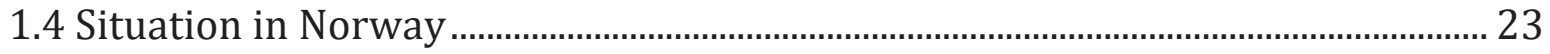

1.4.1 Trends in road traffic injuries and deaths......................................................... 23

1.4.2 Important changes in road safety policies …………………………………… 25

1.4.3 DUI laws and enforcement........................................................................................ 26

1.5 Current knowledge gaps............................................................................................ 29

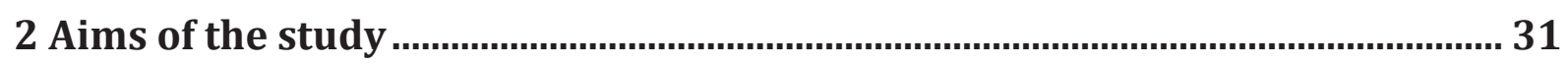

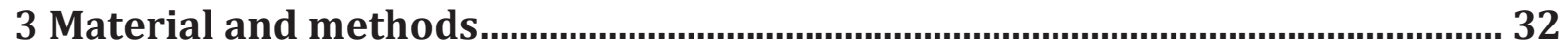

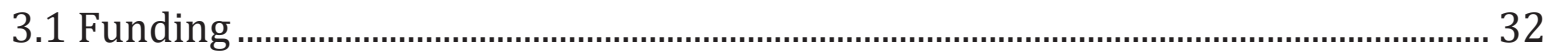

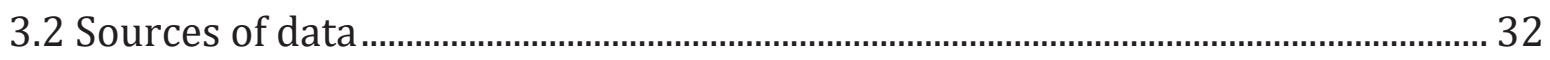

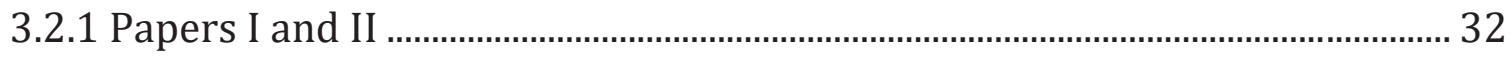

3.2.2 Papers III and IV ........................................................................................................... 32 
3.3 Ethical and legal aspects ........................................................................................ 33

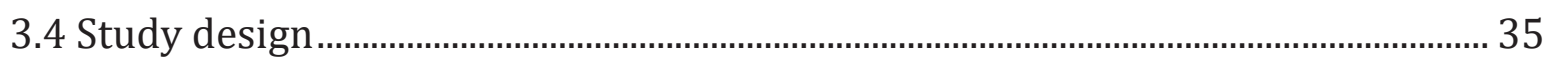

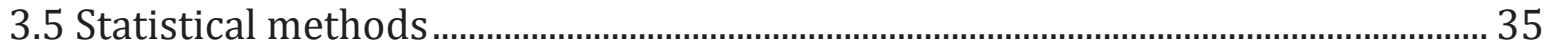

3.5.1 Descriptive and inferential statistics.................................................................. 35

3.5.2 Statistical tests .......................................................................................................... 36

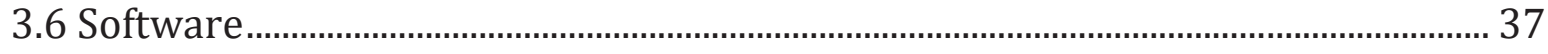

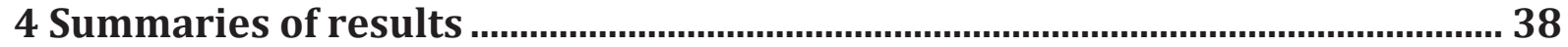

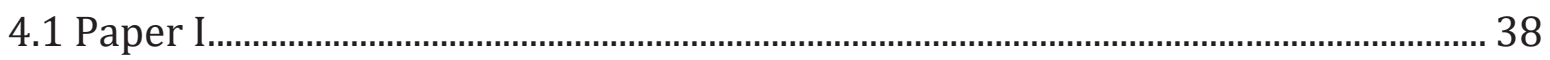

4.2 Paper II................................................................................................................... 40

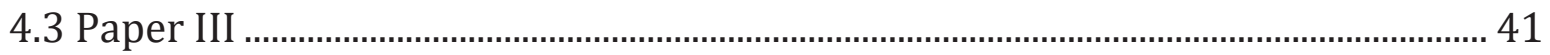

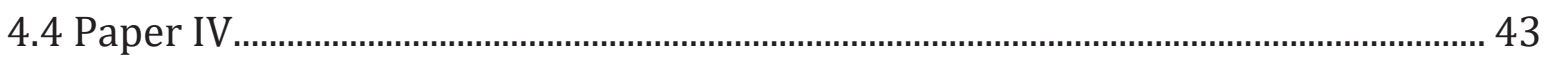

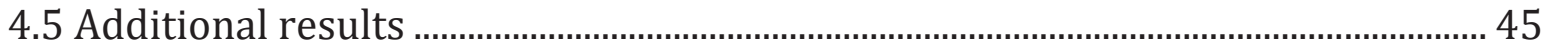

4.5.1 Alcohol results including drivers suspected of only alcohol use .................... 45

4.5.2 THC concentrations …………………....................................................................... 47

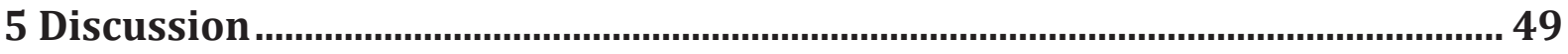

5.1 Trends in psychoactive substance use ......................................................................... 49

5.1.1 Prevalence among drivers arrested or killed...................................................... 49

5.1.2 Trends among arrested drivers ........................................................................... 52

5.1.3 Trends among killed drivers .................................................................................. 60

5.2 Driving errors and characteristics of impaired versus sober killed drivers....... 62

5.2.1 Risk factors associated with drug/alcohol impairment..................................... 62

5.2.2 Risk factors not associated with drug/alcohol impairment ..............................65

5.2.3 Crash characteristics .................................................................................................. 66

5.3 Possible reasons for declining road death numbers................................................... 67

5.3.1 Trends in crash characteristics ............................................................................... 67

5.3.2 Trends in unsafe driving behaviours.................................................................. 68

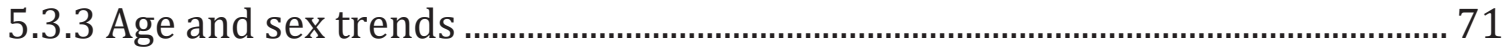

5.4 Methodological considerations................................................................................... 73

5.4.1 Study design ........................................................................................................ 74

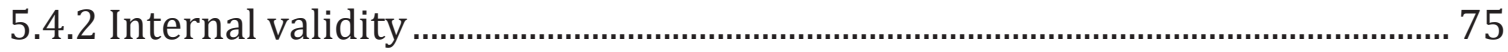

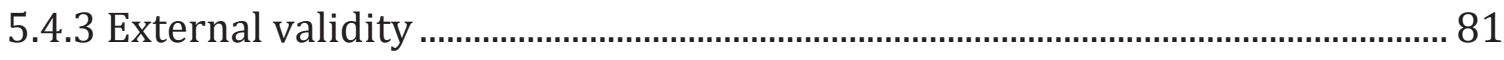

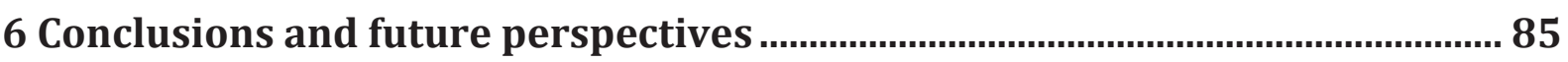




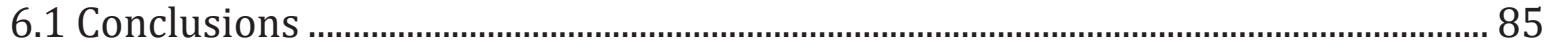

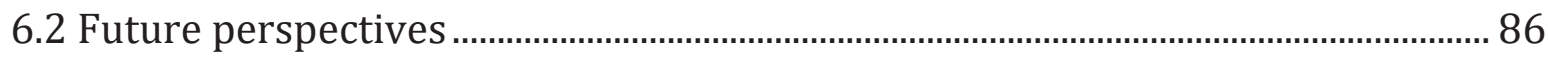

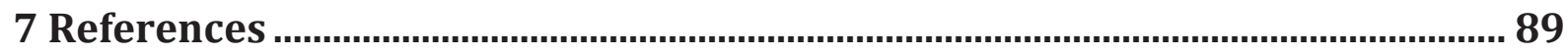

8 Appendices 


\section{Summary}

Driving a motor vehicle is a complex task, and the driver's consumption of alcohol or psychoactive drugs will often negatively influence the driver's reaction time, attention, and other cognitive and psychomotor functions, increasing the risk of a road traffic crash. Other commonly reported risk factors of road traffic crashes are high speed, drowsy driving, and unsafe road infrastructure. The risk factors contributing to injury severity or death include unsafe vehicles, inadequate postcrash care, and non-use of motorcycle helmets or seatbelts.

According to the World Health Organization, about 1.35 million people die each year as a result of road traffic crashes, whereas about 50 million suffer from non-fatal injuries. Vehicle safety features, infrastructure, and the quality of medicinal expertise vary across countries, as well as the prevalence of unsafe driving behaviours, including driving whilst under the influence of alcohol or psychoactive drugs. The most effective intervention to lower the number of severe road traffic crashes might therefore differ across countries. In Norway, the number of fatal road traffic crashes has declined in the past decades; however, the vision is zero lives lost.

The first aim of the work described in this thesis was to investigate retrospectively the trends in psychoactive substance use among motor vehicle drivers (including riders) arrested under suspicion of driving under the influence, and among drivers and riders fatally injured in road traffic crashes. The second aim was to include data from crash investigations records on fatally injured drivers and riders, to examine associations between impairment by alcohol or drugs and other significant driverrelated risk factors of traffic injury. The third aim was to investigate fatal road traffic crashes for possible trends in crash characteristics and unsafe driving behaviours.

We investigated alcohol and drug use among drivers who had been arrested by the police for suspicion of driving under the influence; we used national forensic toxicology data collected in Norway between 1990 and 2015. We also investigated alcohol and drug use among drivers and riders who were fatally injured in road 
traffic crashes, in addition to other driver-related unsafe behaviours and crash characteristics, from 2005 to 2015 using national forensic toxicology data combined with national data from crash investigations.

In both drivers arrested by the police for suspicion of driving under the influence and drivers fatally injured, the prevalence of alcohol consumption declined during the study periods. The prevalence of amphetamine consumption increased among the oldest arrested drivers, that of cannabis use increased among all age groups and the most among the youngest drivers, and that of medicinal drug use declined slightly. Among fatally injured drivers, trends in drug use were not found to be statistically significant. Drug or alcohol concentrations above limits for graded sanctions corresponding to a blood alcohol concentration of $0.5 \mathrm{~g} / \mathrm{kg}$ were found to be associated with non-use of a seatbelt, speeding prior to the crash, and the lack of a valid driving licence. Alcohol was associated with all risk factors, whereas some differences were found across other drug types. A substantial proportion of all drivers fatally injured in a road traffic crash, including those sober, had not used a seatbelt or had been speeding inappropriately, but the proportions showed a decline towards 2015. The prevalence of vehicle safety installations increased significantly during the study period. The distribution of collision type did not change; head-on collisions comprised 54\% of the fatal crashes both in 2005-2010 and 2011-2015. Crash characteristics among motorcycle and moped riders deviated slightly from those found among car and van drivers. Among riders, a blood alcohol concentration of $0.5 \mathrm{~g} / \mathrm{kg}$ or more was found to be associated with non-use of a helmet and lack of a valid driving licence, but not with speeding.

The increasing number of young drivers arrested for driving under the influence of cannabis is concerning and the situation should be watched closely. Decreasing proportions of alcohol findings and of speeding and non-use of seatbelts, and increasing proportions of vehicle safety installations, have accompanied the decreasing number of deaths from road traffic crashes in Norway. Preventive measures seem to have had the best effect on young male drivers; death rates did not decline accordingly among female or older drivers. 


\section{Acknowledgements}

This project would not have been possible without the help and assistance from many others that I hereby wish to thank.

I would like to thank Vigdis Vindenes for hiring me for this PhD project, for providing everything needed in the office, in addition to paying for my attendance at the most relevant conference, which was held in Brazil. I am grateful for the encouragement to present my early results at that conference. Visiting parts of Brazil was a nice break from the everyday $\mathrm{PhD}$ life as well. I am also grateful to my second supervisor Stig Tore Bogstrand for providing the most spot-on critical comments to article drafts, and for a number of times taking initiative to both learning and social activities for the research group members. I am indebted to my principal supervisor Hallvard Gjerde for always being available for a chat or discussion about plans, papers, and everything related to this project, and for all the help, comments, and input to the articles. I count myself lucky to be able to write articles with you. Thank you for the patience during the times I tried to challenge your advice despite knowing that you are one of the most experienced within this research field. I am also grateful to my co-authors Joachim Frost, Anders Holtan, and Magnus Larsson for their valuable feedback on the articles and positive attitude in general during the process of getting them published.

I would like to thank Rita Irene Henriksen at the Norwegian Public Roads Administration for inviting me to join in multidisciplinary crash investigation meetings; the learning experience gave me a strong understanding of the limitations and strengths of the crash data I obtained for analysis. Furthermore, I am grateful to Dag Helge Strand and Thomas Berg for initially introducing me to the field of toxicological analysis. Their in-depth knowledge combined with enthusiasm for improvements in the laboratory proved an amazing source of inspiration. In addition, I am grateful to the many others who contributed in the laboratory to produce high-quality data worth analysing, which ultimately led to this $\mathrm{PhD}$ project financed by the Department of Forensic Sciences. 
Last but not the least, my deepest gratitude goes to Trond Valen for patiently supporting from home this almost never-ending PhD project. You were perfectly right about it not being the best to combine $\mathrm{PhD}$ work with an extensive building project and a baby. In addition, several months on the waiting list for kindergarten tipped the schedule even further. I am forever grateful to my extended family members for their help during this time, especially my parents, grandma, and brothers.

Ambition is the path to success.

Persistence is the vehicle you arrive in.

Bill Bradley

... often helped by some love and support on the way.

Anja Valen 


\section{Acronyms, abbreviations, and terminology}

6-MAM: 6-monoacetylmorphine (metabolite of heroin)

ABS: Anti-lock braking system

ADHD: Attention deficit hyperactivity disorder

ANPR: Automatic number plate recognition

BAC: Blood alcohol concentration (gram alcohol per kg blood or per litre blood [\%o $\mathrm{m} / \mathrm{m}])$

CDB: Cannabidiol (a non-intoxicating component in cannabis)

CI: Confidence interval

Driver: Driver or rider of a motor vehicle

DUI: Driving under the influence

ESC: Electronic stability control

EU: European Union

Forgiving road systems: Roads and roadsides that are designed and built in such a way as to minimise the risk of injury in cases when the driver accidentally is about to drive off the road

MDMA: 3,4-methylenedioxymethamphetamine (also called ecstasy)

Motor vehicle: A motorised carriage used on roads for the transportation of passengers, property, or cargo (e.g. motorcycles, cars, trucks, and buses)

OECD: Organization for Economic Co-operation and Development

OR: Odds ratio

REC: Regional Committees for Medical and Health Research Ethics

Road fatality: Death immediately or within 30 days after a road traffic crash, excluding confirmed suicides

Road traffic injury: Fatal or non-fatal injuries incurred from a road traffic crash Road traffic crash: Collision with another vehicle or object Speeding: Exceeding the posted speed limits or driving faster than the prevailing conditions allow

THC: Tetrahydrocannabinol (the main psychoactive component in cannabis)

UK: United Kingdom

US: United States of America 
WHO: World Health Organization

Z-hypnotics: The sleeping agents zolpidem and zopiclone, which are the z-hypnotics marketed in Norway

The terms 'drug driving' and 'drink driving' are used in this thesis to refer to drivers who are driving relatively shortly after use of psychoactive drugs or alcohol, respectively, implying that the substance could be detected if the drivers' blood is collected and analysed. When the police suspect 'drug driving' or 'drink driving' according to the Road Traffic Act, the term 'suspected of driving under the influence (DUI)' is used; when a drug or alcohol concentration above legal limits defined in the Road Traffic Act is confirmed, the term 'DUI offender' is used. All these terms include, but are not limited to, the cases when the driver's driving skills are impaired by the substances used, referred to as 'drug-impaired' or 'alcohol-impaired' driving.

Throughout the text, 'drivers' include motor vehicle drivers and riders, if not specified otherwise. The terms 'driving under the influence' and 'driver-related risk factors' include both drivers and riders. 


\section{List of papers}

This thesis is based on the following four published papers; they are referred to in the text by their roman numerals. The full-text versions of Papers I-IV, in addition to the supplementary material, can be found in the Appendices at the end of this thesis.

Paper I:

Valen A, Bogstrand ST, Vindenes V, Gjerde H. Toxicological findings in suspected drug-impaired drivers in Norway - Trends during 1990-2015. Forensic Science International 2017;280:15-24.

Paper II:

Valen A, Bogstrand ST, Vindenes V, Gjerde H. Increasing use of cannabis among arrested drivers in Norway. Traffic Injury Prevention 2017;18(8):801-6.

Paper III:

Valen A, Bogstrand ST, Vindenes V, Frost J, Larsson M, Holtan A, Gjerde H. Driverrelated risk factors for fatal road traffic crashes associated with alcohol or drug impairment. Accident Analysis and Prevention 2019;131:191-199.

Paper IV:

Valen A, Bogstrand ST, Vindenes V, Frost J, Larsson M, Holtan A, Gjerde H. Fatally injured drivers in Norway 2005-2015 - Trends in substance use and crash characteristics. Traffic Injury Prevention 2019;20(5):460-466. 


\section{Overview of this thesis}

The work presented in this thesis is based on data recorded in national forensic databases and crash registers; the results include trends in and characteristics of psychoactive substance use and other significant unsafe driving behaviours recorded among drivers (including riders) either arrested under suspicion of driving under the influence or fatally injured in road traffic crashes in Norway. Drivers' knowledge, perceived risks, or attitudes to risk-taking behaviours or driving after using alcohol or drugs have not been studied, although these factors are important to elucidating the reasons for road traffic crash involvement.

Chapter 1 introduces the factors related to the driver, vehicle, and environment that may increase the risk for involvement in a road traffic crash or severe injury when involved in a crash, with particular focus on driverrelated risk factors, including the use of alcohol and psychoactive drugs. Global trends in road fatalities are presented, followed by a description of local trends in Norway. This chapter ends with a description of knowledge gaps in the literature, regarding the trends in and characteristics of unsafe driving, including driving under the influence of drugs or alcohol, the main focus of this study.

Chapter 2 presents the general and specific aims of this study.

Chapter 3 summarises the methods used to collect, link, and analyse register data. This chapter includes a section on the relevant ethical and legal aspects.

Chapter 4 presents the main results of the study, and how each individual paper relates to the study aims. In addition, information relevant to the study aims that was not presented in the papers is included here as additional results. 
Chapter 5 includes a discussion of the main results from the papers: how they relate to one another and how they as a whole elucidate the study aims. The new knowledge found is compared with existing knowledge and literature. This chapter ends with a critical evaluation of the methods used in the study and the validity of the results.

Chapter 6 summarises the main conclusions from this study. In addition, future perspectives and suggested actions are presented and briefly discussed.

Chapter 7 lists all references cited in this thesis.

Chapter 8 includes the appendices Papers I-IV, supplementary material, and an errata list related to the papers. 


\section{Introduction}

Driving a motor vehicle is a complex task, and the driver's use of alcohol or psychoactive drugs will often negatively influence their reaction time, attention, and other cognitive and psychomotor functions, increasing the risk of a road traffic crash. Other commonly reported risk factors of road traffic crashes are high speed, distracted or drowsy/fatigued driving, and unsafe road infrastructure. The risk factors contributing to injury severity or death include unsafe vehicles, inadequate post-crash care, and non-use of motorcycle helmets or seatbelts (1). Drug and drink driving and the other mentioned risk factors have been of concern to traffic safety in decades but continue to cause or contribute to road fatalities worldwide.

Several high-income countries have implemented strategic plans and road safety interventions in the past decades to increase traffic safety (1). The European Union (EU) has developed road safety action programmes, e.g. for the periods 2001-2010 and 2011-2020, measures have included concrete actions and specific targets, with member states being encouraged to participate (2). In Norway, a strategy called Vision Zero was implemented in 2001, based on a Swedish initiative in 1997, aiming at working towards a future in which no-one will be killed or seriously injured in road traffic crashes (3). The Vision Zero strategy was followed by an action plan for enhanced road safety (4). Decreasing numbers of fatal road traffic crashes have been reported in all EU countries in 2000-2015 (5), indicating that the preventive measures have been successful. Fatality numbers have also decreased in Norway and other non-EU high-income countries, such as the United States of America (US), Canada, and Australia (5). Improvements in medical care and technology have most likely contributed to the declining fatality rates $(6,7)$. Whether or not the decreasing rates also are due to changes in driving behaviours/attitude is more difficult to determine; human factors remain the most common cause of road traffic crashes (6). 


\subsection{Risk factors of road traffic injury}

\subsubsection{Haddon Matrix}

William Haddon Jr. published a model, now known as the 'Haddon matrix', where the risk factors of motor vehicle traffic injury are categorised into human, vehicles/equipment, or environmental. These categories are further defined within the three crash phases of pre-crash, during crash, and post-crash (8). The pre-crash risk factors are those that, if prevented, will hinder the crashes from occurring; the during-crash risk factors are those that, if prevented, will decrease the injury severity among those involved in a crash; and the post-crash risk factors are those that, if prevented, will increase the chance of survival after involvement in a crash. The Haddon matrix has been useful for the understanding of the complexity of road traffic crashes, and is a handy tool when making strategies for reducing traffic injury (9). An example of such a matrix is given in Table 1. 


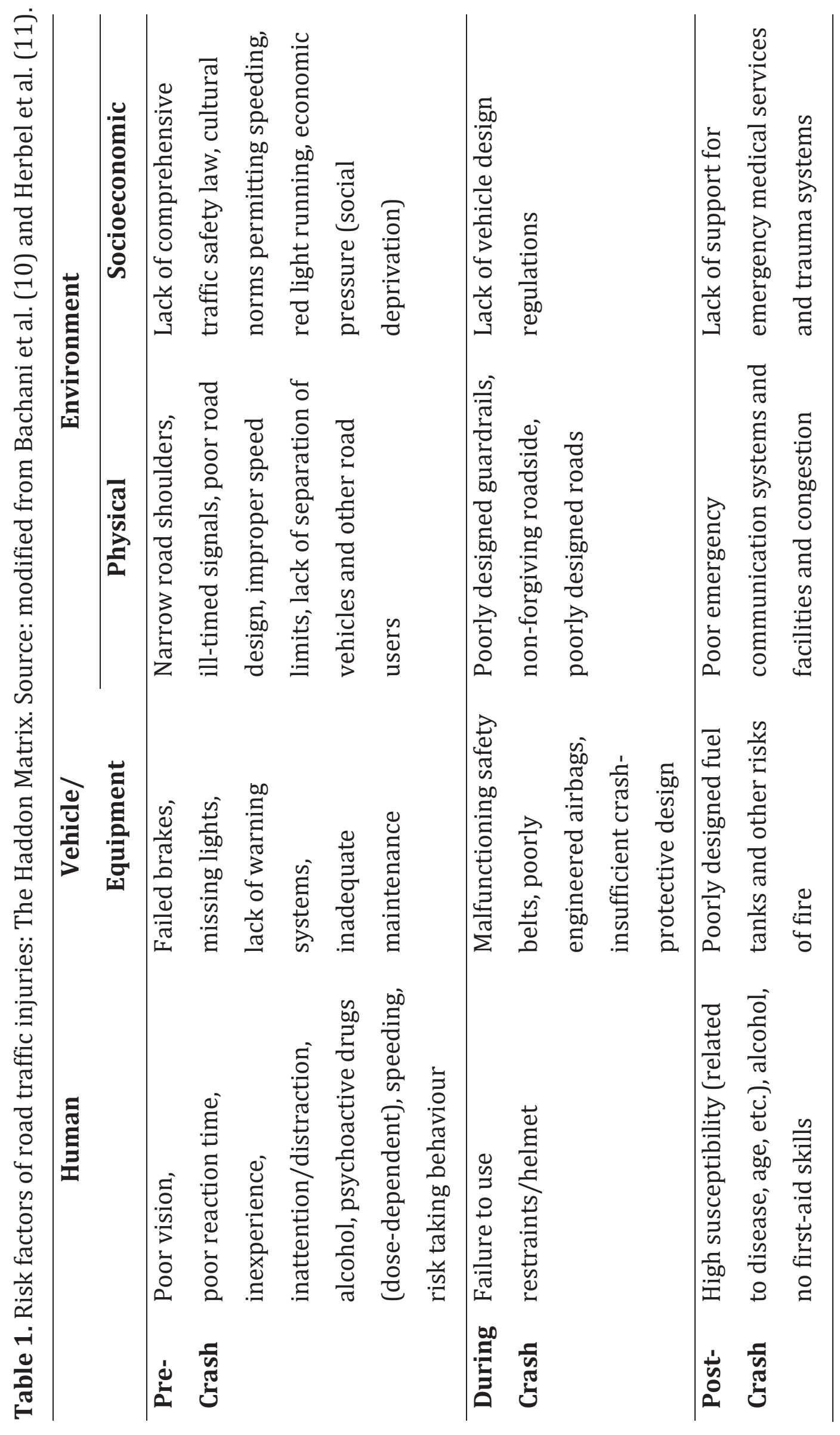




\subsubsection{Human risk factors}

A study by the National Highway Traffic Safety Administration in the US investigated pre-crash events and associated factors critical for the occurrence of 5,470 road traffic crashes, primarily based on data derived from police accident reports. They found the significant reason for the crashes to be the driver in $94 \%$ of the cases. The most prevalent factors were inattention, distractions, speeding, and wrong decisions (12). Another study using filmed pre-crash situations in 905 crashes leading to injury and property damage in the US revealed that driver-related factors, such as fatigue, impairment, errors, and distraction were present in $88 \%$ of the crashes; only $0.1 \%$ involved some form of vehicle failure (13). The described studies indicate that human risk factors are almost always significant contributing causes of road traffic crashes.

\section{Drug/alcohol-impaired driving}

Crash involvement owing to impairment by alcohol or drugs might be difficult to reveal when using filmed pre-crash situations and during post-crash investigation without analysing biological samples. Although not identified in the studies mentioned in the previous section, driving under the influence (DUI) of psychoactive drugs and alcohol pose a high risk of road traffic crash involvement (14). Indeed, the European Transport Safety Council has estimated that at least 5,120 deaths would have been prevented in the EU in 2016 if no drivers had been DUI of alcohol (15). Psychoactive drugs and alcohol reduce cognitive and psychomotor functions, and may reduce driving performance, depending on dose; they are included in the Haddon matrix as human pre-crash risk factors (Table 1). Alcohol may also increase injury severity. It has been associated with longer recovery time in hospital and more injuries after road traffic crash involvement, according to studies comparing impaired and sober drivers involved in similar crashes (16-18). Alcohol is therefore also a post-crash risk factor (Table 1). The negative effects of alcohol and psychoactive drugs on driving performance are explained in section 1.2.

In some cases, the reasons for DUI of alcohol or other psychoactive drugs can be traced to substance use problems, as explained by some Danish convicted drink 
drivers during interviews: When drunk, they do not think of consequences, and driving is a routine behaviour; hence, drink driving has become a routine behaviour (19). Indeed, previous epidemiological studies in Norway have found that a large proportion of drivers arrested for drink driving are heavy drinkers $(20,21)$. Norwegian studies have also revealed that recidivism is common among drivers arrested under suspicion of DUI of alcohol or drugs $(22,23)$. When including previous criminal record for other types of offences, $82 \%$ of the drivers arrested in Norway in 2009 for drink or drug driving had at least one previous criminal record; one-third of the records were related to crime for profit (24). Some of the convicted Danish drivers in the qualitative study did not consider their drinking problematic, rather normal in their environment, and believed that their driving performance is good after drinking (19). Whether the convicted drink drivers 'negotiate guilt and blame by either justifying their DUI (they were "in full control" and hence did not risk other people's lives) or excusing it (they had "lost control" over their alcohol and/or drug intake and therefore did not engage in DUI of their own free will)', might influence the risk of repeated drink driving after arrest (19).

DUI of alcohol or drugs could also be related to factors other than sub-culture or susceptibility to addiction. Examples are life-changing events, such as loss of job or divorce. In addition, people with a lower social position are more prone to drive after drinking. Examples of lower social position found in a Finnish study were a low level of education, unemployment, living alone, and being divorced; among young adolescents (15-24 years), low parental education and income predicted drink driving (25). Furthermore, mental disorders, including depressive, anxiety, and alcohol or drug use disorders, have been found to be more common among drivers arrested under suspicion of drug or drink driving, compared with the general Finnish population (26).

\section{Speeding}

Speeding is one of the most frequently reported significant pre-crash human risk factors of traffic injury. Speeding may be defined as travelling too fast for the conditions or in excess of the posted speed limits, including hazardous driving. High 
and inappropriate speed has been estimated to contribute to about $30 \%$ of road fatalities in high-income countries, and about $50 \%$ of road fatalities in low- and middle-income countries (27). High speed negatively influences both crash risk and crash outcome, and also reduces the time available to react to unexpected events (28).

The risk of being involved in a crash within rural $60 \mathrm{~km} / \mathrm{h}$ zones has been found to double or more for each increase of $5 \mathrm{~km} / \mathrm{h}$ of travelling speed above the speed limit, compared with when driving at $60 \mathrm{~km} / \mathrm{h}$ (1). Furthermore, even only a small increase in speed could result in a major increase in risk of injury in a hypothetical collision, because the energy involved in a collision varies with the square of the velocity (28), and the human body is vulnerable to forces released in a crash. In a meta-analysis, Elvik et al. (29) confirmed a power model proposed by Göran Nilsson, in which the relative change in the number of injured road users or crashes is a function of the relative change in the mean speed of traffic raised to an exponent that increases with the injury or crash severity. This means that reducing speed has an effect on all severity levels but especially on reducing fatal crashes.

Reducing high speed is especially important in populated areas and cities, where roads are shared between motor vehicles and vulnerable road users. Strong speed enforcement could be an effective measure for reducing mean speed. An alternative measure would be to design the roads and streets such that high speed is disfavoured. On highways, however, a forgiving road design might be a solution instead of reducing the driving speed. A forgiving road design includes such elements as wide road shoulders, warning rumble strips and physical separation from traffic in the opposite direction, and no dangerous roadside objects, all of which help prevent crashes or injury if a driver makes a mistake and drives out of the travel line (30). A drawback is the reported risk of more drivers driving above the relatively high speed limits on motorways if the road designs look/appear safe to the driver (31). Speed enforcement therefore seems relevant even on the safest motorways. Other factors influencing the driver's choice of speed could be surface quality, vehicle power, traffic density, and weather conditions (1). 


\section{Non-use of a seatbelt/helmet}

Failure to use a seatbelt or a helmet is the most commonly reported human duringcrash risk factor of severe injury or death (Table 1). Seatbelts have been found to be about $40 \%$ to $50 \%$ effective in preventing serious injuries and fatalities for front seat drivers and passengers involved in crashes, and about 25\% effective in preventing serious and fatal injuries for passengers in rear seats. An estimated 15,200 road deaths in the US were prevented in 2004 solely by seatbelt use, in crashes in which the vehicle occupants would otherwise have died (32). For crash-involved motorcyclists, use of a helmet has been found to reduce serious and fatal head injuries by $20 \%$ to $45 \%$ (1).

Use of seatbelts also reduces the risk of injury when driving at low speed. There is always a risk of being involved in a collision caused by other drivers, where the injury severity of the car occupants driving without a seatbelt will depend, to a large degree, on the speed of the other vehicle. In addition, when involved in even a minor crash, the driver or passenger not using a seatbelt could be severely injured by the airbag when/if it inflates $(33,34)$.

One of the reasons for the non-use of seatbelts might be that the car occupant has not fully understood the risks. When it comes to seatbelt use, only an estimated $88 \%$ and $74 \%$ of car occupants in front and rear seats, respectively, use a seatbelt in the EU, despite seatbelt laws across the EU (35). A study compared the self-reported seatbelt use among university students from 13 European countries in 1990 and 2000 (36). Seatbelt use increased by about $10 \%$ in total; the increase was between $24 \%$ and $64 \%$ in countries where legislation or enforcement related to seatbelt use had been improved during the study period (36). Hence, legislation and enforcement are important for the prevalence of seatbelt use. In addition, the study highlighted the importance of individual belief in the effect of seatbelt use for the use of the same (36). Convenience might have an additional effect. Seatbelt reminders, which from September 2019 became a requirement in all car occupant seats in new cars sold in the EU (35), is likely to have a positive effect on the prevalence of seatbelt use 
because of the annoying sound that rings until the seatbelt is fastened. Seatbelt reminders have already been installed in many new cars sold during the past years, and a positive effect on seatbelt use has been found (37).

\subsubsection{Vehicle-related risk factors}

Vehicle defects are relatively rarely a contributing pre-crash reason for road traffic crashes (about 3\% of road traffic crashes in high-income countries according to the World Health Organization (WHO)), but vehicle design highly influences the severity of human crash injuries during crash and post-crash (1). Vehicle safety, however, has improved during the past decades, especially in high-income countries.

Important improvements in vehicle design in the second part of the $20^{\text {th }}$ century were the three-point seatbelt, airbag, and crashworthy design that aimed at protecting the car occupants (38). In the 1990s, improved versions of anti-lock braking systems (ABS) had become standard in most new cars, and a system called electronic stability control (ESC) increased in prevalence in new cars sold in the late 1990s. ESC systems use ABS as a foundation to add technology that can sense, and then prevent, when loss of control of the vehicle is about to happen (39). From 1997, the European New Car Assessment Programme (Euro NCAP) provided publicly available safety performance tests and ratings of new cars sold in Europe, which could be surmised to have contributed to further improvements in vehicle safety features (40). In addition, EU directives on frontal and side impact protection have contributed to improved car occupant protection in new cars (1).

Cars designed between 2000 and 2010 have been proven safer for car occupants than those designed in 1980-1999; a study based on French crash data noted an almost $50 \%$ decrease in the frequency of severe injuries for belted occupants in newer cars compared with older cars (41). A Danish study also found that newer car generations are associated with lower probability of injury and fatality (42). A study in France investigated decreasing trends during 2000-2009 in both road fatalities and seriously injured car occupants and pedestrians; $72 \%$ of the lives and injuries saved could be explained by safety measures implemented during the same time 
period, whereas $11 \%$ could be directly attributed to improved vehicle safety technologies (38).

\subsubsection{Environmental risk factors}

The environmental risk factors of traffic injury are in the Haddon matrix categorised as physical or socioeconomic factors (Table 1). Included in the socioeconomic risk factors is the lack of comprehensive traffic safety laws. According to WHO, only 28 countries, representing 7\% of the world's population, had laws in 2013 against all of the risk factors speeding, drink driving, and non-use of seatbelts/helmets and child restraints (43). In high-income countries, traffic laws, enforcement, vehicle design regulations, and emergency systems are often quite good, reducing the significance of the socioeconomic environmental risk factors of traffic injury (Table 1). In addition, road standards are high in general. However, environmental risk factors, both socioeconomic and physical, are often significant or contributing causes of road fatalities in low- and middle-income countries. Vehicle safety features that are standard in new cars in high-income countries are often not standard fittings in vehicles in low-income countries owing to lack of vehicle design regulations (1). About $50 \%$ of the roads in low- and middle-income countries are classified as falling under the highest risk category based on inspections/assessments done by International Road Assessment Programme partners; 84\% of the roads assessed where pedestrians were present had no footpaths (43). The absence of footpaths, in addition to a high share of pedestrians and cyclists compared with cars and buses in low-income countries, can explain the majority of road injuries occurring to vulnerable road users outside vehicles in low-income countries (1). This is in contrast to the trend in high-income countries, like Norway, where the majority of both road fatalities and severe injuries occur to car occupants (44).

Although environmental risk factors constitute a less significant problem in highincome countries, road quality and safety do vary both within and between highincome countries. Optimizing all roads comes at a high economic cost (45). Increased use of automatic speed enforcement systems could be an alternative for reducing the risk of traffic injury on roads that are less safe by design, as in the typical Norwegian 
rural road shown in Figure 1. According to the Organization for Economic Cooperation and Development (OECD), Norway was the third wealthiest country per capita in 2002, after the US and Luxemburg, and yet Norway lagged most other industrialised countries by about 30-60 years in 2005 when considering the prevalence of constructed modern trunk roads and motorways, which are the safest types of roads (46). However, many of the Norwegian roads have been significantly improved in the years following the implementation of Vision Zero in 2001, especially in terms of the physical separation of vehicles (47) and making roads safer by the use of efficient speed enforcement camera systems (48). In France, the implementation of automatic speed camera enforcement was found to be the major reason for the decline in road fatalities and severe injuries in 2000-2009 (38). Soole et al. (49) summarised their review article on average speed enforcement as follows: 'Although comparatively expensive, average speed enforcement is a highly reliable and cost-effective approach to speed enforcement that is able to produce considerable returns on investment through reduced social and economic costs associated with crashes'.

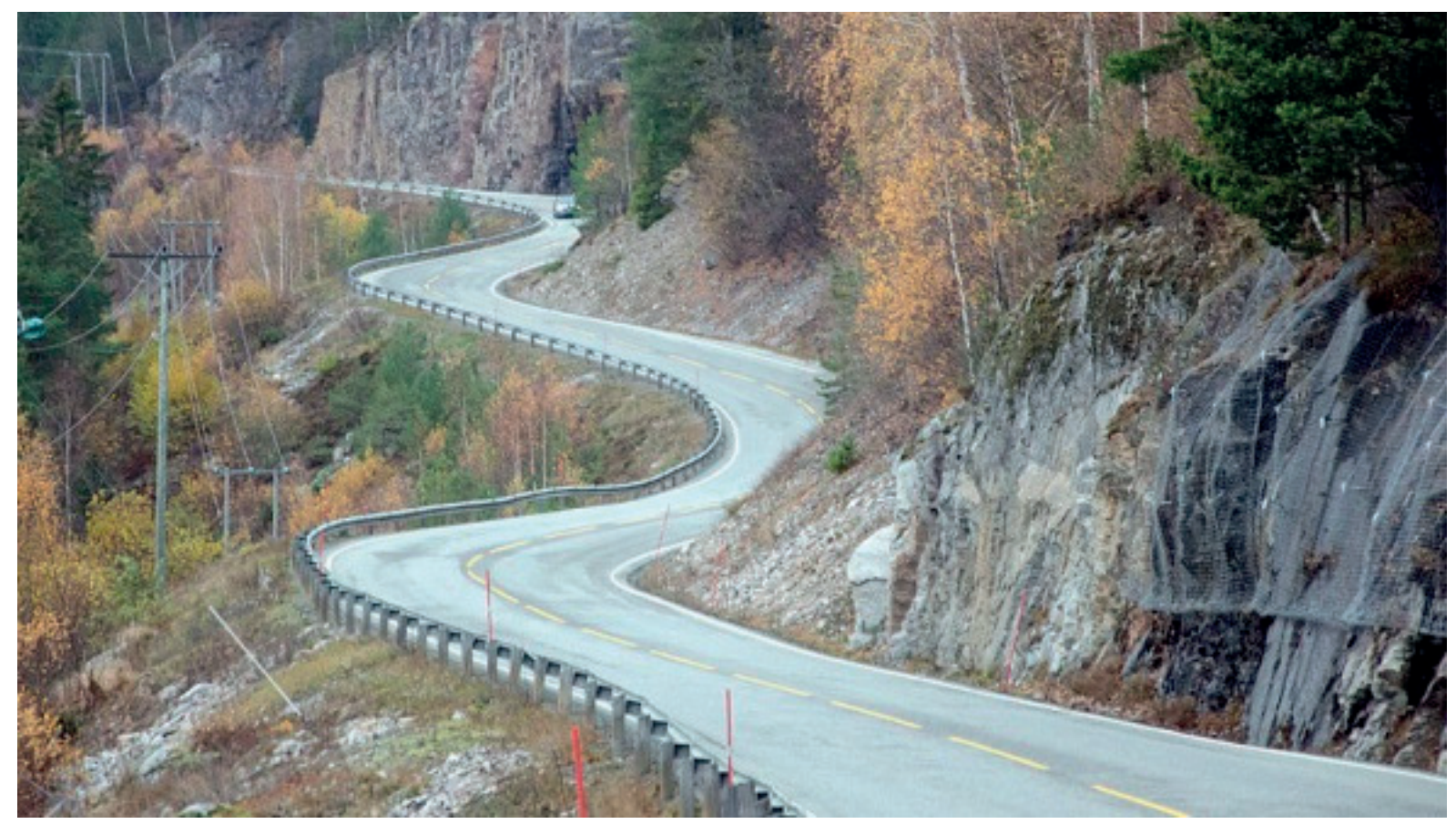

Figure 1: A road in southern Norway. Photo: Wikimedia Commons (Riksvei 36 in Seljord by Peter Fiskerstrand [CC BY-SA 4.0]). 


\subsubsection{Aspects regarding traffic injury prevention}

In theory, most risk factors of traffic injury can be eliminated or reduced by improving the road systems, enhancing vehicle safety design, and implementing strong enforcement for unsafe driving. Uniform improvements, however, will not benefit all drivers equally; an example is that crash-involved older drivers and female drivers have been found to sustain significantly more severe injuries than younger drivers and male drivers, when comparing equal types of road traffic crashes $(50,51)$. Human factors like old age and illness will influence the risks of traffic injuries but cannot be directly prevented. Special preventive measures might therefore be necessary for some groups within the population.

In high-income countries, where road and vehicle standards are already at a fairly good level, spending resources on reducing the human risk factors of traffic injury might be necessary to reduce further the number of road traffic deaths. More extensive use of average-speed camera systems is likely to have a positive effect on both speed and traffic injury on roads where installed $(38,49)$. Camera systems might also detect non-use of seatbelts among drivers and passengers, and automatically identify the vehicle and send out a fine to the car owner. Such an approach to seatbelt enforcement is likely to be more efficient than the current practice, as the chance of being punished for non-use increases. These systems are still developing, but roadside cameras that can detect non-use of a seatbelt in the driver's seat was installed in 2017 in Spain (52); instalment of similar cameras in Saudi Arabia has been shown to increase the prevalence of seatbelt use (53). Such systems, however, come at a high economic cost, and issues related to privacy and storage of sensitive data need to be resolved as well.

The strong enforcement of road traffic laws is based on the traditional deterrence theory that criminal activity could be avoided if people fear being punished (54). Strong enforcement, fines, and prison sentences might prevent many drivers from breaking traffic laws but might not have the same preventive effect on all drivers. As described by Lee (55), 'for punishment to deter crime, a potential offender must have the mental capacity to grasp the consequences of [their] actions'. When intoxicated 
by psychoactive drugs or alcohol, the driver's capacity for rational thinking might be reduced, leading to an underestimation of the negative consequences of unsafe driving, risk of causing a road traffic crash with injuries, and risk of economic loss or imprisonment. For some drivers, other types of sanctions, like compulsory education programmes for those arrested for unsafe driving, might have a better effect at preventing repeated offences.

In some cases, the reasons for breaking traffic laws, including speed limit and seatbelt laws, could be impulsivity or low anger management, suicidal thoughts, or a general high risk-taking personality. Some risk factors might also be related, such as being young male, illicit drug use, and risk-taking personality or culture. A study comparing toxicological findings in drivers killed in road traffic crashes in 20012002 in four northern European countries found that a $66 \%$ of the youngest drivers had used psychoactive substances shortly before driving (56). These fatalities might have been related to the effects of the substances used in combination with unsafe driving as a consequence of risk-taking behaviour or culture. However, there are no adequate methods or systems for identifying people at high risk of drug/drink driving prior to crash involvement or arresting for observed unsafe driving. 


\subsection{Substances that may increase the risk of a road traffic crash}

When investigating substances that may increase the risk of crash, researchers have used both observational and experimental designs; both have their advantages and limitations. The main difference is that in experimental studies, the researchers intervene, such as by administration of a psychoactive substance before testing driving performance, whereas in observational studies, the researchers only observe their study subjects in their natural setting (57). The associations found between substance use and crash involvement, in observational studies, will not only be influenced by the effects of the detected substances; factors related to the substance user are likely to influence the crash risk. Controlling with potential confounding variables is difficult in observational studies; therefore, researchers should be careful not to interpret associations found in observational studies as causal (58). Experimental studies have the benefit of the ability to control factors other than the studied effects of drug or alcohol, thereby potentially revealing the causal effects of the substances investigated $(59,60)$. The drug concentrations and combinations administered to volunteers in experimental studies will, in many cases, be lower and different than those being used by drug and drink drivers present in everyday road traffic, for ethical reasons. Therefore, the impairing effects of substance use found in experimental studies may not always reflect all risks associated with those substances in everyday road traffic (61).

After alcohol, cannabis is the most frequently detected psychoactive substance among crash-involved drivers, followed by benzodiazepines, cocaine, amphetamines, and opioids $(62,63)$. Use of substances within all these drug classes have been found to be associated with increased crash risk in observational studies $(61,64,65)$ and to negatively affect driving ability in experimental studies $(63,66)$. Meanwhile, drugs like antidepressants, antipsychotics, antihistamines, and anticonvulsants may also affect the ability to drive safely, but these play a minor role in road traffic crashes (67-69). 
The substances most frequently detected in road traffic crashes might not necessarily be those posing the highest risk of injury to drivers. The Driving Under the Influence of Drugs, Alcohol and Medicines (DRUID) project conducted an observational study that calculated the risks of drivers getting seriously injured or killed when DUI of different substances: they found high blood alcohol concentration (BAC) (>1.2g/L) and alcohol combined with other psychoactive drugs to pose a 20200 times higher risk compared with driving sober (70). A 5-30 times higher risk of serious injury or death was found for drivers with medium BAC (0.8-1.2 g/L) or who consumed amphetamines or a combination of multiple psychoactive drugs. Medium increased risk (2-10 times that of sober drivers) was found for BAC between 0.5-0.8 $\mathrm{g} / \mathrm{L}$ or consumption of cocaine, illicit opiates, medicinal opioids, benzodiazepines, or z-hypnotics. A relatively low risk of severe injury or death (1-3 times) was found for drivers with low BAC $(<0.5 \mathrm{~g} / \mathrm{L})$ or who had used cannabis.

\subsubsection{Alcohol}

The adverse effect of alcohol (ethanol) on driving skills was already commented on in 1904, and studies performed over the subsequent decades have produced overwhelming evidence that alcohol significantly impairs driving performance (16, 71-74). In experimental laboratory studies, alcohol has been found to reduce reaction time and the ability to maintain a position on a road/lane, as well as to divide attention between multiple sources of information and operations $(16,62$, 71). Alcohol impairs driving performance in a dose response manner, as revealed in experimental field and observational studies $(16,62,71,72,75)$. The risk of crash involvement starts to increase significantly at a BAC of $0.4 \mathrm{~g} / \mathrm{L}(73,76)$. However, individual differences have been noted in performance at the same BAC levels (16), and the risk of crash involvement depends not only on the BAC level but also on the frequency of drinking (75), as well as whether the BAC level is increasing or decreasing, with the latter associated with acute alcohol tolerance $(77,78)$.

\subsubsection{Cannabis}

Experimental studies have generally shown that use of cannabis impairs cognitive and psychomotor skills central in driving performance, both among regular and non- 
regular users. The documented impairing effects include reduced attention, reduced memory function, longer reaction time, and reduced ability to maintain the correct road position, and tend to be dose related $(62,66,69,79-81)$. The level of cannabisinduced impairment varies among individuals, dependent on the tolerance level, which might improve with frequent use $(69,82,83)$. The effects of cannabis also vary with the route of administration and individual vulnerability to psychoactive effects (69).

Observational studies might appear inconclusive regarding the road traffic crash risk of cannabis. However, several studies investigating the effect of cannabis on road traffic crash involvement have failed at or not focused on distinguishing between acute cannabis intoxication and recent use of cannabis $(58,81,84)$. The concentration of tetrahydrocannabinol (THC; the main psychoactive compound in cannabis) in the blood increases to maximum immediately after smoking and then drops quickly, whereas the impairing effects might last a few hours (85). Traces of THC may be detected in blood samples for several hours longer, for up to several days among frequent users, without causing significant impairment $(86,87)$. Cannabinoid metabolites in urine or blood/plasma will not reflect impairment; they only show that cannabis was used recently $(79,88)$. In addition, even when using an adequate lower limit of concentration for inclusion, the often long period from arrest for cannabis-impaired driving to blood sample collection may contribute to an underestimation of the effect of cannabis on driving performance $(85,89)$.

\subsubsection{Stimulants}

Stimulants are popular drugs of abuse, and are also used for the treatment of attention deficit hyperactivity disorder (ADHD) and narcolepsy, particularly amphetamine (racemic amphetamine and dextroamphetamine) and methylphenidate; methamphetamine has also been used in this manner (90-93). These prescription drugs are in the US classified as Schedule II drugs under the Controlled Substances Act because of their high potential for abuse and addiction $(94,95)$. 
Amphetamines and cocaine are among the most common stimulants with abuse potential that are frequently detected among drivers (69). These drugs are described in more detail in the next sections, along with 3,4-methylenedioxymethamphetamine (MDMA; ecstasy), a stimulant drug more often used in settings like music festivals and nightclubs (96-99). Non-medical use of stimulants will generally increase alertness, mood, and energy, at initial use, but could lead to adverse effects at higher doses or after chronic use (100-103). Stimulants may impair the ability to drive safely both during the acute stimulating phase and during withdrawal after repeated intake or binging $(101,104)$. There is, for ethical reasons, a lack of experimental studies that test driving performance at high concentrations of stimulants.

\section{Amphetamines}

Small doses of amphetamines (amphetamine and methamphetamine) might improve psychomotor skills, but some studies have reported that use may reduce divided attention, meaning that the driver's ability to attend to potential unforeseen hazards is reduced (69). The chemical structure of methamphetamine is similar to that of amphetamine except for an extra methyl group. Methamphetamine seems to be slightly more potent or act for a longer time than amphetamine, but their effects are almost indistinguishable (105-107). The use of higher doses of amphetamines often cause euphoria, feelings of increased physical and mental capacity, and rapid flow of ideas (63), but after repeated administration, euphoria will eventually be substituted with anxiety, bad mood, and even hallucinations and paranoia. Such a trip often ends with fatigue, exhaustion, and psychosis when the drug is cleared from the body (101). In experimental studies, the doses used have been too low to be representative of amphetamine misuse (69). Observational studies show significant associations between higher concentrations of amphetamine and increased risk of road traffic crash $(61)$ and road traffic injury $(70,108)$.

\section{MDMA}

MDMA is structurally similar to amphetamine, but an attached methylenedioxy group gives the drug hallucinogenic effects in addition to stimulant effects (100). Kuypers et al. (109) tested the effects of MDMA during the night and early in the 
morning after a night of sleep deprivation. They found that MDMA slows reaction time and impairs performance in critical tracking and divided attention tasks, whereas performance in some other tasks is not affected or improved. The participants with MDMA felt less sleepy during the night, compared with those administered with placebo. In another experimental study, actual driving tests were conducted in the evening and in the morning after a night of sleep loss. MDMA did not affect actual driving performance but also did not compensate for the impairing effects of sleep loss (110). The implications might be that MDMA users decide to drive after staying up all night, because they feel energetic or alert, not being able to experience the impairing effects of sleep deprivation to the same degree as drug-free drivers (110). An observational study design may not distinguish the possible impairing effects of MDMA from those of sleep deprivation.

\section{Cocaine}

The effects of cocaine use resemble those of amphetamines, which at initial use increase alertness, mood, and energy, but at higher doses or after chronic use lead to adverse effects like restlessness, paranoia, and sleeplessness (100). Cocaine has been found to improve the ability to maintain attention and alertness over prolonged periods of time, but also impair complex decision making and increase risk taking behaviour (63). In some but not all observational studies, cocaine has been found to be associated with road traffic crash involvement; the associations found have been weaker compared with amphetamines (61). Cocaine has a short half-life and is metabolised to several metabolites (100), which poses a challenge to the study of cocaine's effects on crash involvement in observational studies that use drug tests. Stoduto et al. (111) found past-year self-reported collision involvement to be twice as prevalent among cocaine users compared with non-users.

\subsubsection{Medicinal drugs}

Benzodiazepines and z-hypnotics are often prescribed for treatment of insomnia and anxiety-related disorders $(112,113)$. Opioids are often prescribed for acute and chronic pain relief (114). However, these medicinal drugs are relatively often misused, either by use of higher doses than prescribed or by combining with other 
drugs. The drugs might also be obtained from illegal sources. Therapeutic use of some medicinal substances might also lead to reduced driving performance. Doserelated impairment has been documented for benzodiazepines, z-hypnotics, and some opioids $(115,116)$.

\section{Benzodiazepines}

Benzodiazepines have sedative effects and can adversely affect driving performance $(64,117-119)$. The magnitude of impairment might decrease over time when benzodiazepine drugs are used in more than three to four weeks. Despite the assumed reduced impairment owing to tolerance, elevated risk of road traffic crash has been found after one year of benzodiazepine use (118). The adverse effects most frequently encountered among users of benzodiazepines are impaired mental or motor functions, light-headedness, and drowsiness. Impairment the next morning, however, depends on the dose taken and time interval since the last dose, in addition to the half-life of the drug. Short-acting benzodiazepines, namely, triazolam and midazolam, are the least likely to have impairing effects in the morning. Meanwhile, examples of medium-acting benzodiazepines are alprazolam, bromazepam, and oxazepam; and examples of long-acting benzodiazepines are clonazepam, diazepam, flunitrazepam, and nitrazepam (69).

\section{Z-hypnotics}

Prescription of benzodiazepines as hypnotic drugs has been reduced in many countries during the past decade, whereas prescription of other hypnotics has increased. Z-hypnotics, including zopiclone, zolpidem, and zaleplon, have sedative effects and are pharmacologically similar to benzodiazepines; they were developed to improve the traditional benzodiazepine hypnotics. However, the introduction of zopiclone turned out to be of no improvement of road traffic safety, as determined by several on-the-road studies $(120,121)$. Deviation of lateral position (weaving of the car) has been reported (69). Zopiclone has an intermediate half-life, whereas zolpidem has a short half-life (119). Zolpidem is therefore less likely to cause nextmorning impairment. Even so, zolpidem taken in the evening has been found to cause occasional next-morning driving impairment, especially in women (121). 


\section{Opioids}

Opioids, such as morphine, hydrocodone, codeine, and oxycodone, are often prescribed for pain relief. Methadone and buprenorphine are also used to reduce pain and in the treatment of former heroin addicts with opioid maintenance therapy. Heroin is an illegal opioid no longer used in treatment; chronic heroin use might have long-lasting effects on driving performance, including both reduced cognitive and psychomotor skills (69). Other opioids used in medicinal treatment are also relatively frequently abused. Regardless of the purpose of use, opioids may induce sedation and sleep, in addition to pupillary constriction, and thus might result in reduced driving performance (114). Mailis-Gagnon et al. (122) concluded in a review that 'the commonly held concept that chronic pain patients on stable opioids can safely drive cannot be generalised to all such patients in everyday practice, but may be applicable to only a subset who meet certain criteria'. Untreated chronic pain might however also lead to reduced driving performance.

Single-dose administration of morphine to healthy volunteers has not been found to impair psychomotor skills in some experimental studies reviewed, although impairment in attention, reaction time, and visual functions were noted in some of the studies (123). According to another review, experimental studies on codeine, methadone, morphine, and oxycodone have shown that use of opioids is likely to impair functions like divided attention, which is relevant when driving; impairment tends to be more pronounced in individuals with no history of opioid use (124). Strand et al. (125) confirmed that buprenorphine and methadone have impairing potential in opioid-naïve subjects. Heroin in the blood is rapidly converted to 6monoacetylmorphine (6-MAM), which thereafter more slowly metabolises to the main psychoactive substance morphine. Heroin is therefore difficult to detect and study (69).

\subsubsection{Combined substance use}

The simultaneous use of two or more psychoactive substances may increase the risk of both road traffic crash involvement and health implications. According to 
observational studies, combined substance use, including drug-drug and drugalcohol combinations, is quite common among drivers apprehended by the police for suspicion of substance use $(23,126,127)$ and among substance-positive seriously injured and fatally injured drivers $(128,129)$. Meanwhile, combined substance use is less prevalent among drivers in normal traffic, suggesting that drivers combining substances are at a profoundly high risk of traffic injury $(129,130)$, especially when combining psychoactive drugs and alcohol (65).

Few experimental studies have compared the effects on driving skills of drugs alone with drug-drug or drug-alcohol combination. Benzodiazepines or opioids combined with alcohol or each other can be life threatening, which explains the lack of experimental studies on these combinations $(69,131)$. Cannabis-alcohol combination has been found to cause increased impairment compared with that caused by either substance alone (69). The stimulatory effects of dexamphetamine or amphetamine are not sufficient to overcome the sedative effects of alcohol. The use of MDMA, meanwhile, can reduce some but reinforce other negative effects of alcohol. However, there are large individual variations in sensitivity to combinations of amphetamine or MDMA and alcohol (69). 


\subsection{Global trends in fatal road traffic crashes}

According to the WHO's global status report on road safety, approximately 1.35 million people died in 2016 as a result of road traffic crashes, and up to 50 million more people suffered non-fatal injuries. The number of road traffic deaths per 100,000 inhabitants is substantially higher in low- and middle-income than in highincome countries, and between 2013 and 2016, no reduction in road traffic deaths was observed in any low-income country, whereas some reduction was observed in 48 middle- and high-income countries (132). In high-income countries, the decline in motor vehicle fatalities during the past decades might be explained by policy initiatives like the implementation of road safety interventions, resulting in improved infrastructure, reduced rescue time, improved medical treatments, and more safe vehicles (6). The declining trend in road traffic deaths in some highincome countries has flattened in recent years, however: in both Sweden and the United Kingdom (UK), the decreasing death rates flattened after 2010, and in the US, no further decrease in death rate was seen after 2009 (132). The EU set an ambitious target of halving the number of road deaths between 2010 and 2020; this was not reached owing to a very marginal decrease in the total EU fatality number after 2013 (133).

When comparing high-income OECD countries in 2015, Norway had the lowest number of road fatalities, at 2.3 road deaths per 100,000 inhabitants, followed by Sweden (2.6) and the UK (2.8). The highest road death numbers were found in the US with 10.9 deaths per 100,000 inhabitants, slightly more than in Latvia (9.5) and Lithuania (8.3). Latvia recorded the best improvement rate in 2000-2015, and Lithuania had the sixth best rate, whereas Norway, Sweden, and UK, countries with low road death numbers, were among the 15 worst improving countries among 32 high-income OECD members $(5,134)$. These trends might indicate that further reduction of low death rates can be more challenging than reduction of high death rates. However, the US did not follow the same pattern; the US had both high road death number per inhabitants and the sixth slowest improvement rate in 2000-2015 $(5,134)$. In the US, an official target of zero road deaths was announced by the 
United States Department of Transportation in 2015 (135). Similar strategies were implemented in Sweden in 1997 and in Norway in 2001, and have probably contributed to the very low road death numbers in these countries.

The number of alcohol-related road fatalities has generally decreased in high-income countries, along with the decreasing trends in total road fatality numbers. In some countries, however, a decrease in the annual road fatality numbers has been combined with an increase in the proportion of alcohol-related road deaths, like in Sweden in the years between 2010 and 2017(136). This might indicate that preventive measures have had a better effect on non-alcohol-related road traffic crashes than on alcohol-related road traffic crashes during those years. It could also indicate increasing use of alcohol among drivers during those years. A direct comparison of alcohol or drug prevalence trends among fatally injured drivers in different countries, therefore, has limited value if not discussed in relation to the different nations' trends in total numbers of road traffic crashes, history of interventions, safety campaigns, legislation, and enforcement, among other aspects. An alternative is to compare the individual countries' relative rates of improvement in alcohol- versus non-alcohol-related fatalities. Between 2006 and 2016, 17 out of 26 countries studied in Europe had faster declining rates for alcohol-related road fatalities than for road fatalities of other causes (15).

Investigating trends in absolute fatality numbers is useful on a national level, to monitor the traffic safety status and evaluate whether or not implemented measures have had a positive effect on road safety. Comparison between similar countries regarding which substances are the most prevalent, on the rise, or declining might also be informative, as new trends in substance use might spread to neighbour countries. 


\subsection{Situation in Norway}

\subsubsection{Trends in road traffic injuries and deaths}

Norway is, as previously mentioned, one of the countries with the lowest number of fatalities from road traffic crashes. In 2015, the Nordic countries Norway, Sweden, Denmark, and Finland, had 2.2, 2.6, 3.1, and 4.9 road traffic deaths per 100,000 inhabitants, respectively, whereas the average global number was about 17 (137).

Both the numbers of killed and severely injured road users in Norway peaked in 1970, and thereafter declined until today (Fig. 2). A similar turning point in the trend in fatalities after about 1970 was seen in several other European countries, which most likely can be explained by changes in road safety policies (138). In Norway, the increase in both fatally and severely injured road users during the 1940s to 1970 was probably mainly due to the fact that speed limits were increased several times (139). At the same time, the number of privately owned cars in Norway increased steadily, from about 2,000 per 100,000 inhabitants in 1950 to about 20,000 in 1970 (140). It is likely that the implementation of seatbelt legislation had a large impact in reducing the number of road traffic fatalities after 1970 (Fig. 2); see section 1.4.2.

Although laws and enforcement focus on drivers, the fatality numbers among other types of road users have also declined (Fig. 3). Road improvements for better separation of different groups of road users might have contributed to the decrease in pedestrian fatalities. 

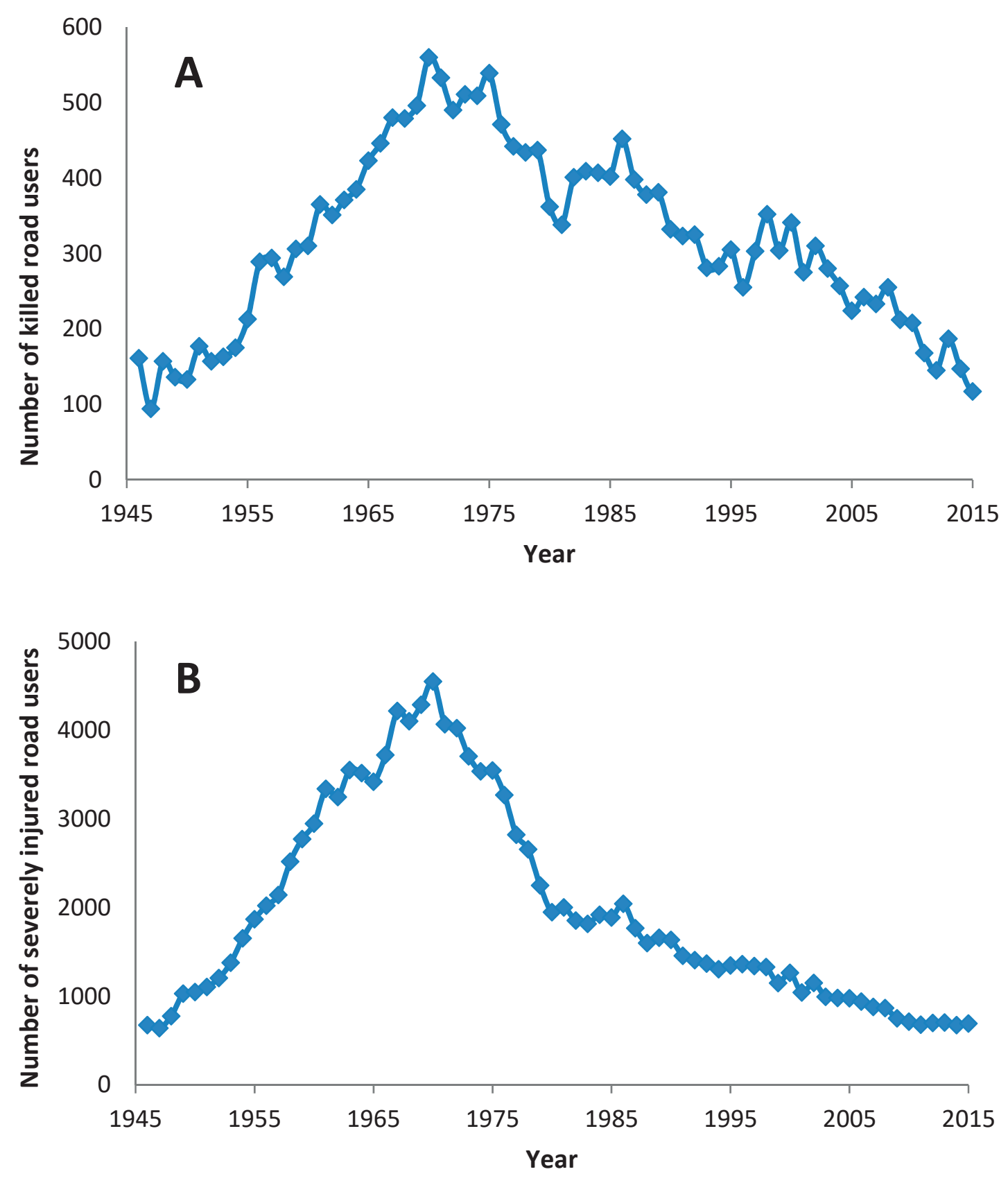

Figure 2. Number of killed (A) and severely injured (B) road users in Norway per year. Source: Statistics Norway 


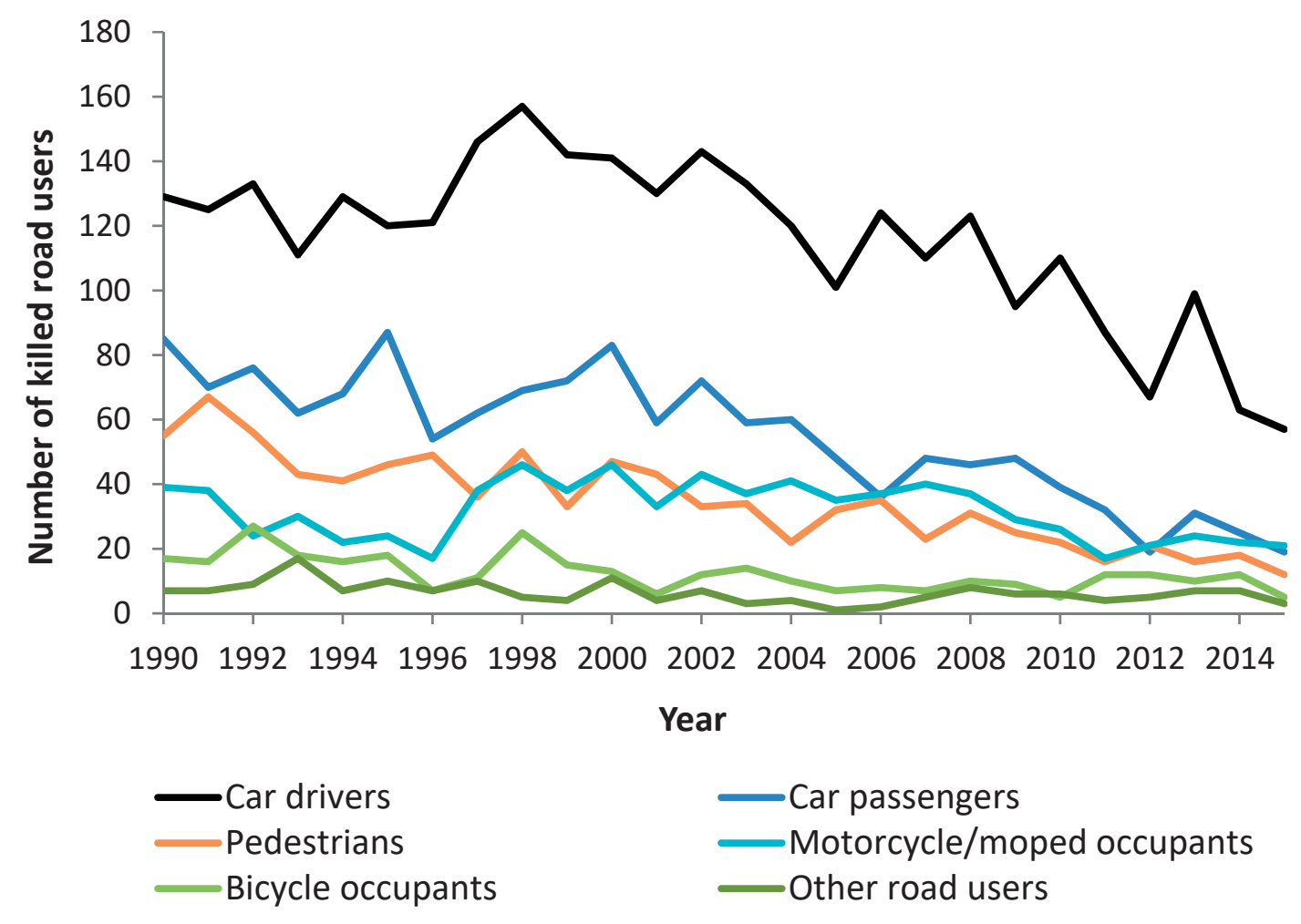

Figure 3. Number of killed road users per year in Norway, grouped by vehicle type. Source: Statistics Norway

\subsubsection{Important changes in road safety policies}

The increasing numbers of injured and killed road users during the 1940s to 1970 (Fig. 2) called for action. In 1970, the government decided that from 1971, all new cars and vans sold in Norway should have seatbelts installed in front seats; from 1975, the use of seatbelts in front seats was required (141). A fine for not using a seatbelt was introduced in 1979. From 1984, the instalment of seatbelts in the back seat of new cars was mandatory, and in 1985, the use of those seatbelts was required for passengers aged above 15 years. In 1988, securing children in cars, in the back seat, became a legal requirement (33).

Many other measures have probably contributed to the decline in severe road traffic crashes at different points between 1970 and the present. In 1980, speed limits were reduced from $80 \mathrm{~km} / \mathrm{h}$ to 70 or $60 \mathrm{~km} / \mathrm{h}$ on about $10 \%$ of Norway's main roads (142). The increasing rate in private car ownership became less steep after 1987 
(140). The alcohol limit for driving was in 2001 lowered from 0.5 to $0.2 \mathrm{~g} / \mathrm{kg}$ blood (143). Norway implemented early strict enforcement for drink driving; laws and enforcement for drink and drug driving have been enhanced and adapted several times (as explained in section 1.4.3). In addition, the enforcement of measures against a variety of other unsafe driving behaviours improved over the years. Examples of more recent changes include the following:

1) In 2004, the implementation of a new system with penalty points in addition to fines for breaking traffic rules, like illegal overtaking, speeding, and red light driving, where the driver's licence will be suspended after 8 points (144);

2) In 2009, the installation of speed cameras that detect average speed over a distance on a few roads, thereby increasing the risk of being arrested for speeding (48);

3) Testing of automatic number plate recognition (ANPR) equipment in all police districts in 2010-2012 and permanent instalment in some cars from 2013, primarily those operated by the Mobile Police Service (the Norwegian traffic police), which increased the possibility for them to recognize cars owned by previously convicted drivers $(145,146)$;

4) From 2012, extending the possibility for the police to use signs and symptoms testing when they suspect DUI of drugs or alcohol (147).

In addition to stricter laws and stronger enforcement, education and use of information campaigns might also have contributed to reducing the traffic injury numbers.

\subsubsection{DUI laws and enforcement}

The prevalence of alcohol use among drivers in normal traffic in Norway is low compared with countries in other parts of Europe and the US (65). The low prevalence in Norway is likely due to a long tradition of strict legislation, enforcement, and punishment for drink driving (Table 2), combined with public information campaigns. In 1936, Norway was the first country to implement a legal limit for DUI of alcohol. The limit was set at $0.5 \mathrm{~g}$ alcohol per $\mathrm{kg}$ blood, based on studies where impairment among arrested drivers had been compared across 
different BAC levels (148). Drivers convicted for DUI of alcohol were faced with fines and prison sentence. Both the enforcement and sentencing have always been strict in Norway, when compared with the other Nordic countries (54). During traffic controls, the police could make random breath tests for alcohol without prior suspicion of alcohol use; suspicion was neither needed to alcohol-test a driver who had been involved in an accident or committed a violation of traffic rules. The purpose was to enhance the deterrent effect of the law. This is in contrast to in England, where weak enforcement of the law has been suggested as an explanation for the lack of long-time effect on alcohol-related accidents, following the introduction of per se limit for alcohol in England in 1967 (54).

The alcohol limit of $0.5 \mathrm{~g} / \mathrm{kg}$ blood remained in Norwegian law until 2001 when it was lowered to $0.2 \mathrm{~g} / \mathrm{kg}$. Although a BAC of $0.2 \mathrm{~g} / \mathrm{kg}$ does not necessary significantly impair the driver's driving skill, the idea was to highlight to the citizens that alcohol should not be used in combination with driving (143). The legal limit is absolute (per se), meaning that anyone driving with BAC at or above $0.2 \mathrm{~g} / \mathrm{kg}$ might risk getting punished for doing so, regardless of whether or not the driver is impaired by the alcohol used, or whether or not they had been driving unsafely. Reduced punishment owing to tolerance is not considered in drink driving cases in Norway.

For non-alcohol psychoactive drugs, evaluation of the degree of impairment and possible tolerance from drug(s) taken had to be performed to convict a driver for DUI of drugs. In 2012, legal per se concentration limits for 20 drugs in blood, corresponding to BAC of $0.2 \mathrm{~g} / \mathrm{kg}$, were implemented in the Norwegian Road Traffic Act. This simplified the process of convicting drivers under the influence of drugs, in line with the process of convicting drivers under the influence of alcohol (149). After 2012 , evaluation of the degree of impairment or tolerance was performed only in cases where drugs other than the 20 included had been used, where two or more substances had been combined, and where the driver had valid prescription for the drug found. Maximum limits for the daily doses of prescribed psychoactive drugs allowed in combination with driving were specified in 2011 (150); the requirements were later revised with stricter dose limits (151). After an evaluation and revision of 
the legal limits in 2012, eight more drugs were included with legal limits in 2016 (152).

In contrast to alcohol, a relatively high prevalence of other psychoactive drugs has been found among Norwegian drivers compared with drivers in other European countries, as reported by the DRUID project (65). The reason might be that preventive measures against drug driving have been few in Norway prior the time of the DRUID project, whereas there has been a long tradition of strict enforcement and a diversity of preventive measures against drink driving.

Table 2. Sanctions given for driving with blood alcohol concentration in Norway to date.

\begin{tabular}{|c|c|}
\hline $\begin{array}{l}\text { Blood alcohol } \\
\text { concentration }\end{array}$ & Sanction \\
\hline $\begin{array}{l}\text { Between } 0.2 \\
\text { and } \\
0.5 \mathrm{~g} / \mathrm{kg}\end{array}$ & $\begin{array}{l}\text { - Fine equivalent to about one gross monthly wage of the } \\
\text { offender } \\
\text { - Driver gets a criminal record } \\
\text { - Usually the driver keeps their driver's licence; exceptions are } \\
\text { some special conditions and novice drivers, who get a } \\
\text { minimum six months of driving ban }\end{array}$ \\
\hline $\begin{array}{l}\text { Between } 0.5 \\
\text { and } \\
1.2 \mathrm{~g} / \mathrm{kg}\end{array}$ & $\begin{array}{l}\text { - Fine equivalent to about } 1.5 \text { gross monthly wage of the } \\
\text { offender } \\
\text { - Conditional sentence in most cases, imprisonment can occur if } \\
\text { conditions set by the court are not fulfilled } \\
\text { - Suspension of driver's license for a minimum of one year }\end{array}$ \\
\hline Above $1.2 \mathrm{~g} / \mathrm{kg}$ & $\begin{array}{l}\text { - Fine equivalent to about } 1.5 \text { gross monthly wage of the } \\
\text { offender } \\
\text { - Unconditional sentence of imprisonment: minimum of } 21 \text { days } \\
\text { - Suspension of driver's license for a minimum of two years }\end{array}$ \\
\hline
\end{tabular}




\subsection{Current knowledge gaps}

Prior to the start of this study, annual reports on drug findings in blood samples from arrested drivers in Norway had been published, but the analytical cut-off concentrations used have varied over time, as well as the types of drugs included in analytical testing. A thorough investigation of long-term trends in the use of psychoactive substances had not been performed among Norwegians suspected of drug or drink driving. Furthermore, the characteristics of substance-using drivers had not been explored in depth.

Analytical findings on alcohol and drugs in blood samples from drivers killed in road traffic crashes had been published for some time periods: 1989-1990 (153), 20012002 (56), and 2006-2008 (154). These studies used varying cut-offs and analytical repertoires. Studies of drivers and motorcycle riders killed in road traffic crashes during 2001-2010 $(155,156)$ used the legislative limits introduced in 2012 as cutoffs and presented data for selected age groups and sex. More recent data had not been published.

The proportion of different unsafe driving behaviours recorded in fatal road traffic crash reports had previously been investigated by the Norwegian Public Roads Administration (157). However, there was lack of knowledge regarding trends in unsafe driving behaviours among those fatally injured, which could decline in accordance with the declining fatality numbers, but also potentially increase in prevalence as a consequence of recent safety improvements that reduce the risk the most among those who do only minor driving errors.

Associations between crash characteristics related to the driver and recent drug or alcohol use have been investigated in several American studies (158-160). However, few studies have focused on impairment by drug or alcohol when investigating road traffic crash data. Studies that included drug metabolites in the urine as indicator of drug exposure, or traces of drugs in the blood with unknown analytical cut-offs, or inactive metabolites in the blood as a measure of recent drug use, such as those 
based on the American nationwide Fatality Analysis Reporting System (FARS) database, might underestimate the effect of the drugs on driving performance, because the reported drug findings may not indicate impairment from the drugs (58, 161). A study on the association between likely impairment from alcohol or drugs, speeding, and seatbelt use among fatally injured car drivers in Norway had been performed using data for 2005-2010 (162). However, it had a weak statistical power and had not included other driver-related risk factors. A more comprehensive study of a larger number of cases, and including more driver-related risk factors, should therefore be performed to shed light on which driver-related errors are strongly associated with alcohol or drug impairment. 


\section{Aims of the study}

The overall aims of this study were to investigate trends in the use of psychoactive substances and other common unsafe driving behaviours among drivers, and to investigate crash characteristics and the associations between impairment from alcohol or drugs and other significant driver-related risk factors of road traffic injury.

The specific aims were as follows:

1. Study long-term and recent trends in psychoactive substance use among drivers in Norway

a. among those suspected by the police of DUI of drugs or alcohol (Papers I and II, additional data in Section 4.5)

b. among those fatally injured in road traffic crashes (Paper IV)

2. Investigate associations between impairment from different psychoactive substances and other driver-related risk factors contributing to fatal road traffic crashes (Paper III)

3. Investigate prevalence and trends in crash characteristics and recorded significant unsafe driving behaviours among fatally injured drivers (Papers III and IV) 


\section{Material and methods}

\subsection{Funding}

This research did not receive any specific grant from funding agencies. The work was supported by the Norwegian Institute of Public Health and Oslo University Hospital. The institutional responsibility for the toxicological investigation of blood samples from arrested or killed drivers and associated research projects was transferred from the Norwegian Institute of Public Health to Oslo University Hospital on 1 January 2017.

\subsection{Sources of data}

\subsubsection{Papers I and II}

Papers I and II were based on data from two in-house forensic databases: a former Access database (years 1990-1999) and a newer in-use SQL database (2000-2015). The databases contained results from all the toxicological investigations of blood samples performed in Norway, in the cases where drivers were arrested by the police under suspicion of DUI of drugs or alcohol. Paper I used toxicological results from both databases; Paper II was based on the newer database.

Database providers extracted data, which were stored in a folder with restricted access. Direct personal identification information, like names, addresses, phone numbers, and national identity numbers, was not extracted and not available to the researchers.

\subsubsection{Papers III and IV}

Papers III and IV were based on data from motor vehicle drivers and riders fatally injured in 2005-2015. Four sources of data were linked: an in-house SQL database 
containing toxicological results from about $90 \%$ of the fatally injured drivers subject to autopsy in Norway, forensic toxicology data from St. Olav University Hospital (the remaining autopsies [about 10\%] performed in Norway per year), Road Traffic Accident Registry operated by Statistics Norway, and Crash Investigation Team Database operated by the Norwegian Public Roads Administration. The two latter registers include information about all fatal road traffic crashes, except fatal crashes regarded as suicides.

Handling of data containing national identity numbers and other directly identifiable information was performed by Statistics Norway. A research database without direct personal identification information was transferred to the researchers and stored in a folder with restricted access.

\subsection{Ethical and legal aspects}

There are ethical principles that should be reflected on before the start of any research project involving humans or collected material or data from humans. The Declaration of Helsinki, developed by the World Medical Association in 1964 and later updated, summarizes the core ethical principles and provides guidelines to be used by researchers. Examples include respecting and protecting the research subjects and protecting the confidentiality of their personal information, careful assessment of risks and benefits to the individuals and population of study participants, to assure that the goal of new knowledge never takes precedence over the rights and safety of research participants. Furthermore, candidates should be given the information needed in order for them to make an informed decision whether or not to participate in the studies, both initially and during the course of research (163).

The Declaration of Helsinki further states that a research protocol must be made and approved by an independent research ethics committee before the start of a study involving humans or collected material or data from humans (163). The exception is 
projects handling data anonymously; they do not need approval from the Regional Committees for Medical and Health Research Ethics (REC), as stated in the Norwegian Act on Medical and Health Research of June 2008 (164).

Being arrested under suspicion of DUI of drugs or alcohol or failing to drive according to traffic rules prior to being fatally injured in a road traffic crash can be classified as highly sensitive personal information. Confidentiality of personal information was, according to ethical principles (59), guaranteed during all stages of this study.

The legal owner of the forensic toxicology data used in the present study is the Norwegian Higher Prosecuting Authority, and according to the data processing agreement, only anonymous statistics could be prepared, if no further approval was given by an ethical committee. This applied to the study of arrested drivers (Papers I and II).

For the study of fatally injured drivers (Papers III and IV), the Council for Confidentiality and Research of the Norwegian Ministry of Justice gave exemption from the duty of confidentiality, and the study was approved by the Higher Prosecution Authority of Norway. They also approved the coupling of forensic data with the Crash Investigation Team Database and the Road Traffic Accident database. The risks and benefits of the research project, for participants and for society, was evaluated by the Regional Committee for Medical and Health Research Ethics; they found the study worthy of approval (approval no. 2010/2191). The approval included an exemption from collecting the drivers' or next of kin's informed consent. Such an exception, however, did not apply to drivers who either themselves or via next of kin have disapproved use of their material or data for research purposes. All killed drivers in this study were therefore searched in the Norwegian Registry of Withdrawal from Biological Research Consent and Registry of Autopsy Material Research Refusal. None of the drivers were included in those registries; hence, the quality and representability of the results from this study are high. In 2015, Oslo University Hospital changed its routines and is now informing the next of kin of dead 
people subject to autopsy about research projects and how they can withdraw from the studies. Lack of such active information given from the hospital prior to 2015 might contribute to explaining the absence of fatally injured drivers on the research reservation lists.

\subsection{Study design}

The study used retrospective time series cross-sectional (Papers I, II, and IV, as well as Section 4.5) and retrospective cross-sectional (Paper III) designs.

\subsection{Statistical methods}

\subsubsection{Descriptive and inferential statistics}

The purpose of descriptive statistics is to present and summarize data in a meaningful manner, in aid of interpretation. Inferential statistics is used to test hypotheses, examine relations between variables, and generalize results or predict trends in a larger population based on a sample $(59,165,166)$.

Descriptive statistics was presented in all papers, including age and sex distribution, and time of crash, using graphs and figures of patterns and possible trends. Papers I and II presented only descriptive statistics. In Papers III and IV, all fatally injured drivers were included, and descriptive statistics were applied to describe their characteristics. The fatally injured drivers were also considered a sample, and inferential statistics was applied to investigate associations and trends that might be generalizable to a broader population of drivers. The idea behind this type of testing was that whether or not driving unsafely leads to road traffic crash involvement is random, to some degree, as is whether or not drivers involved in road traffic crashes end up as fatally injured or as survivors. Those fatally injured might thus be considered a sample from the total number of drivers at high risk of being fatally injured in a road traffic crash. 


\subsubsection{Statistical tests}

Neither the arrested nor the fatally injured drivers were found to be normally distributed when considering their age; hence, non-parametric tests were used (59). Both bivariate and multivariable statistical tests were used.

\section{Chi-squared test}

The bivariate Pearson's chi-squared test was used in Papers I, III, and IV to test for significant differences between groups. A significance level of 0.05 was set. The chisquared test compares observed frequencies to the frequencies expected in the absence of associations between variables (167).

\section{Wilcoxon-Mann-Whitney}

Differences between two medians were compared by a Wilcoxon-Mann-Whitney test in Paper I. An assumption for this test is that the variances of two distributions of datapoints compared are equal. The shape of the distributions should also be similar, although normal distribution is not required (168).

\section{Joinpoint regression}

Joinpoint regression (webpage https://surveillance.cancer.gov/joinpoint/) was used in Paper II to test whether slopes of the trend lines were significantly different from zero, and whether time points showed significant changes in the slope of the regression line. Paper IV also used Joinpoint regression to assess the annual percent change in number of fatally injured drivers during the study period, including 95\% confidence intervals.

\section{Logistic regression analysis}

Multivariable logistic regression can be used to test the effect of several risk factors (exposure variables) on a binary outcome variable; the result will indicate how much an increment in each exposure variable affects the odds of the outcome when the effect of the other exposure variables is adjusted for (169). Exposure variables found to be related to the outcome variable do not necessarily mean that the exposure 
variable can cause the change in the outcome variable, as they both could be related via other variables not included in the model (called confounders). If the confounders are known and can be measured, including them in the regression model will adjust for their effects (170). However, it is often difficult to determine whether all relevant confounders are accounted for. Logistic regression models can therefore not determine causality; relations between variables are therefore often referred to as associations. Multivariable logistic regression was used in Paper III to determine the odds ratios for the associations between impairment by drug or alcohol and different driver-related risk factors, adjusted for the confounding variables of age and sex. The odds ratios were adjusted for other co-variables and substance groups in additional tests. In Paper IV, multivariable logistic regression was used to calculate age- and sex-adjusted odds ratios for speeding, non-use of a seatbelt, and alcohol use prevalence among drivers fatally injured in 2011-2015 compared with 2005-2010.

\subsection{Software}

The Joinpoint software (Joinpoint Program Version 4.3.1.0) from the Surveillance Research Program of the US National Cancer Institute was used to identify significant changes in trends. All other statistical analyses were performed using SPSS version 23 or 25 (IBM Corp., Armonk, NY, USA). Figures were constructed using Microsoft Excel 2010. 


\section{Summaries of results}

\subsection{Paper I}

\section{Toxicological findings in suspected drug-impaired drivers in Norway - Trends during 1990-2015}

The annual number of motor vehicle drivers arrested by the police suspected of DUI of alcohol or drugs was approximately 10,000 during the entire study period from 1990 to 2015 (average of 9,536, range of 8,257-10,647). The proportion of these drivers suspected by the police of drugs, and for whom toxicological analysis of drugs in addition to alcohol was requested, increased from 21\% in 1990 to 59\% in 2015; the total was 112,348 for $1990-2015$; $87 \%$ were male drivers. Results from the drivers analysed for only alcohol are given in section 4.5.

The most detected substance group among the DUI of drugs suspects was alcohol (39.8\%), followed by benzodiazepines (including z-hypnotics) (36.0\%) and stimulants (32.2\%), mainly amphetamines. Cannabis (THC) was found in $21.5 \%$ of the investigated drivers; opioids in $11.3 \%$. The possibility to detect low concentrations has improved over time with better methods and instrumentation. We used the highest cut-off concentration limits used during 1990-2015 as cut-offs for all years. This made the comparison of prevalence over time possible but also likely resulted in an underestimation of the total prevalence of drugs and alcohol among these drivers.

The annual prevalence distribution of the different substance groups did not change much during the 26-year study period, although the type of benzodiazepines and opioids changed. Benzodiazepines detected were mainly diazepam and flunitrazepam between 1990 and 2002, after which diazepam continued to be prevalent, whereas flunitrazepam was substituted by clonazepam. For opioids, 
morphine and codeine completely dominated in the 1990s, but were later partly replaced by methadone and buprenorphine, and after 2010 also by tramadol and oxycodone.

The population of drug-positive drivers aged during the study period, both in total and within all substance group strata. The annual number of drivers aged $\geq 40$ years increased within all substance groups during the study period, whereas no further increase in the annual number of young people ( $<30$ years old) who combined substance use and driving was observed after about 2002, except for those using cannabis. Among all drivers, cannabis (THC) was the most frequently detected individual drug in 2015. It should be noted that owing to some inconsistency in the type of samples analysed for drugs in addition to alcohol in the 1990s, those samples analysed between 2000 and 2015 were investigated in more depth. Psychoactive drugs and/or alcohol were present in $91 \% \pm 2 \%$ of the suspected drug drivers; psychoactive drugs were present in $71 \% \pm 4 \%$. The decreasing prevalence of benzodiazepines and opioids and increasing prevalence of cannabis were revealed among all age groups tested, whereas the prevalence of stimulants (basically amphetamines) decreased among the youngest and increased among the oldest. These findings were valid for both female and male drivers.

The results from Paper I showed a slight change in the types of substances used by arrested drivers in Norway in the past decades. A high degree of recidivism among older drug-using drivers might help explain the increase in age among the DUI offenders. Furthermore, the results suggest that fewer young adults were recruited to drug use and driving, except for cannabis use. DUI offenders are often initially arrested by the police for unsafe driving or involvement in non-fatal road traffic crashes, of which the latter also might indicate unsafe driving, and after further inspection they are suspected of DUI of drugs or alcohol. The high prevalence of psychoactive substances found among these drivers indicates a relation between unsafe driving behaviours and the substances used. 


\subsection{Paper II}

\section{Increasing use of cannabis among arrested drivers in Norway}

This paper reported an investigation on the increasing trend in cannabis use among motor vehicle drivers arrested by the police during 2000-2015. The findings revealed that the number of cannabis-positive arrested drivers increased slightly from $2000(n=870)$ to $2008(n=1016)$, and then escalated further in $2015(n=$ 2024). When correcting for the increase in number of drivers suspected of DUI of drugs, no increase or decrease in prevalence was observed from 2000 to 2008; by 2015 , the prevalence of cannabis findings had increased by $48 \%$. Findings of only cannabis (no alcohol or other drug detected) increased the most, from 178 cases in 2008 to 782 cases in 2015: an increase in prevalence of $227 \%$ (339\% when not correcting for the increase in drivers suspected of DUI of drugs). Similar trends were observed among male and female drivers. Male drivers constituted $93 \%$ of the cannabis-positive drivers.

Young drivers with median age between 22 and 25 years dominated the cases where only cannabis was detected during the study period. Drivers combining cannabis with other drugs were older and showed an increased median age during the study period. A significant change in trend was observed in 2008/2009; the annual numbers of both cannabis-only and multidrug (including cannabis) findings increased significantly faster after 2008/2009 than before. Cannabis in combination with alcohol was also investigated; a slight increase was observed during the study period, but no change in trend was observed.

Many drug users combining cannabis with other drugs were likely problem drug users, some with a long history of drug use. The results further indicated that an increasing number of young people were DUI of cannabis after 2008. Cannabis was the only substance detected in 39\% of the cannabis-positive DUI of drugs suspects in 2015, which may indicate that cannabis use alone might reduce driving performance, at least among young drivers. 


\subsection{Paper III}

\section{Driver-related risk factors for fatal road traffic crashes associated with alcohol or drug impairment}

The contribution of driver-related risk factors in fatal road traffic crashes has been evaluated by crash investigation teams since 2005. Recorded risk factors in fatal crashes that occurred during 2005-2015 were coupled to forensic toxicology data and investigated in Paper III. The purpose was to study associations between risk factors and impairment by drugs or alcohol, separately for car/van drivers and motorcycle/moped riders. A total of $63 \%$ of both fatally injured drivers and riders had been investigated for substance use and otherwise fulfilled the quality requirements for inclusion in this study: 602 drivers and 170 riders. Impairment was defined as having drug or alcohol concentrations above the limits of the graded sanction corresponding to a BAC of $0.5 \mathrm{~g} / \mathrm{kg}$, or for stimulants, concentrations five times or more than the legislative limits. Being sober was defined as not having concentrations of substances above the legislative limits corresponding to a BAC of $0.2 \mathrm{~g} / \mathrm{kg}$.

Male drivers and riders dominated the fatally injured. The proportions of female victims were higher among sober (21.5\%) than among impaired (9.5\%) drivers and riders. The age distributions of impaired versus sober drivers and riders were also different, as impairment was more common among the youngest age groups. The impaired drivers were significantly more often killed at night-time, killed in singlevehicle crashes, and had been using a vehicle older than 10 years when killed, compared with the killed sober drivers. Among the riders, the same differences were found, except for the age of the vehicle.

Among the drivers, the risk factors significantly associated with impairment from drugs or alcohol after sex and age adjustment were speeding (OR, 3.97; 95\% CI, 2.58-6.11), not having a valid driving licence (OR, 23.1; 95\% CI, 8.05-66.0), and nonuse of a seatbelt (OR, 4.27; 95\% CI, 2.85-6.41). When categorised into substance 
groups, speeding was found to be significantly associated with impairment from alcohol and from stimulants (mainly amphetamines); not having a valid driving licence was found to be significantly associated with all substance groups tested (alcohol, stimulants, cannabis, and at least one of the medicinal drugs benzodiazepines, opioids, or z-hypnotics); non-use of a seatbelt was found to be significantly associated with all substance groups except cannabis.

A lower proportion of the fatally injured riders compared with the drivers were impaired by drugs or alcohol (20\% vs. 31\%, respectively). Among riders, the risk factors significantly associated with impairment after sex and age adjustment were not having a valid driving licence (OR, 17.4; 95\% CI, 6.05-49.9) and non-use of a helmet (OR, 3.67; 95\% CI, 1.45-9.26). Alcohol was found to be significantly associated with both risk factors.

When considering the sober drivers and riders only, speeding was recorded among $32 \%$ of the drivers and $53 \%$ of the riders; non-use of a seatbelt/helmet was recorded among $30 \%$ of the drivers and $13 \%$ of the riders; no valid driving licence was recorded among $1 \%$ of the drivers and $10 \%$ of the riders. All these proportions were higher among the impaired drivers and riders. The risk factors of speeding, not having a valid driving licence, and non-use of a seatbelt were slightly more prevalent in single-vehicle crashes compared with all crashes, both among sober and impaired drivers.

The results indicated a strong and positive association between impaired driving from drugs or alcohol and some driver-related risk factors of fatal road traffic crashes. The study could not prove causality. Nonetheless, it is highly likely that impairment from drugs or alcohol may increase the risk of driving errors. Preventive measures should be sought to reduce the possibility of driving after use of psychoactive substances. The results further indicated that measures for preventing speeding, non-use of a seatbelt/helmet, and riding without a valid driving licence should be maintained to reduce the number of sober drivers and riders involved in fatal road traffic crashes as well. 


\subsection{Paper IV}

\section{Fatally injured drivers in Norway 2005-2015 - Trends in substance use and crash characteristics}

Paper IV describes the prevalence and trends in crash characteristics and substance use along with other unsafe driving behaviours recorded among car/van drivers and motorcycle/moped riders who were fatally injured in road traffic crashes in Norway. The aim of this study was to investigate whether fatal crash characteristics, vehicle safety features, and prevalence of drugs and alcohol among fatally injured drivers and riders changed in 2005-2015, accompanying the reduction in road fatalities.

A significantly smaller proportion of car/van drivers who had been fatally injured in 2011-2015 had been speeding (34.1\%) or not used a seatbelt (33.8\%), compared with those fatally injured in 2005-2010 (44.9\% vs. 43.7\%, respectively). The youngest drivers had more frequently been speeding and not used a seatbelt compared with drivers aged $>45$ years; male drivers had significantly more frequently been speeding or not used a seatbelt compared with female drivers. A declining trend in fatal road traffic crashes was found to be steeper for young and male drivers, resulting in a higher proportion of female and older drivers among those fatally injured in the latter part of the study period. The sex- and age-adjusted ORs were 0.71 (95\% CI, 0.525-0.966) for speeding in 2011-2015, and 0.71 (95\% CI, 0.535-0.947) for non-use of a seatbelt in 2011-2015 when using data from 20052010 as reference. Declining trends in speeding and non-use of a helmet were also found among motorcycle/moped riders, but these did not reach statistical significance.

Alcohol above legal limits ( $0.2 \mathrm{~g} / \mathrm{kg}$ blood) was detected in $22 \%$ of the investigated drivers and in $12 \%$ of the riders. Drugs above the legal limits corresponding to 0.2 $\mathrm{g} / \mathrm{kg}$ alcohol in the blood were detected in $22 \%$ of the investigated drivers (medicinal drugs, 15\%; stimulants, 8\%; cannabis, 7\%) and in 15\% of the riders (medicinal drugs, 7\%; stimulants, 9\%; cannabis, 6\%). The prevalence of alcohol 
consumption above $0.5 \mathrm{~g} / \mathrm{kg}$ among drivers was found to decline significantly from $24 \%$ in $2005-2010$ to $14 \%$ in $2011-2015$ ( $\mathrm{p}=0.003$ ): the sex- and age-adjusted OR was 0.555 ( $95 \% \mathrm{CI}, 0.351-0.877 ; \mathrm{p}=0.012$ ). Among riders, alcohol use prevalence declined from $15 \%$ in $2005-2010$ to $5 \%$ in $2011-2015$ ( $p=0.059$ ).

Alcohol had more frequently been used than other drugs among the drivers killed in roadway departure crashes, which almost always were single-vehicle crashes (46.1\% for alcohol and $29.8 \%$ for drugs). In contrast, drugs had more frequently been used than alcohol among drivers killed in multiple-vehicle crashes $113.9 \%$ for drugs and 7.4\% for alcohol). Furthermore, drugs were more frequently used among drivers fatally injured on weekdays (18.7\% for drugs and $8.1 \%$ for alcohol), compared with weeknights and weekends, when alcohol dominated. Similar trends were found for riders.

In general, the distribution of collision types did not change during the study period, but riders had more often been killed in collisions in junctions (21\%) compared with drivers (5\%). Riders were most frequently killed in roadway departures (39\%), and drivers, in head-on collisions (54\%). The proportion of crash-involved cars and motorcycles with ABS and ESC increased significantly from the first time period to 2011-2015.

Thus, the preventive measures implemented have helped reduce speeding and nonuse of a seatbelt among the general population of drivers, because the reduction among the fatally injured could not solely be explained by the changing sex and age distributions in the two time periods compared. The declining prevalence of alcohol use among fatally injured drivers indicated that preventive measures have had a positive effect on high-risk or recidivist drink drivers as well. The observed changes towards more vehicle safety installations and lower prevalence of unsafe driving among the fatally injured drivers and riders may reflect the general trends that contributed to the decreasing road death numbers in Norway. 


\subsection{Additional results}

One of the aims of this study was to document trends in psychoactive substance use among drivers arrested under suspicion of DUI of drugs or alcohol. Included in Papers I and II were all drivers analysed for alcohol in addition to drugs; however, drivers subjected to only alcohol analysis were missing. The alcohol-only samples were probably often from cases in which the police felt quite confident that the driver was impaired by alcohol; hence, those samples might include higher alcohol concentrations than the samples where drugs were suspected. The results from the alcohol-only samples were included as additional results in this thesis (section 4.5.1) to reveal a total unbiased trend in alcohol use prevalence among all DUI suspects in Norway.

When considering those suspected of DUI of drugs, the causes or background situation for arrest by the police were not known except in the cases where the drivers had been involved in non-fatal road traffic crashes. However, background data for the alcohol-only breath samples were available and are included here (section 4.5.1).

Trends in THC concentrations and time from apprehension of drivers till blood sample collection are of relevance when discussing alternative explanations for the observed sharp increase in number of cannabis-positive drivers. The data were not included in Paper II owing to limited space but are given in section 4.5.2.

\subsubsection{Alcohol results including drivers suspected of only alcohol use}

The alcohol results reported in Papers I and II were from drivers (including riders) suspected of DUI of drugs. Figure 4 shows the results when drivers (including riders) suspected of only alcohol use were also included, both those analysed for only alcohol in blood samples and in breath samples taken by Intoxylizer or Evidenzer instrumentation. The figure shows declining trends in alcohol, both in total number of alcohol findings and proportion of samples testing positive for alcohol at or above the legal limits stated in the Norwegian Road Traffic Act: $0.2 \mathrm{~g}$ alcohol per kg blood 
or $0.1 \mathrm{mg}$ alcohol per litre breath (171). The prevalence of alcohol use declined by 14.9\% from 2008 to 2015 (Fig. 4).
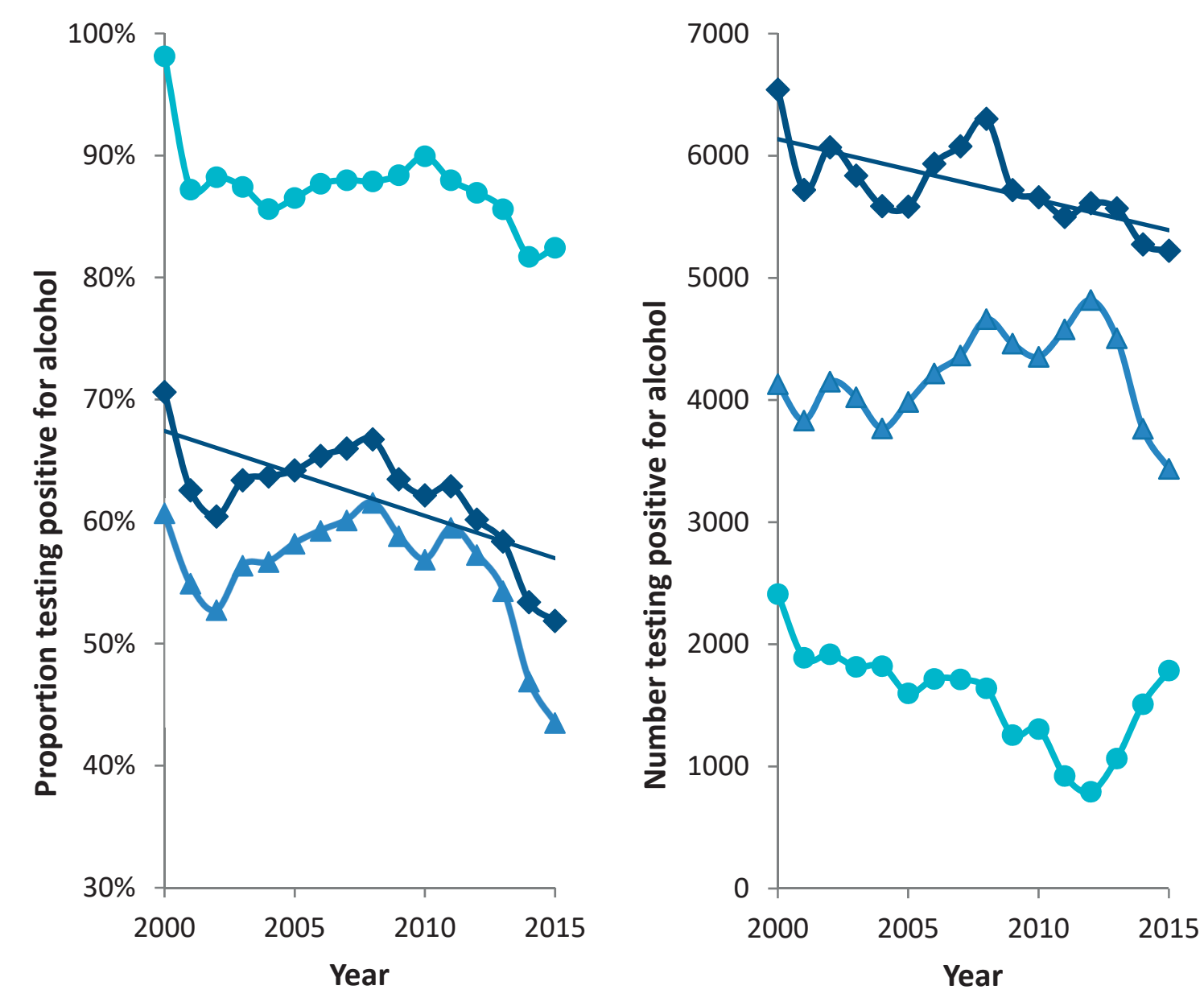

-Blood samples

- Blood samples

-Breath samples

-Breath samples

$\leadsto$ Blood + breath samples

$\neg$ Blood + breath samples

Figure 4. Left: proportion of drivers suspected of driving under the influence of drugs or of alcohol found positive for alcohol at or above $0.2 \mathrm{~g} / \mathrm{kg}$ in the blood or 0.1 $\mathrm{mg} / \mathrm{L}$ in breath. Right: the number of alcohol findings at or above $0.2 \mathrm{~g} / \mathrm{kg}$ in the blood or $0.1 \mathrm{mg} / \mathrm{L}$ in breath. Source of breath samples: Police data 
The breath samples analysed with Intoxylizer (2000-2012) were taken based on suspicion of alcohol use in the following circumstances: involvement in non-fatal road traffic crash (41.8\%); tips from family, friends, or observers of unsafe driving (30.3\%); planned traffic control by the police (20.1\%); other or unknown reason (7.7\%). The breath samples analysed with Evidenzer (2013-2015) were more often taken after planned traffic control by the police (55.2\%) and much less often taken after involvement in non-fatal road traffic crashes (9.1\%), compared with the previously taken breath samples. 'Tips' was the reason in $29.4 \%$ of the cases; other or unknown reason constituted $6.4 \%$ of these breath samples.

Drivers testing positive for alcohol at or above $0.2 \mathrm{~g} / \mathrm{kg}$ in the blood or $0.1 \mathrm{mg} / \mathrm{L}$ in breath increased in age during the study period. The number of alcohol-positive drivers aged $\geq 40$ years increased slightly from 2000 to 2012, and thereafter declined sharply; the number of alcohol-positive drivers aged $<20,20-29$, and 30-39 years declined after 2008 in addition to a faster decline after 2012.

\subsubsection{THC concentrations}

Detected mean and median concentrations of THC in samples from those suspected of DUI of drugs declined sharply from 1990 to 1994, and thereafter increased slightly to the same level as in 1990, in 2009, followed by a more rapid increase during 2009-2015 (Fig. 5). The same trend was found for all age groups: <20, 20-29, 30-39, and $40+$ years. Samples with concentrations in the range $2.0-4.9 \mathrm{ng} / \mathrm{ml}$ and above $5.0 \mathrm{ng} / \mathrm{ml}$ increased in numbers after 2008/2009, but the highest concentration increased the most, resulting in a continuous increased prevalence of $5.0+\mathrm{ng} / \mathrm{ml}$ samples. The number of samples with concentrations below the per se limit, in the range 1.25-1.99 ng/ml remained stable in 2000-2015 (concentrations below the per se limit not included in Fig. 5). When considering only samples where THC was the only substance detected, $55 \%$ had THC concentrations below $5.0 \mathrm{ng} / \mathrm{mL}$ in $2000-$ 2015.

Time from apprehension till blood samples collection decreased evenly during the period with recorded times-2002-2015. Median time decreased by 22 minutes in 
2002-2015, and by 12 minutes from 2008 to 2015. From the same period, the decrease for the 25 th and 75th percentiles was 10 and 20 minutes, respectively, and may partly explain the increase in THC concentration.

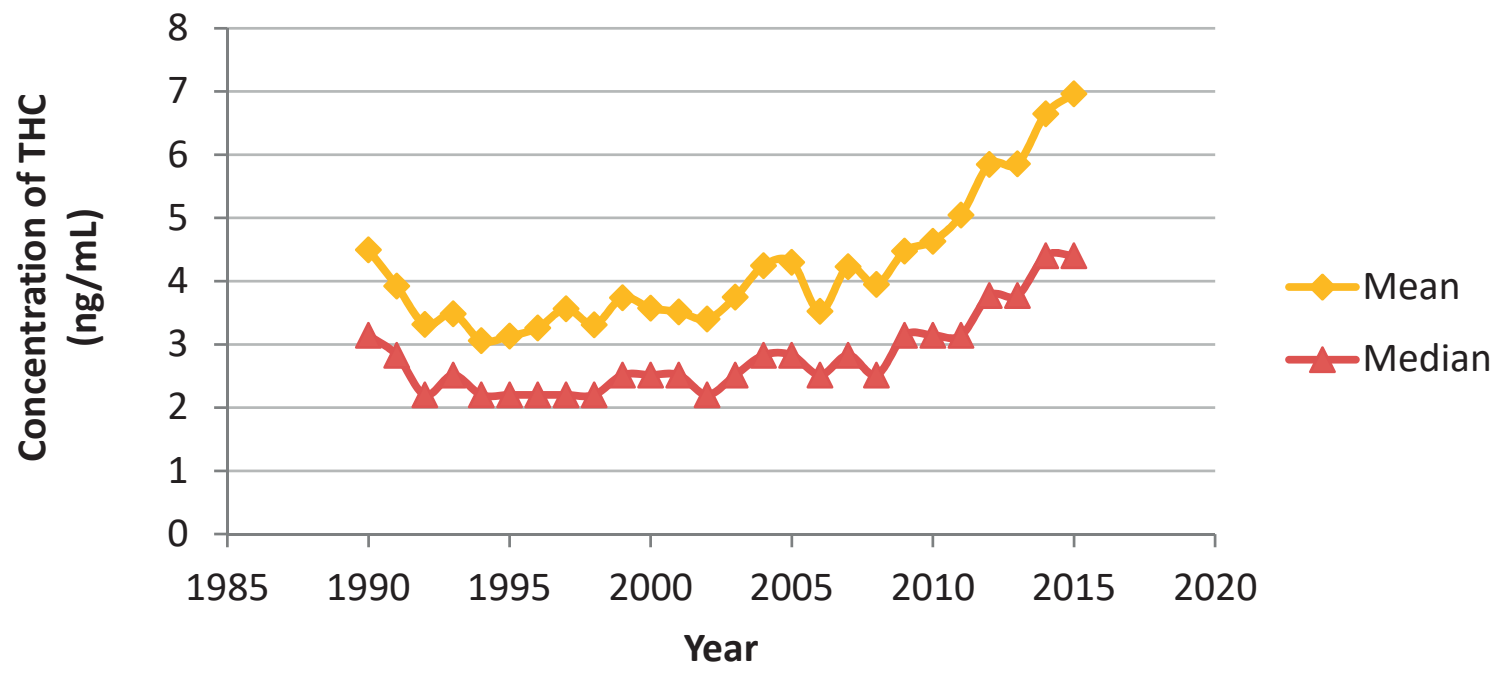

Figure 5. Mean and median tetrahydrocannabinol (THC) concentrations (ng/mL) detected among Norwegian drivers suspected of driving under the influence of drugs in 1990-2015. 


\section{Discussion}

The main findings in this study can be summarised as follows. The prevalence of alcohol use declined during the study period, both among motor vehicle drivers arrested under suspicion of DUI of alcohol or drugs and among fatally injured drivers. Among arrested drivers, the prevalence of amphetamine use increased among the oldest group, whereas that of cannabis use increased among all age groups, and the most among the youngest drivers. Among fatally injured drivers, no statistically significant change in prevalence was observed for any drug group. Furthermore, a substantial proportion of all the drivers and riders fatally injured in a road traffic crash, including those who were sober, had not used a seatbelt or a helmet, or had been speeding inappropriately, but the proportions of these reasons were declining. Concentrations of alcohol or drugs indicating impairment among car and van drivers were found to be associated with non-use of a seatbelt, speeding, and lack of a valid driving licence. Alcohol was associated with all risk factors, whereas some differences were found across other drug types. Among motorcycle and moped riders, alcohol was found to be associated with non-use of a helmet and lack of a valid driving licence. The prevalence of vehicle safety installations increased during the study period. Crash characteristics among riders deviated slightly from those found among drivers.

\subsection{Trends in psychoactive substance use}

\subsubsection{Prevalence among drivers arrested or killed}

The most common psychoactive substances used by Norwegian drivers who were either fatally injured in road traffic crashes or arrested for suspicion of DUI were alcohol, benzodiazepines, amphetamines, and cannabis (THC); other drugs, like opioids, z-hypnotics, MDMA, and cocaine, were less frequently or rarely detected. The prevalence order of these substances was equal among both the DUI suspects and fatally injured, although the prevalence numbers were higher in the former 
(Papers I, IV). The reason for this higher prevalence among arrested drivers was that they often were arrested and subjected to alcohol and drug testing owing to aberrant driving, whereas for killed drivers, blood samples were collected to confirm or reject alcohol or drug impairment as contributing cause of the crash. Judging impairment in a crash scene situation is difficult, and many of the killed drivers were confirmed to be sober. Among arrested drivers, those who tested negative for substances had often been involved in a road traffic crash (Paper I).

Norwegian drivers arrested for suspicion of DUI included both drivers and riders of all sorts of motor vehicles; the data could not be split by vehicle type as this information was not present in the database. Among the fatally injured, drivers and riders could be separated. Among the fatally injured riders, impairment by alcohol and drugs was less prevalent compared with the fatally injured drivers (Paper IV), probably because of the vulnerability of the riders; even minor mistakes can more easily lead to a fatal road traffic crash for a motorcycle rider than for a car driver, both because the car is more stable and because the driver is protected by the vehicle body during a crash, whereas the rider has a high risk of severe injury or death when involved in a crash (172).

A 2019 meta-analysis (173) found 12 adequate papers published between 2011 and 2018 reporting alcohol use prevalence among fatally injured motorcycle riders. The prevalence of alcohol use estimated based on those 12 studies was 30\% (95\% CI, 25-35\%), with greater prevalence among those aged 25-35 years. Five of the 12 studies were from the US; only one was from Europe. The findings were therefore not fully representative of riders killed in European countries, as confirmed in our study that revealed a $12 \%$ prevalence of alcohol use among fatally injured motorcycle riders in Norway (Paper IV). The higher prevalence of alcohol use among those aged 25-34 years compared with among both younger and older riders, was also found in our study (Paper IV).

The psychoactive substances and prevalence order (alcohol with the highest prevalence, followed by benzodiazepines, amphetamines, and cannabis) found 
among the Norwegian DUI suspects correspond with findings reported in other Nordic countries. The exact same prevalence order of substance groups was found among DUI suspects in Finland investigated for drugs in 2000-2007 (174). Findings among DUI suspects in Sweden in 2001-2004 were also similar, except that benzodiazepines were less frequently detected (126). DUI suspects in Denmark in 1997-2008 were also most frequently using benzodiazepines, although they were significantly less frequently using amphetamines and more often using cannabis and cocaine (175). A difference in stimulant use between Denmark and other Nordic countries is also evident from drug seizure data $(176,177)$.

Among fatally injured drivers in other Nordic countries, the reported prevalence order of psychoactive substances correspond with the findings in Norway. The total prevalence of substances found were also similar; of investigated drivers, 35.5\% were positive for psychoactive drugs or alcohol in Norway (Paper IV) in 2005-2015 compared with 42.8\% in Finland in 2006-2008; the numbers are probably more similar because $7 \%$ of the drivers in Finland tested positive for antidepressants (178), which were not included in our study. Seriously injured drivers in two regions in Denmark had used drugs or alcohol in 34\% of the cases in 2007-2010 (179). Alcohol was equally frequently detected (21\%) among fatally injured drivers in Sweden in 2008-2011 as in Norway in 2005-2015; illicit drugs had slightly lower prevalence in Sweden than in Norway (180). Of the fatally injured drivers in Sweden, 95\% are subject to autopsy (180), compared with less than 70\% in Norway. In Finland, all fatally injured drivers are subject to autopsy (181). The Norwegian numbers might therefore be slightly overestimated owing to selection bias.

When comparing prevalence of drugs and alcohol use among drivers worldwide, larger variations have been found. Gonzalez-Wilhelm (182) published a review of papers reporting prevalence of alcohol and illicit drugs being detected in the blood among different categories of drivers worldwide between 1990 and 2005. In general, direct comparison was difficult owing to the inclusion of different age groups of drivers in the studies compared, use of different cut-off values, examination of different time periods, and consideration of different types of vehicles involved. In 
addition, some studies were excluded from the result comparison owing to suspicion of over- or underestimation because their results clearly deviated from those of other studies. For these reasons, the conclusions regarding prevalence of drugs and alcohol use in the review were few: alcohol was stated as generally the most prevalent among drivers, and among illicit drugs, cannabinoids was the most frequently detected. The review suggested the following possible prevalence characteristics: low prevalence of cocaine in Scandinavian countries, high prevalence of amphetamines in Norway and Sweden, low prevalence of cannabis and amphetamines among Scottish drivers, low prevalence of cannabis and high prevalence of opiates in Australia. Reports from the DRUID project, which used the same study protocol across different European countries, later confirmed that amphetamines are more prevalent among drivers in general road traffic in northern Europe, in addition to medicinal psychoactive drugs, whereas cannabis and cocaine are more prevalent among drivers in southern and western Europe, in addition to alcohol (130).

\subsubsection{Trends among arrested drivers}

Among the Norwegian DUI suspects, the prevalence of alcohol use declined in 20002015, mainly because of declining numbers of alcohol-positive drivers aged below 40 years after 2008; the number of alcohol-positive drivers aged $>40$ years declined after 2012 (section 4.5.1). Among DUI of drugs suspects, the prevalence of amphetamine use rose steadily in 2000-2015 among drivers aged 30+ years, but declined among drivers aged < 30 years; cannabis use increased among all age groups and the most among the youngest drivers after 2008. Meanwhile, the prevalence of other drug classes declined (Papers I, II).

A declining trend in benzodiazepine use among DUI of drugs suspects was found in the neighbouring country Denmark in 1997-2008, and diazepam was the most frequently detected benzodiazepine (175). In Norway, diazepam was also the most frequently detected, but the decrease in benzodiazepine use among DUI of drugs suspects started later, after 2002 (Paper I). In Finland, the number of amphetamine findings started to increase rapidly among DUI of drugs suspects after 2002, 
resulting in a slightly declining prevalence of benzodiazepine use and increasing prevalence of amphetamine use in 2002-2007 (174). In a Swedish study, amphetamine use prevalence among DUI of drugs suspects was found to increase from 1990 to 1995, and thereafter remained stable (until 2003) (183), which was in accordance with the trend in amphetamine/methamphetamine use detected among DUI of drugs suspects in Norway from 1990 (Paper I). In Scotland, benzodiazepine and opioid use among DUI of drugs suspects doubled in prevalence from 1996-2000 to 2003 , followed by a minor decrease for benzodiazepines and a moderate decrease for opioids from 2003 to 2008; no significant changes in prevalence were found for cannabis or amphetamine use during all study years (184). In Norway, the most marked trend changes occurred in 2008. For future road safety intervention planning, recent trends are more important. However, the literature available on trends in drug prevalence among arrested drivers in other Nordic countries after 2008 is limited. A study of DUI suspects in 2015/2016 in eastern Denmark used results from 2008 for comparison; stimulant and cannabis use increased, whereas opioid and benzodiazepine use decreased in prevalence (177). These results are in line with our findings on Norwegian DUI of drugs suspects (Papers I, II).

\section{Trends in relation to drivers' age}

Age distributions changed during the study period; the proportion of drivers aged 40 years or older increased among benzodiazepine-, opioid-, amphetamine-, and cannabis-positive drivers from 2000 to 2015. This might be described as the consequence of fewer young drivers recruited to driving after drug use in 20012002 (Paper I), combined with a cohort effect, which means that those who start drug driving at a young age tend to continue to use drugs and drive while growing older, resulting in an increasing number of drug drivers turning 40 years for every study year. Christophersen et al. (23) found a high re-arrest rate among DUI suspects, confirming that many substance users continue to drive under the influence while growing older. Although a cohort effect was observed among the arrested drivers, our study did not use a cohort design; we were unable to follow individual drivers over time. The observed cohort effect might be influenced by selection bias. 
A continuous increase in age was also observed among the arrested alcohol-positive drivers, but here the reason was the declining number of young alcohol-positive drivers rather than the increasing numbers of older ones, especially after 2008 (section 4.5.1).

\section{Alcohol}

A higher level of enforcement and reduced per capita consumption of alcohol was correlated to the reduced level of drink driving in some investigated countries (185). The declining alcohol use prevalence among DUI suspects below age 40 years after 2008 in Norway may be related to the alcohol sales in Norway, which after an increasing trend started to decline in 2008: alcohol sold in Norway increased continuously from 5.7 litres per capita in 2000 to 6.8 litres per capita in 2008, but thereafter declined to 6.0 litres in 2015, and 5.9 litres per capita in $2017(186,187)$. In addition, some alcohol is brought into Norway from sales at airports, ferries, or at the Swedish border; the sales numbers from these sources have increased slightly from the first registration in 2010, and was 0.8 litres per capita in 2017(187). The available numbers may indicate a slight decline in total alcohol consumption in Norway after 2008, at least among parts of the population, as those buying alcohol at airports and the borders do not necessary include all age groups. A positive correlation between changes in sales of alcohol and in the number of drink drivers in Norway and Sweden has been reported (188), although the findings for Norway did not include the period of 1990-2010, when sales numbers increased while the number of drink drivers declined (189). The trend in drink drivers in Norway in 1990-2010 could have been influenced by the reduction in 2001 of the legal limit for alcohol from 0.5 to $0.2 \mathrm{~g} / \mathrm{kg}$, which could have had a preventative effect. Another possibility is that the relation between alcohol consumption in the general population and drink drivers in recent years is valid only among the youngest drivers. In population surveys among young adolescents, alcohol use has been reported to decline continuously from 1999 to 2015 (187); the declining alcohol consumption among the new generations could be related to the decline in young drivers in their 20s being arrested for drink driving in the past years (Paper I). 
2008 can be characterised as the year when the financial crisis reached Norway and Europe. A relation between economic recessions and changes in the number of traffic fatalities has been shown in some countries in previous recessions, and in all investigated OECD countries during the 2008 recession; economic recession has been associated with a disproportionate reduction in driving among high-risk drivers (190). The same mechanisms might have influenced the results in Norway in 2008. A combination of the 2008 recession and declining sales of alcohol might be related to the decline in number of arrested young alcohol-positive drivers after 2008. A study on alcohol-positive fatally injured drivers from Finland supports the theory; this investigation of all fatal road traffic crashes in 2000-2016 revealed a strong positive correlation between recorded alcohol consumption and the number of alcohol-related fatal road traffic crashes, and a strong negative correlation between the alcohol price index (changes in retail prices owing to inflation and taxes) and number of alcohol-related fatal road traffic crashes (181).

We are not aware of any change in enforcement, laws, or other factors in 2008 that could explain the trend change among young arrested drivers. In 2012, however, legal limits for drugs other than alcohol were implemented, and the police had extended possibility to use signs and symptoms testing. The attention to easier methods in mass media for the police to convict drug driving could have resulted in an increased perceived risk for being arrested for drink driving after 2012, preventing more people from driving after use of alcohol. This could be related to our finding that the number of all alcohol-positive drivers declined after 2012; the decline in number of those aged below 40 years occurred at an even higher rate and that in those aged 40+ began in 2012 (section 4.5.1).

\section{Medicinal drugs}

The annual number of findings of opioids, benzodiazepines, and z-hypnotics among DUI of drugs suspects remained stable in 2000-2015, although the prevalence decreased owing to the increasing number of drug-investigated drivers testing positive for only illicit drugs (Paper I). 
The medicinal drugs used by suspects of DUI of drugs could have been purchased at pharmacies based on valid prescriptions but could also have been obtained from illegal sources. In Sweden, more than half of the arrested drivers who tested positive for benzodiazepines, z-hypnotics, or tramadol had obtained the drugs from the illicit market; for flunitrazepam and diazepam, the proportion was about 75\% (191). The situation could be similar in Norway. The number of prescriptions of benzodiazepines and opioids per population has declined in Norway during the past years (192) but may be unrelated to the declining prevalence of medicinal drug use among DUI of drugs suspects based on the following:

1) In most cases, benzodiazepines are prescribed to users aged above 60 years (193), whereas the majority of the DUI of drugs suspects who had used benzodiazepines were aged under 40 years (Paper I).

2) Benzodiazepines (including z-hypnotics) or opioids detected among DUI of drugs suspects were rarely found without additional presence of drugs from other drug classes (Paper I). In addition, the concentrations found among the suspects were often higher than common therapeutic levels. Only $0.9 \%$ of the suspects who tested positive for benzodiazepines or z-hypnotics in 2013-2015 could have been using allowed therapeutic doses; some had concentrations above the legislative limits (194).

3) The most detected benzodiazepine among the DUI of drugs suspects was clonazepam (Paper I), which is rarely prescribed, and only to about 10,000 users in Norway in 2015. As a comparison, diazepam was prescribed much more often, to about 110,000 users in 2015 (193). According to seizure statistics, however, the proportion of clonazepam seizures among all benzodiazepine seizures increased from 14\% in 2005 to about 50\% in $2015(195,196)$. Clonazepam was thus mainly obtained from the illicit drug market.

There seems to be a good correlation between benzodiazepine seizures and use among arrested drivers; other examples of positive correlations between benzodiazepines used by DUI of drugs suspects and seizure statistics are given in a previous study (197). 


\section{Illicit drugs}

For substances that are relatively frequently used, seizure statistics from customs and police can be a good indicator of the changes in availability of the substance. In Norway, the frequency of both cocaine and amphetamine/methamphetamine seizures increased slightly in 2006-2015; however, the total amounts did not increase significantly, and the potency decreased. Cannabis seizures dominate the seizure statistics, and the potency of drugs seized has increased over time (195). The annual number of cannabis seizures remained at about 4,500 between 1990 and 1996, and thereafter started to increase for every year between 1997 and 2001, followed by plateau, and finally another increasing trend from 2008 to 2013 (198). Both the changes in trend towards increase in number of seizures registered in 1997 and in 2008 were reflected among drivers arrested by the police suspected of DUI of drugs (Paper I). The prevalence of cannabis use among the drivers increased in 1997; however, no further increase was noted after 1999. Meanwhile, cannabis use also increased among drivers between 2013 and 2015. Despite these minor differences, the seizure statistics indicate an increased availability of cannabis in Norway in those years where we observed an increasing trend in drivers being arrested and found positive for cannabis.

The largest increase in cannabis-positive drivers, both in numbers and prevalence, occurred after 2008, which showed a marked trend change (Paper II). The availability of cannabis increased sharply after 2008, based on the seizure statistics, and this was likely related to the observed increase in use of cannabis among arrested drivers. However, there may be other possible explanations for the increasing trend among drivers. Two roadside surveys performed in 2008-2009 and 2016-2017 did not find an increased prevalence of cannabis (THC) use among drivers in random road traffic (199), suggesting that the increase in number among arrested drivers might have a different explanation than the increased number of cannabis-using drivers. The stable trend found when comparing these two roadside surveys could be influenced by the implementation of roadside drug tests in 2015, which received media coverage and could have led to a preventive effect in 2016- 
2017, the years after our study of arrested drivers ended. Thus, any direct comparison is difficult.

A review by Cascini et al. described a tendency of increase in THC content in cannabis products worldwide in 1979-2009 (200). A comprehensive study in France revealed that the THC content in cannabis resin seized in France increased slowly in 1992-2009 and thereafter increased from $10 \%$ in 2009 to $23 \%$ in mid-2016; THC content in herbal cannabis increased from $2 \%$ in 1995 to $7 \%$ in 2009 , and to $13 \%$ in 2015 (201). In the US, a gradual increase in THC content in cannabis products was observed in 1995-2014 (202). Higher THC concentrations in cannabis products might have led to more significant impairment among users. With higher impairment, the crash risk and chance of being arrested are likely to increase; hence, some of the observed increases in the number of DUI of drugs suspects testing positive for THC might have been caused by the higher proportion of them being arrested, and not due to a higher number of cannabis-using drivers.

The hypothesis related to the increased potency of cannabis products is rather complicated to verify in Norway. An analysis of cannabis products seized in Norway in 2013-2014 did not reveal high-potency cannabis (203). Meanwhile, our results showed an increase in mean THC concentrations detected among arrested drivers from $4.5 \mathrm{ng} / \mathrm{ml}$ in 2009 to $7.0 \mathrm{ng} / \mathrm{ml}$ in 2015 (section 4.5.2), which might indicate an increase in THC concentrations in cannabis products used in Norway, despite the lack of such findings in the analysed seizure samples. Further complicating the picture is the fact that a part of the increase in detected THC concentrations was most likely due to reduced time from the police's apprehension of drivers till blood sample collection. Because the THC concentration in the blood drops fast after intake, the median decrease in time to blood sample collection from 2008 to 2015 of 12 minutes (section 4.5.2) could slightly increase the median THC concentration measured (85). Moreover, as both concentration intake of THC and time of intake prior to apprehension are unknown, it is not possible to calculate and state exactly how much reduced time to blood sample collection contributed to the observed increase in THC concentrations. Nonetheless, the increasing THC concentrations in 
cannabis products is not likely to explain fully the trend change towards more cannabis-positive arrested drivers after 2008/2009, because the number of those who were multi-substance users with additional use of cannabis increased faster after 2008/2009 (Paper II), and they would probably have been detected by the police for impaired driving even without additional use of cannabis.

The Mobile Police Service, which arrested about $12 \%$ of the drivers included in this study, has announced that they have gradually improved their skills in recognizing the signs and symptoms of drug use through training programmes. They have also stated that traffic controls in recent years have, to a higher degree, focused on places with expected high prevalence of drug and drink driving (personal information from G. B. Clausen, The Mobile Police Service). In addition, the Mobile Police Service has implemented ANPR equipment, which enables them to recognize easily cars owned by drivers who have been convicted for DUI or involved in drug-related crime, thereby increasing the chance of apprehension. Based on the samples analysed for only alcohol, an increased proportion of the drivers at the end of the study period had been arrested under suspicion after being observed in traffic controls, compared with in the first years when more samples were taken of drivers involved in road traffic crashes (section 4.5.1). Some studies have reported that cannabis users might be able to compensate for some of the impairing effects they notice, e.g. by taking fewer risks and driving more slowly (204-206), although they are not able to compensate for slow reaction during unexpected events and some other impairing effects of cannabis $(79,206)$. A higher proportion of cannabis-using drivers who drive relatively carefully, despite showing some symptoms of cannabis use, might have been arrested because of the improved skills among the police. We would expect the total numbers of DUI suspects to increase, or the proportion of the analysed suspects found positive for drugs or alcohol to increase, if the increase in cannabis findings was due to increased skills among the police; however, both trends remained stable (Paper I). Meanwhile, we were unable to identify and separate samples from drivers arrested by the Mobile Police Service from the remaining samples from other police divisions. Such data might reveal different concurrent trends. 
The final conclusion on this matter is that we do not have sufficient information to be able to describe to what extent the observed increase in cannabis use among arrested drivers could be explained by reasons other than an increase in use of cannabis combined with driving. The observed increase could be due to a combination of increased availability of cannabis, increased potency of cannabis products, and improved skills among the police. It could also be that more people who use cannabis now combine use with driving, because of the more liberal attitudes towards cannabis use in society. Norway has had a relatively tempered public debate on cannabis decriminalisation and legalisation in the past few years, with the involvement of politicians, the police, researchers, doctors, and both conservative and liberal organisations; the debate can be characterised as polarised (207). Legalisation and decriminalisation of cannabis in some US states during the past years have probably contributed to fuelling the Norwegian debate. The polarised debate might have contributed to the lower risk perception or broader acceptance of cannabis use among Norwegians in the past few years. A study among 15-16-year-olds in Norway showed that although use opportunities were stable in the years 2007, 2011, and 2015, use among those with such opportunities increased significantly during the period (208).

\subsubsection{Trends among killed drivers}

In our study of fatally injured drivers and riders, we found a decline in alcohol use prevalence (Paper IV), which correlated with the trend revealed among the arrested DUI suspects in Norway (Papers I and II, additional results section 4.5.1), in addition to international trends. Christophersen et al. (209) compared published studies from Brazil, Australia, Norway, Spain, and the US, and found that a general trend in highincome countries was the decreasing proportion of alcohol-related road traffic crashes and increasing proportion of cannabis- and stimulant-related fatal road traffic crashes in the past decades. Our study did not have sufficient statistical power to analyse a possible trend in stimulants and cannabis among fatally injured drivers in Norway. An increase in stimulant use among the oldest arrested drivers in the past years (Paper I) might indicate a similar trend among fatally injured drivers, if 
the data were analysed by age groups. The prevalence order of substance groups found among fatally injured (Paper IV) and arrested drivers (Paper I) was the same, which strengthens the theory that arrested drivers suspected of DUI and users of drugs and alcohol fatally injured in road traffic crashes belong to the same subpopulation of high-risk drivers. The argumentation for this is as follows: in cases of DUI of psychoactive substances, the driving performance and attention are often reduced. Whether the drug- or alcohol-influenced driving trip ends as a road traffic crash or not is related to several factors, such as the degree of intoxication or impairment, speed, road traffic density, road conditions, weather, and risk-taking behaviour, as well as any random factor. In other words, arrested substance-positive drivers could have ended up being fatally injured in a road traffic crash instead of arrested by the police. Owing to the low number of fatally injured drivers in Norway, statistically verifying the findings is difficult. Trends among arrested drivers were therefore used as proxy for trends among fatally injured drivers.

Other countries have been able to report trends in drug use among fatally injured drivers. In Canada, findings of cannabis and cocaine increased significantly among fatally injured drivers between 2000 and 2012 (210). In six US states with high investigation rate, the use of cannabis and psychoactive medicinal drugs increased significantly among fatally injured drivers between 1999 and 2010; alcohol use prevalence remained stable at about 39\% (211). It should however be mentioned that the database used in this US study (211) only contained information about the top three substance groups detected in the drivers blood or urine (161), which limits the interpretation of the drug trends found. Another study from the US found that alcohol-related traffic deaths involving 18-24-year-olds increased in number from 1998 to 2005, but then declined until 2014 (212). Between 2007 and 2017, the prevalence of positive drug tests increased significantly among fatally injured drivers, indicating an increasing problem with drug driving in the US. However, reliable trends in individual drugs used during this period could not be found, because the FARS database only records up to three drug test results $(213,214)$. 
In six US states, opioid use increased seven-fold among fatally injured drivers investigated in 1995-2015 (215). Moreover, the increase in opioid use among drivers in the US reflects a national problematic situation where misuse of and overdoses from opioids in the population has increased, initiated by aggressive prescribing practices (216). Meanwhile, opioids were rarely detected among the Norwegian fatally injured drivers (Paper IV); Norway has not experienced a similar opioid crisis so far.

\subsection{Driving errors and characteristics of impaired versus sober killed drivers}

\subsubsection{Risk factors associated with drug/alcohol impairment}

When comparing data from fatally injured drivers impaired by drugs or alcohol (above concentrations corresponding to BAC $0.5 \mathrm{~g} / \mathrm{kg}$ ) to those sober, positive associations were found between impairment and the driver-related risk factors of speeding, non-use of a seatbelt, and not having a valid driving licence (Paper III). Among riders, being impaired from alcohol was associated with non-use of a helmet and not having a valid driving licence (Paper III).

Associations between substance use and the risk factors of road traffic injury have also been investigated by other researchers. A national survey in Spain investigated associations between reported use of cannabis or cocaine and non-use of motorcycle helmet or seatbelt, and found, by multivariable logistic regression, use of cocaine, but not cannabis, to be associated with non-use of protective gear (217). Cannabis was neither associated with non-use of a helmet or seatbelt in our study (Paper III). Cocaine was not investigated in depth in our study because only one driver and one rider had cocaine detected in their blood, which did not exceed the concentration limit for inclusion. Another survey was performed in Texas among women aged 1624 years to investigate the associations between prescription drug misuse and pastmonth risky driving behaviours. Using multivariable logistic regression, the study found associations between past month prescription misuse and both drink driving 
and non-use of a seatbelt (218). In our study, we found medicinal drugs to be associated with non-use of a seatbelt. The combined effect of alcohol and medicinal drugs was not investigated in our study; we isolated the effect of medicinal drugs by including interaction terms in the regression model (Paper III). The additional use of illicit substances or alcohol among $62 \%$ of the Norwegian drivers who had used medicinal drugs when fatally injured in a crash implies that their use of medicines might be classified as prescription misuse as well.

In a study using data from fatal road traffic crashes in the US, speeding and other unsafe driving behaviours were tested across drug and alcohol groups by multivariable logistic regression; associations were found between speeding and the substance classes of cannabis, stimulants, and alcohol, and between non-use of a seatbelt and the same substance classes, in addition to medicinal drugs (159). In comparison, our study found speeding to be associated with stimulants and alcohol, but not with cannabis use; non-use of a seatbelt was associated with all substance classes except cannabis. The difference in associations found between cannabis and unsafe driving behaviours could be attributed to the low statistical power in our study, or to the different selection bias when choosing drivers to test for toxicological analysis between the US and Norway. It could also be due to better awareness among users in Norway about the impairing effects of cannabis; hence, more cannabis-impaired drivers in Norway might have attempted to compensate for the impairing effects by driving slowly and using a seatbelt.

In all, the associations between impairment by drugs or alcohol and unsafe driving behaviours found in our study were in line with the associations reported in other studies. However, the interpretation of the results is not as straightforward. There is evidence from experimental studies that all the psychoactive substance groups included in our study reduce driving performance to some degree $(63,66)$. In Paper III, we used graded sanction limits corresponding to a BAC of $0.5 \mathrm{~g} / \mathrm{kg}$ for inclusion in the impairment group, which is about 2.5 times higher than the Norwegian per se limits; for stimulants, concentrations five times the per se limits were used. This was done to ensure that the selected drivers were likely impaired by the detected 
substances. However, whether the impairing effects of the drugs and alcohol constituted the main reasons for the recorded driving errors leading to fatal road traffic crashes cannot be documented. It could be that those willing to disobey the laws and social norms by taking illegal drugs or alcohol prior to driving have impulsive or sensation-seeking personality or low risk aversion, which could lead them to drive unsafely even when not under the influence of illegal drugs or alcohol. High sensation seekers more often take risks in traffic, in addition to being more prone to abuse drugs (219). However, based on evidence of the psychoactive drugs' effects on driving performance from experimental studies $(63,66)$, and the overrepresentation of psychoactive substances in the investigated road traffic crashes found in this study compared with normal traffic (199), the explanation that solely risk-taking personality traits lead to significant unsafe driving behaviour when psychoactive substances had been used seems unlikely.

When it comes to cannabis, which has recently become a legal recreational substance in some countries and states, different levels of acceptable use in different regions might influence the associations found between cannabis use and unsafe driving. If cannabis use is not accepted in society, a larger proportion of those still using it will be more likely to have a higher risk-taking behaviour, which also might lead to unsafe driving. In Norway, the recreational use of cannabis is illegal and is expected to be rare compared with many other European countries (220). However, in Paper III, we did not find any association between cannabis impairment and unsafe driving behaviours among killed drivers and riders, except for driving without having a valid driving licence.

Based on the results from Paper II, arrested young drivers who had only used cannabis were expected to have been driving unsafely because the initial cause of attention from the police is often aberrant or dangerous driving or crash involvement (section 4.2). However, cannabis-positive young drivers could not be investigated separately from the fatally injured drivers owing to the low statistical power of the study. A recent case-control study investigated crash responsibility across different substance groups and concentrations (221). They did not investigate 
young drivers separately but emphasised that 'the risk associated with cannabis may be higher in young drivers who have a high crash risk at baseline, or in inexperienced cannabis users who may be less able to compensate for cannabisinduced impairment'. Further investigations of the crash risk among cannabis-using young drivers are needed.

We found impaired driving from alcohol or other psychoactive drugs to be associated with the risk factors of speeding, non-use of a seatbelt, and lack of a valid driving licence. However, owing to overlapping confidence intervals, we could not determine which of the drug classes posed the highest risk of each of the risk factors. Nonetheless, we confirmed that alcohol was associated with most risk factors and can be expected to be a stronger risk factor for unsafe driving that leads to driver fatality compared with the other drugs investigated.

\subsubsection{Risk factors not associated with drug/alcohol impairment}

Drowsy/fatigue driving was not found to be associated with impairment by drugs or alcohol in our study (Paper III). Kalsi et al. (222) reported that falling asleep (fatigue cases excluded) while driving is neither related to substance use among fatally injured drivers in Finland. Meanwhile, we found that drowsy/fatigued driving was commonly recorded among sober drivers (20\%) as an important contributing factor in road traffic crashes (Paper III). Among the preventive measures implemented in Norway is the installation of roadside billboards reminding drivers to take a nap if tired. However, our results indicated that more effort should be exerted to prevent crashes caused by drowsy/fatigued drivers.

Very few of the fatally injured drivers in Norway were recorded as attributed to the use of a mobile phone, but other forms of distractions were relatively frequently reported as contributing causes for road traffic crashes (14\% among sober and 9\% among drugs/alcohol-impaired drivers, Paper III). Distracted driving leading to errors and crash might be difficult to verify by crash investigators and might thus be underreported. In the US, distracted driving-related crashes were cited in about onethird of the cases reported to be related to alcohol use in 2009 (223). Meanwhile, we 
did not find any association between distracted driving and impairment from alcohol in our study among Norwegian fatally injured drivers. This could have been because only the risk factors evaluated to be of significant importance were recorded in the database used in our study. The assessment by the crash investigation teams in Norway and in the US might also differ. A study from Finland investigated observational failures/distractions as an immediate cause for fatal road traffic crashes and found that this played a role in drivers aged 60 years and older (224). If this applies to the Norwegian fatally injured drivers as well, that distraction primarily leads to fatal crashes among the oldest drivers, then it might explain the lack of association between distracted driving and alcohol in our study, as very few of the fatally injured drivers aged above 45 years had used alcohol compared with the younger drivers (Paper IV).

\subsubsection{Crash characteristics}

Characteristics of the road traffic crashes killing impaired drivers were that they often occurred at night time, often were single-vehicle crashes, and with the vehicles often being older than 10 years, compared with the road traffic crashes killing sober drivers (Paper III). Impaired drivers were more often male and young compared with the sober drivers. These findings were as expected and have been reported in most studies investigating fatally injured drivers. However, one of the more surprising results in our study was that as many as 30\% of the sober drivers had not used a seatbelt when involved in a crash. Although perhaps not being culpable of all crashes, the sober drivers who had not used a seatbelt were still partly responsible for the fatal outcome.

Based on unpublished research conducted in Finland (181), alcohol-related health problems (cognitive impairment, hangover, liver disease) can cause accidents even if the driver is sober. We did not investigate health status in this study owing to the low quality of the available data. The impact of alcohol on fatalities in Norway might also be larger than estimated from those positive for alcohol. 
The higher proportion of drugs found among fatally injured drivers involved in multi-vehicle crashes and the higher proportion of alcohol found among those killed in roadway departure crashes (single-vehicle crashes) might suggest that alcohol is a more significant cause of crash than drugs, probably because the average impairment level among drink drivers is higher than the average among drug drivers (225). In addition, impairment from alcohol consumption but not from medicinal drugs or cannabis was found to be associated with speeding in Paper III. The different psychoactive effects of the different substances are, in addition to the dose taken, likely to influence the risk of a fatal road traffic crash. It could thus be an advantage to investigate differences in crash characteristics across different substance groups, in addition to those in crashes involving impaired versus sober drivers. Such a research would require a relatively large sample size to reveal all possible differences among substance groups.

\subsection{Possible reasons for declining road death numbers}

\subsubsection{Trends in crash characteristics}

The number of drivers and riders fatally injured in road traffic crashes in Norway declined significantly in 2005-2015 (Paper IV). Road improvements, such as separating lanes with rumble strips, which occurred during the study period (47), in addition to the sale of safer cars (indicated by the increased proportion of ESC and ABS safety features, Paper IV), likely had a significant effect on the fatality rate.

Except for the proportion of ESC and ABS, other investigated crash characteristics did not change much during the study period. The proportion of fatal head-on crashes could have been expected to decrease with the instalment of rumble strips and physical separation barriers at more road kilometres during the study period. However, the proportion of head-on crashes remained at 54\%. This outcome could partly be explained by a competing effect related to the observed decline in alcohol impairment among fatally injured drivers, which could have contributed to reducing the roadway departure crashes the most; a higher proportion of alcohol use was 
found in roadway departure crashes (basically single-vehicle) compared with multiple-vehicle crashes.

The crash characteristics related to time of the crash changed somewhat during the study period. Both for car/van drivers and for motorcycle/moped riders, a lower proportion of the fatal road traffic crashes occurred at night in the latter part of the study period (Paper IV). The proportion of fatal road traffic crashes during weekends was also reduced, although the difference was not statistically significant.

Traditionally, risks of traffic injury are the highest during night-time weekends. Bjørnskau described the reduction in risk of traffic injury at night in Norway, especially among young drivers (226). The declining proportion of young drivers and riders fatally injured in road traffic crashes in 2005-2015 might be related to the decline in the proportion of fatal night-time road traffic crashes compared with daytime weekday crashed (Paper IV). In Denmark, similar findings were reported by Bernhoft et al. (227), including a markedly steeper decline in young fatally injured drivers (<25 years old) in 1978-2004 compared with the older age groups, and characteristics like weekend nights being the typical time of accident among the youngest drivers. These findings in Denmark could be connected because, as described by Bernhoft et al. (227) and translated by Fynbo (19): 'For younger drivers, DUI has not (yet) become a natural occurrence of everyday life, rather it relates to something special like weekend parties, road raging or other social events, and therefore the young drink-drivers are "more likely to be affected by anti-DUI campaigns and/or police controls than ... older persons where a small - but stable group - apparently continue to drink and drive [no matter what]'

\subsubsection{Trends in unsafe driving behaviours}

Improving cars, roads, and roadsides can mitigate driving errors and lead to reduced fatality numbers. However, the same efforts could also lead to a higher prevalence of some unsafe driving behaviours, such as speeding. Our results showed that the proportion of alcohol impairment, speeding, and non-use of seatbelts among fatally injured drivers in Norway declined significantly from 2005-2010 to 2011-2015 
(Paper IV). Therefore, additional preventive measures targeting unsafe human behaviours have been successful, to a large extent.

The fatality numbers from road traffic crashes have been reported to decline in several high-income countries. The types of preventive measures performed that helped reduce the fatality numbers have tended to differ across countries. In Germany, fatalities in road crashes declined in 1994-2002, as did the proportion of the crashes related to alcohol; stricter legal limits for BAC among drivers and the use of breath tests for alcohol among drivers were pointed as contributing causes (228). In Sweden, the fatality numbers of drivers declined in 2000-2009, whereas the proportion of drivers with BAC of $>0.2 \mathrm{~g} / \mathrm{kg}$ remained relatively stable at about $24 \%$ (136), which might indicate a lack of successful measures preventing people from driving after use of alcohol in this period, but that other general measures targeted all drivers. In Norway, declining fatality rates were accompanied by the declining prevalence of alcohol use among fatally injured drivers (Paper IV). The fatalities declined the most among the youngest drivers, who had most often used alcohol, which rarely was present among fatally injured drivers aged above 45 years. Declining trends in self-reported use of alcohol among young adolescents in Norway and declining numbers of alcohol-positive young arrested drivers during the past years, as discussed in section 5.1.2, could also be related to the declining alcohol trends among fatally injured drivers. In general, declining trends in alcohol use might therefore have contributed to the declining road fatality numbers in Norway. Furthermore, the reduction of the legal BAC limit in 2001 and implementation of legal limits for drugs other than alcohol in 2012, in addition to media attention on the increased risk for arrest, could have prevented more people from driving shortly after drinking in the years after modifications were made to the Road Traffic Act. As mentioned previously, 17 out of the 26 countries studied in Europe had a faster declining rate for alcohol-related road deaths than for road fatalities of other causes between 2006 and 2016 (15). Norway was not included in this study, but the results presented in the present thesis showed that alcohol-related road deaths declined faster than road deaths caused by all other causes in Norway as well (Paper IV). 
Norway has implemented a long list of different measures to reduce speeding, such as information campaigns, installation of speed cameras that detect average speed over a distance, placement of billboards along the roadside to encourage safe driving, roadside controls, strict enforcement, and reduced speed limits on some roads. The efforts seem to have had positive effects, as fewer drivers in normal traffic drive above the highest speed limits (229). In addition, the proportion of fatal road traffic crashes where speeding was reported as a significant contributing factor has declined (Paper IV). Hence, reduced speed might have contributed to the decrease in road fatalities in Norway in 2005-2015. In several countries, the instalment of speed cameras has been pointed out as a major reason for decreasing the numbers of fatal and serious crashes $(38,49,230)$. In Norway, the installation of speed cameras in 2004-2010 led to decreased road traffic crashes with human injury by $9 \%$ up to 3 km downstream of the cameras; road traffic crashes with severe or fatal injuries were reduced by 39\% (231). There is more potential for further reduction of speedrelated injuries, as the regulations for where to allow for the instalment of speed cameras have been strict. Moreover, the testing and installation of speed cameras that detect the average speed, which have been found to be more effective than traditional speed cameras, have been slow in Norway compared with many other countries (48).

As for speeding, different measures have been initiated to reduce non-use of a seatbelt among drivers in Norway. Examples are roadside controls, strict enforcement with fines, and information campaigns, and from 2003, the use of billboards along the roadside that evoke feelings of responsibility over others as a measure to encourage safe driving (Fig. 6). A study performed by recording seatbelt use in normal traffic showed a gradual increase in the proportion of drivers and passengers that used a seatbelt in Norway from 2006 to 2013 (232). This, combined with a higher degree of seatbelt use among those fatally injured in the latter part of the study period (Paper IV), leads us to conclude that a higher degree of seatbelt use might have contributed to the decline in road fatalities in Norway during the past years. In the US, an increasing trend in seatbelt use among drivers in normal traffic in 
2000-2017 was accompanied with a decline in the proportion of fatally injured vehicle occupants that were unrestrained (only daytime cases reported) (233).

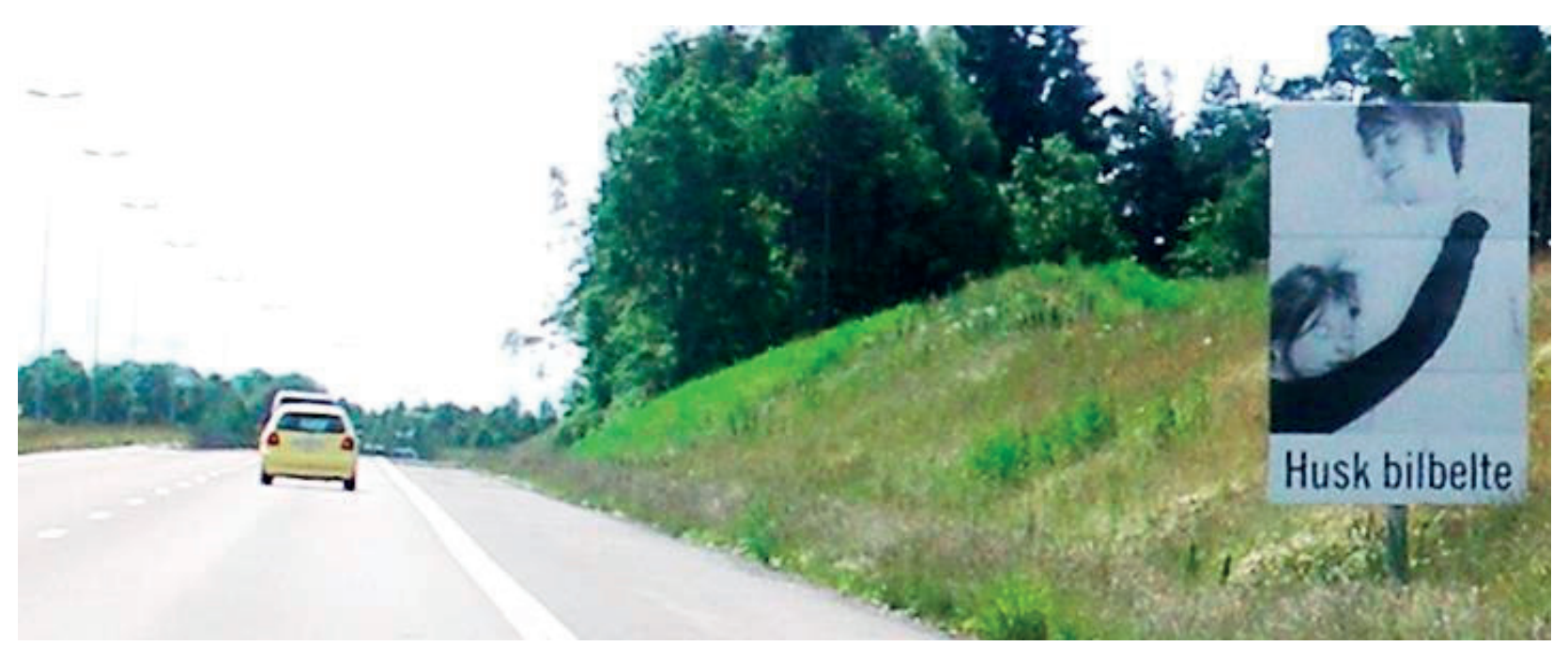

Figure 6. Remember seatbelt. Billboard along the roadside in Norway. Photo: Wikimedia Commons (Guttorm Flatabø [CC BY-SA 2.5])

\subsubsection{Age and sex trends}

Young drivers have been described as at an increased risk of dying in road traffic crashes owing to immature decision-making combined with a higher degree of impulsivity and sensation-seeking behaviour, with the latter seen particularly among men (234). Non-use of a seatbelt, speeding, and impairment from alcohol were more often risk factors among male than female drivers, and more frequent among drivers aged below 45 years than among those aged above 45 years (Paper IV). General measures aimed at preventing non-use of seatbelts, speeding, and drink driving will therefore, logically, have a potential for improvement among young male drivers. Our study showed that preventive measures seemed to have been more successful in reducing fatalities among young males than among female and older drivers. The proportion of female drivers and the oldest drivers increased among the fatally injured drivers during the study period, although fatalities involving these groups also declined in absolute numbers. 
As in Norway, the road fatalities in metropolitan France decreased at a higher rate among drivers aged below 45 years compared with those aged above 45 years from 2005 to 2013 (end of study); the proportion of drivers aged 15-25 years decreased the most (234). In Australia, Canada, South Africa, the UK, and the US, the decreasing number of young road fatalities could be partly explained by the implementation of a graduated driver licensing programme that requires young drivers to avoid high-risk driving conditions for some time after they finish the driving licence course. Examples are restrictions like adult supervision when driving, daytime driving only, and passenger limits (234). Norway does not seem to have such targeted measures, indicating room for further improvements.

The continuous decrease during the past years in number and proportion of younger arrested substance-positive drivers (except for cannabis-positive ones) compared with older ones (Papers I and II, additional results section 4.5.1) might be related to the steeper decrease in young fatally injured drivers compared with older drivers. Other unsafe driving behaviours, like speeding and non-use of seatbelts, were not recorded among the arrested drivers and could therefore not be compared with those fatally injured. In Denmark, in contrast to the case in Norway, the conviction numbers of young alcohol-impaired drivers increased in 1997-2004, but, like in Norway, fatal crashes involving younger drivers was reduced at a steeper rate compared with fatalities among drivers above age 25 years (227). It has been suggested that the trends in Denmark could be partly explained by the traffic police having increased their efforts in arresting young drink-drivers in particular, in addition to the successful reduction in recidivism in this group $(19,227)$. In Denmark, all drivers convicted of DUI of alcohol must pass an alcohol and traffic safety course to be able to return to driving legally (19). In Norway, similar courses are used only in very few situations. The traffic police in Norway may have increased their efforts in arresting cannabis-using young drivers, whose numbers increased after 2008. However, the data did not reveal indications of any total increase in effort because the total number of DUI suspects and the proportion of them found positive for alcohol or drugs remained stable during the study period (Paper I). The causation explaining the observed trends among arrested and fatally injured drivers in Norway 
remain somewhat undiscovered. In Denmark, Fynbo (19) wrote that 'young people's drinking and driving habits in general may have undergone a relatively significant change over the last couple of decades compared to older drivers', which also might help explain how the number of fatalities and convictions has dropped so differently among young and old drivers in Denmark in 1978-2004. The indications of a more significant decrease in alcohol consumption among young adolescents in Norway, compared with adults, are in line with this description.

For motorcycle/moped riders, the trends seem to be similar, except that the proportion of female riders remained stable instead of increasing and that the number of fatally injured riders aged 45+ years showed a tendency of increase during the study period, in contrast to the decline observed for younger riders and all drivers (Paper IV). The trends observed could be due to improvements targeting younger riders more than older ones, or to the increasing number of older motorcycle riders. The declining numbers of fatally injured riders aged $<45$ years could be related to the declining proportions of speeding, non-use of helmet, and use of alcohol in fatally injured riders (Paper IV). Although not investigated, older riders might be more careful not to drive unsafely compared with younger riders, like we found for car/van drivers fatally injured in road traffic crashes. If this is the case, then mitigating the mentioned risk factors among riders will have a minor effect among the oldest riders, who constituted the largest part of the fatally injured riders in Norway.

\subsection{Methodological considerations}

Methodological issues that might have influenced the results or interpretation of the results are discussed in this section. These issues are closely related to the study design. 


\subsubsection{Study design}

The present work used retrospective cross-sectional registry and retrospective timeseries cross-sectional register study designs. Retrospective studies designed as cross-sectional are well suited and often used to determining the prevalence of conditions and incidence of events. Cross-sectional studies might also be repeated, and used to study trends in prevalence over time, called time-series. This design will not give any information about trends on an individual level but only consider the total prevalence in the population at different time points. Trends determined from repeated cross-sectional studies might be influenced by selection bias (235).

Cross-sectional studies are also well suited to assessing associations between variables in a population. However, cross-sectional studies generally cannot prove causal relations between variables, such as independent and dependent variables, as both types of variables are assessed at the same time $(59,235)$. If the independent variable is an inherent characteristic, like sex, and the dependent variable is something developed over time, the cause and effect could only go one way. Caution in the interpretation of results is important also in these situations because the association observed between variables could be due to other confounding variables, and alternative explanations for the results should always be considered (236). Parts of the discussion sections, both in the papers and in this thesis, focused on alternative explanations for the interpretations of the results.

Register studies, including those used in this study, often use data originally collected for other purposes than research, called secondary data when used for research purposes. An advantage of using secondary data is that they are inexpensive and take a short time to collect compared with primary data; indeed, secondary data often yield larger datasets, which have better statistical power (236). Another advantage with use of secondary and register data is that recall bias is not an issue, unlike in population surveys where self-reported drug-use and other sensitive topics are often underreported $(237,238)$. The disadvantage with use of secondary data is that the researcher cannot influence the data collection, including the selection of study subjects (leading to the risk of selection bias), measurement 
techniques (leading to the risk of information bias), and the variables to include (leading to the risk of confounding effects that cannot be adjusted for). These limitations are further discussed below.

\subsubsection{Internal validity}

Internal validity is the degree to which the observed findings in a study sample lead to correct conclusions/interpretations regarding that particular study sample (239). An alternatively description is as follows: 'internal validity means that the study measured what it set out to' (240). In Papers I and II, this was determining the prevalence and trends in drug use among suspects arrested for DUI of drugs. In Paper III, the purpose was to measure the associations between impairment by drugs or alcohol and other recorded risk factors of traffic injury among fatally injured drivers. In Paper IV, the purpose was to measure the prevalence and trends in impairment by drugs and alcohol and other recorded risk factors of traffic injury among fatally injured drivers, in addition to investigating possible trends in crash characteristics. In this chapter, different aspects that could have influenced the internal validity in Papers I-IV are discussed. Some important factors affecting the internal validity are sample size, information bias, selection bias, and confounding. Those factors are discussed below.

\section{Sample size}

The sample size of arrested drivers (Papers I and II) constituted more than 100,000 cases and can be described as very large. The sample included all drivers suspected by the police of DUI of drugs and subjected to blood sampling for analysis of drugs in addition to alcohol during the study periods. Consequently, the reported prevalence numbers and trends can be considered reliable and not subject to random errors. Differences between groups tested in a large dataset might be statistically significant, as in cases when the difference is minimal and carries no practical implication (241). P-values denoting statistical significance between groups were not given much weight in the results discussions in Papers I and II. 
For the studies of fatally injured drivers (Papers III and IV), almost all killed car/van drivers and motorcycle/moped riders who were subject to toxicological investigation were included. The exception was about $5 \%$ of drivers and riders killed in road traffic crashes during the study period, for whom digitised data were not available. The collected sample size is adequate; however, when categorised into smaller groups/strata, such as based on age groups or substances used, the size of the groups were too small in some cases to make reliable conclusions. Some tendencies were found but were not statistically significant. With a lower sample size, the difference between groups must be larger than that in a larger dataset to gain statistical significance. Nonetheless, the lack of statistical significance does not immediately mean that the tendencies or trends found are false (241), only that the results be interpreted with care. Some of the results in Papers III and IV that were not statistically significant were thus given little or no attention in the discussion here.

\section{Information bias}

Inaccurate measurements or misclassification, described as information bias, might reduce the internal validity of a study (242). In all the papers, measurements were analyses of substances in blood samples, which could give the best possible correlations between detected concentrations and level of impairment caused by drugs or alcohol. The laboratories were accredited, the methods used for sample preparation and detection were validated after international standards, and the laboratories participated in international inter-laboratory comparisons of test samples. The risk of false positive results was thus minimal, and the reliability of the toxicological methods used was good. Measurement errors at low concentrations is a well-known issue, and lower cut-off concentrations for reported results were therefore restrictive, referring to those used both by the laboratory and in this study. Some improvements in detecting lower concentrations were reported in the laboratory during the study period. These were corrected for by using relatively high lower cut-off concentrations for the results included in this study. Some random errors might have been committed by laboratory personnel handling the samples or might have occurred in the verification of the results. Random errors might also have 
occurred when data were manually plotted or scanned into databases. A significance level of 5\% was used in all statistical testing, meaning that some random errors were calculated for. Post-mortem changes in substance concentrations in the blood might have slightly lowered the internal validity in Papers III and IV $(243,244)$.

A strength of our study (Paper III), compared with previous ones, is that we analysed for a comprehensive number of psychoactive substances in blood samples; practically all samples were analysed for the same drugs and information of all drugs was available to the researchers. In addition, we used the same cut-off concentrations consistently during the study period and made a clear distinction between sober and impaired drivers. Thus, the calculated ORs (Paper III) with a higher probability reflected the effects of the psychoactive substances on driving performance, compared with other studies that calculated ORs based on recent use of psychoactive substances. Some studies have partly based on urine drug testing or low drug concentration cut-offs in blood samples, which may not reflect impairment, and might therefore introduce bias to the calculated ORs downwards (158-160). Meanwhile, our study had one limitation related to this context. Methylphenidate is included in the Norwegian Road Traffic Act; however, with the lack of literature confirming its role in increased crash risk or reduced driving performance, this drug should have been left out of our study. The one case we found that fulfilled our inclusion criteria of five times the per se limit of methylphenidate was not likely to have influenced our study results significantly.

In addition to the substances that are assigned with legislative limits, some other drugs may also reduce the ability to drive safely, such as some antidepressants, antipsychotics, anticonvulsants. However, few drivers are convicted for driving under the influence of those types of substances in Norway so the impact of not including them in our study is small. The so-called Novel Psychoactive Substances (245) were neither included in our study. They may reduce driving performance, but are rarely analysed for because of the very quick shift in individual substances available on the market, each expected to be rarely used. 
In Papers III and IV, the other source of data was the Crash Investigation Team Database. Data recorded in this database are generally expected to be relatively consistent, as the variables recorded are described in schemas used by crash investigators. Misclassifications might have occurred because the crash scene situation is often complex and complicated to analyse; thus, caution is needed when interpreting any of the findings not found to be statistically significant. Information on health issues was excluded from the present study, as the recording of health data had not been done in a systematic and controlled manner for many years (Magnus Larsson, personal communication). For all variables other than driving licence status and non-use of a seatbelt, only variables evaluated by multidisciplinary teams as significant to the road traffic crash or fatal outcome of the crash were included in the database, and thus also in this study. Some non-significant but occurring driving errors were likely to have been left out from some of the crash reports. It might be that some risk factors, such as lack of experience or being tired, were reported less often among drivers who were clearly impaired by drugs/alcohol than among sober drivers. A likely consequence would be that some actuals associations were not discovered in this study. However, the possible under-reporting of some risk factors is not likely to affect the validity of the associations found in this study, but the ORs reported might have been inaccurate.

\section{Selection bias}

In Papers I and II, the included drivers constituted 100\% of all drivers arrested under suspicion of DUI of drugs, all of whom were subjected to toxicological analysis. The police selected the drivers based on suspicion; thus, the drivers were not a random sample of drug drivers in road traffic. Given that the purpose was to study prevalence and trends among arrested DUI of drugs suspects, selection bias from our side did not occur. However, it is likely that some drivers suspected by the police of DUI of drugs were tested only for alcohol in the first part of the study period, because of less focus on drug driving and because convicting drivers for drug driving only became easier for the police after the per se limits were implemented in 2012. We therefore focused most on prevalence trends in drugs detected among those 
investigated for drugs, instead of trends in exact annual numbers of drug-positive drivers, both in the papers and in this thesis.

Drivers arrested under suspicion of DUI of only alcohol were included in this thesis in section 4.5.1. Thus, this work included $100 \%$ of all drivers arrested under suspicion of drug or alcohol use. There was no selection bias when handling these drivers together for the purpose of studying trends in alcohol use among arrested drivers suspected of DUI of alcohol or drugs.

In Papers III and IV, the target population was the fatally injured car/van drivers and motorcycle/moped riders. Drivers of other vehicle types were not studied because they were few (about 10\% of all fatalities) and constituted a non-homogeneous population that included drivers of buses, minibuses, trams, tractors, lorries, trucks, snowmobiles, and all-terrain vehicles. In addition, data on other types of motor vehicles were not available to the researchers in the first years of the study period. The unknown proportion of other types of vehicles used by the arrested DUI suspects makes a direct comparison of findings among arrested drivers/riders and fatally injured drivers/riders somewhat inaccurate.

In Paper III, the included drivers and riders constituted 63\% of the fatally injured drivers and riders in Norway in 2005-2015; the remaining drivers were not analysed for alcohol or drugs. The decision made by the police on whether or not to test for alcohol or drugs may have caused some selection bias affecting the internal validity. It is possible that the police prioritise testing of drivers who presented characteristics or behaviour assumed to be associated with DUI.

In Paper IV, all drivers and riders were included when assessing the prevalence and trends of other driver-related risk factors of road traffic crash. When analysing impairment by drugs or alcohol, only the $63 \%$ who had been subjected to alcohol and drug testing could be included. The potential selection bias in Paper IV is therefore limited to the results regarding substance use. There could have been a change in selection bias over time; we discovered that age, sex, road traffic crash 
type, and other variables differed among those subjected to toxicological investigation and those not, and also that the differences changed over time (Paper IV, supplementary table). Thus, changes in selection bias might have influenced the observed trends in drugs and alcohol use among fatally injured drivers.

\section{Confounders}

Confounding variables are associated with both risk factor (exposure variable) and outcome variable and might be the cause of the association measured between the two. It is therefore important to know about and adjust for confounding variables before claiming that the risk factor resulted in variation in the outcome variable. The problem is that confounding variables often are unknown, known but unrecorded, or impossible to measure and adjust for.

Age and sex are often considered as confounders. We adjusted for age and sex in Papers III and IV (confounding was not an issue in Papers I and II). High risk-taking personality, impulsivity, and cultural factors were probably confounding variables influencing most of the results presented in Paper III. We were not able to adjust for these factors, although adjusting for age and sex probably resulted in adjustment for some of the confounding effects, as high-risk driving tends to be more prevalent among young men. The lack of adjustment for personality and cultural factors was, however, unlikely to affect our results significantly, only the interpretation of the results. Furthermore, problematic drug users often have somatic or mental diseases, either as a consequence of their drug use or the other way around, which might also reduce their driving skills. We could not adjust for such variables. We found and reported associations between different substance groups and unsafe driving behaviours but had thus too limited information to claim that the effects of the drugs alone caused the unsafe driving behaviours.

Other factors likely to influence injury severity when involved in a road traffic crash are the safety features and crash-worthy design of the vehicle. As an indicator of the safety level of the vehicle, we used the age of the vehicle (more or less than 10 years). This and some other variables related to the crash were adjusted for in an 
additional model (Paper III). These variables were either confounders or effect modificators (only associated with either the outcome or exposure variables). The purpose was to isolate the effects of the drugs on driving performance as much as possible by comparing equal groups of drivers and conditions. This additional model changed the results only slightly, implying that the associations found in our study were robust. Effect modificators are not necessary to adjust for, but they should ideally be reported, as they might result in high associations between substance use and the risk factors for only some of the participants included, not all (59).

\subsubsection{External validity}

External validity is the ability to generalise study results to a more universal population. In comparison with experimental studies, observational studies like the cross-sectional studies used in our study, tend to have higher external validity (236). However, as with internal validity, a small sample size or improper selection of the sample might also lower external validity (246).

\section{Generalizability of study results: trends in use of psychoactive substances}

The study population used in Papers I and II was large but selected by the police based on suspicion of DUI of drugs; the drivers included in section 4.5.1 (additional results) in this thesis were selected based on suspicion of DUI of alcohol. The risk for arrest by the police was the highest for those who were the most impaired, as random roadside controls could detect only a small part of DUI suspects; most were flagged for observed unsafe driving. The trends in substances used by arrested drivers might therefore not reflect trends in drug and alcohol use among drug or drink drivers who were not arrested by the police.

The reasons for police apprehension during the study period could have changed. The Mobile Police Force has attempted to focus their random roadside controls to times and places where they are more likely to detect drug and drink drivers. Moreover, there has likely been a higher proportion of roadside controls detecting DUI suspects in the latter part of the study period; this assumption is based on the reported source of the only-alcohol samples (additional results, section 4.5.1). 
Change in police procedures has therefore likely influenced the trend results and generalizability of the results, the degree of which is difficult to estimate.

Comparing our results with those in similar studies performed in different settings might give a better idea of the external validity of our results. The trends found in our study were in line with those found among DUI suspects in other countries (mentioned in section 5.1.2), and similar to the trends found among the fatally injured drivers investigated for drugs and alcohol, although the drug trends were not statistically significant (Paper IV).

Our results did not resemble findings from studies of drug and alcohol use by drivers in normal road traffic (199). Meanwhile, the decline in alcohol use coincided with the reported trend in the general population (187), and illicit drug trends among the DUI offenders were in line with seizure statistics in Norway (described in section 5.1.2).

Trends in the use of psychoactive substances in the general population might be related to those among high-risk drug users. A strong positive association have been found in some countries between changes in mean consumption of alcohol in the population and changes in the prevalence of heavy drinkers (247). DUI suspects or substance-positive fatally injured drivers can be classified as high-risk drug/alcohol users, and comparing them with the general population in terms of trends in drug and alcohol use is therefore relevant. Revealing population trends, however, is difficult as participation in population surveys is voluntary and under-reporting is a well-known problem. In Norway, self-reported alcohol consumption is about half of the amount consumed indicated by revenues from alcohol sale (187). Thus, it is expected that some people drink significantly more than reported in the population surveys. In addition, trends in use of drugs or alcohol in the population do not necessarily mean that the trends can be reflected among those driving after use. Roadside surveys are therefore needed. The problem is that these surveys, like population surveys, are subject to under-reporting because participation is voluntary. The most comprehensive roadside survey in Norway was performed in $2008 / 2009$ and repeated in 2016/2017 (199). The proportion of alcohol and 
cannabis use among the drivers did not change, and the proportion of use of other drugs declined. However, the statistical power of the study was not large enough to detect a possible decrease in alcohol use, and the study results may not necessarily contradict the alcohol trend found among arrested drivers. The latter roadside survey was performed the year after our last study year and after the police started using mobile drug tests in the end of 2015 (Dräger DrugTest 5000). Information on the media about the police's new tools for detecting drug use at roadside controls could have influenced people's driving behaviour after drug use. In this case, the trend results reported among drivers in normal traffic and among arrested drivers would be less comparable. It can be concluded that other studies from other settings neither confirm nor contradict the trends revealed among arrested drivers when the different limitations in study design are taken into consideration. The generalizability of our study results thus remains unsure. Trends in substance use among the DUI suspects resembled those in seizure statistics and could therefore reflect the availability of illegal drugs, in addition to trends in use among high-risk drug users who are not necessarily drivers. Trends among the DUI suspects were also likely influenced by the skills and praxis of the police. Trends among DUI suspects could also reflect trends in substance use in a broader population, but we lacked sufficient information to conclude on this matter.

\section{Generalizability of study results: associations between drug/alcohol impairment and unsafe driving behaviours}

The associations found between impairment by drugs or alcohol and other risk factors of traffic injury (Paper III) were based on the data of $63 \%$ of the fatally injured drivers and riders. There might have been some selection bias, which could have made the investigated drivers less representative of all fatally injured drivers. However, the associations presented in Paper III between impairment by alcohol or drugs and speeding, non-use of a seatbelt, and not having a valid driving licence are likely to be valid also among other groups of alcohol- or drug-impaired drivers; however, the ORs will not be the same. Similar results were found in other international studies among both fatally injured drivers and living drivers responding to questionnaires (mentioned in section 5.2.1). 
If we had included only drivers culpable for crashes, then the calculated ORs would also be different. Most drivers testing positive for drugs or alcohol are found to at least partly be responsible for the collisions $(248,249)$. If a non-responsible driver did not use a seatbelt, they may still have contributed to the fatal outcome of the crash. By including non-responsible drivers in the analyses, the calculated ORs might better represent all drivers at risk of being fatally injured in a road traffic crash.

The associations reported in our study between individual substance groups and other risk factors were based on a low sample size. Nonetheless, most of the associations found were seen in European and US literature as well.

\section{Generalizability of study results: trends in unsafe driving behaviours and crash characteristics}

The study population in Paper IV was originally selected based on the outcome severity of those involved in road traffic crashes; those investigated for drugs and alcohol in Papers III and IV were also potentially influenced by suspicion of substance use by the police. The study subjects were therefore not selected randomly from the population of crash-involved drivers nor from the general population of drivers. The findings may represent trends among drivers at high risk of traffic injury. Because speeding, non-use of a seatbelt, and alcohol impairment declined both among those fatally injured and among the general driving population (except alcohol use, which is not confirmed in normal traffic), the general risk of fatal road traffic crash has likely been reduced during the study period, including among those not ending up being killed in a road traffic crash. A reduced risk of traffic injury in Norway was also report by Torkel Bjørnskau; the risk of getting injured or killed when driving a car declined from 2005 to 2013/2014 across all age groups when adjusted for kilometres driven (226).

Meanwhile, trends in crash characteristics, such as the proportion of head-on crashes, are not relevant to generalise to other groups of drivers. 


\section{Conclusions and future perspectives}

\subsection{Conclusions}

In 2000-2015, the numbers and proportions of drivers (including riders) arrested in Norway under suspicion of DUI of alcohol or drugs and testing positive for alcohol or drugs remained fairly stable. Drivers who tested positive for cannabis increased in number and proportion after 2008, whereas drivers testing positive for alcohol decreased in both aspects. The prevalence of amphetamine use increased among drivers aged $30+$ years and decreased among younger drivers ( $<30$ years). The prevalence of benzodiazepine and opioid use decreased slightly or remained stable, dependent on the age group investigated. Furthermore, we found that drivers and riders fatally injured in road traffic crashes had alcohol concentrations above the graded sanction limit of $0.5 \mathrm{~g} / \mathrm{kg}$ less frequently in 2011-2015 compared with the earlier years of 2005-2010. These trends were in line with trends found among arrested and crash-involved drivers in other European countries, but cannot necessarily be generalised to other drivers than drug and drink drivers at high risk of being arrested or involved in a road traffic crash in Norway.

Among fatally injured car/van drivers, associations were found between being impaired by alcohol or drugs and other risk factors, like speeding, non-use of a seatbelt, and not having a valid driving licence. Impairment from alcohol and stimulants (mainly amphetamines) was associated with all risk factors; impairment from medicinal drugs, with all except speeding; and impairment from cannabis, with not having a valid driving licence. Among fatally injured motorcycle/moped riders, impairment from alcohol was associated with non-use of a helmet and not having a valid driving licence. The associations found will likely be generalizable to a broader population, although the ORs may differ in magnitude. Among the riders, there was not enough statistical power to detect possible associations between other drugs used and unsafe driving behaviours. 
Furthermore, we found that the prevalence of other unsafe driving behaviours, like speeding and non-use of a seatbelt, declined among the fatally injured car/van drivers in Norway. Similar trends were found among motorcycle/moped riders, but not to a statistically significant degree. The observed decline in both speeding and non-use of a seatbelt, which had also been reported in normal traffic, might have contributed to the decline in road fatalities in Norway. These trends were in line with those found in other European countries and in the US. We also investigated some crash characteristics. Safety installations like ABS and ESC increased during the study period and might have contributed to preventing severe road traffic crashes. The proportion of the crashes that were head-on collisions remained stable during the study period, suggesting further potential for preventing fatal road traffic crashes, such as by separating traffic that goes in different directions.

\subsection{Future perspectives}

There is currently no adequate system for detecting drivers at high risk of impaired driving prior to arrest for unsafe driving or involvement in a road traffic crash. A significant risk factor of a DUI offence is to have been arrested for DUI previously $(22,23,250)$. The identification of young drivers at risk of such behaviour and the prevention of initiation of drug and drink driving would be crucial in preventing repeated offences and risks posed to other road users. In addition to preventing young drivers from starting to combine driving with substance use, more could be done to prevent DUI offenders from repeating their behaviour. Annually, only a small proportion of convicted DUI offenders, about 500, are sentenced to rehabilitation (251). This number should be increased significantly. The rehabilitation programme should also be evaluated to determine whether it can reduce the incidence of repeated DUI even further.

Only fatally injured drivers were included in this study when investigating significant unsafe driving behaviours leading to fatality. This could be justified by the fact that 
killed road users during the past years in Norway have been dominated by car occupants (44). However, it could be that some drugs used by drivers cause impairment that leads to driving errors, thereby posing a high risk of injury to other vulnerable road users, but rarely to fatality of the driver themselves, who, in contrast to pedestrians and cyclists, would be protected by the car bodywork when involved in a crash. Future studies may investigate the total harm caused by psychoactive substance use in traffic; that is, including harm to road users other than the motor vehicle drivers themselves.

Norway is a country with an exceptionally low road fatality rate compared with many other countries. However, the aim is to work towards a future with no one killed or seriously injured, as stated in the Vision Zero initiative of 2001. Driverrelated risk factors of fatal road traffic crashes were found in this study to be highly prevalent among drivers fatally injured in Norway, both among those impaired by alcohol or drugs and among sober drivers. Most of the fatalities reported the non-use of a seatbelt or a helmet, speeding, or alcohol-impairment, although the numbers showed declining trends during the study period. General preventive measures, including average speed cameras, information campaigns, and roadside controls, should be continued to reduce further or prevent an increase in the fatalities caused by unsafe driving behaviours. In addition, to prevent the fatalities where none of the mentioned risk factors were present, which to a large extent involve drivers and riders aged $45+$ years based on this study, other measures should be sought.

With Vision Zero, the government acknowledges that drivers will commit errors but that the responsibility should not only be on the driver but also on those designing the road system. Some of the current improvements made to the road system will reduce the injury severity of vehicle occupants in the scenario of a road traffic crash. Older people are more vulnerable to injuries from minor crashes compared with younger drivers $(50,253)$; some of the road system improvements might therefore not have fully good effects on the fatality rate or rate of severe injury among older drivers even if they show total effects. Specific solutions for protecting older drivers 
from severe injuries when involved in less severe crashes should be investigated and implemented.

The Norwegian Government has set a target of 500 killed or seriously injured road users for 2024 and a target of 350 for 2030; the number was 771 in 2017 (252). The potential for improving road safety in Norway in 2018-2030 by means of 33 road safety measures has been analysed by Elvik and Høye (252). They concluded that it is possible to reach the 2024 target of maximum 500 killed or severely injured by implementing all measures consistently. Further reduction to maximum 350 in 2030 was however described as difficult to reach; killed road users could be reduced to below 100 per year if measures are used maximally, but the number of severely injured road users is more challenging to reduce.

The newest vehicle safety standards proposed by the EU to be included in new motor vehicles from year 2022 include systems that monitor lane keeping and drowsiness or distraction, as well as intelligent systems for assisted speeding and braking and detecting vulnerable road users $(254,255)$. All these features will help the driver and other road users from being involved in a road traffic crash that is due to driver error or inattention. However, the future where all vehicles have these safety features may not be realised for a while. Work towards promoting better attitudes to safe driving should be given priority in the meantime. 


\section{References}

1. Peden M, Scurfield R, Sleet D, Mohan D, Hyder AA, Jarawan E, et al. World report on road traffic injury prevention. Geneva, Switzerland: World Health Organization; 2004. [Available from: https://www.who.int/publications/i/item/world-reporton-road-traffic-injury-prevention]

2. European Commission. Towards a European road safety area: policy orientations on road safety 2011-2020. Brussels, Belgium: European Commission; 2010. [Available from: https://ec.europa.eu/transport/sites/transport/files/road safety/pdf/ com 20072010 en.pdf]

3. Elvebakk B, Steiro T. First principles, second hand: Perceptions and interpretations of vision zero in Norway. Safety Science. 2009;47(7):958-66.

4. Ministry of Transport and Communications. Road Safety in Norway - Strategy 2002-2011. Oslo, Norway: Ministry of Transport and Communications; 2002. [Available from:

https://www.regjeringen.no/globalassets/upload/kilde/sd/bro/2002/0001/ $\mathrm{ddd} / \mathrm{pdfv} / 160260-\mathrm{road}$ safety.pdf]

5. OECD. Road accidents. Paris, France: OECD iLibrary; 2019. doi: 10.1787/2fe1b899en.

6. Orsi C, Bertuccio P, Morandi A, Levi F, Bosetti C, La Vecchia C. Trends in motor vehicle crash mortality in Europe, 1980-2007. Safety Science. 2012;50(4):100918.

7. European Commission. Post-impact Care. Brussels, Belgium: European Commission Directorate General for Transport; 2018. [Available from: https://ec.europa.eu/transport/road safety/sites/roadsafety/files/pdf/ersosynth esis2018-postimpactcare.pdf]

8. Haddon W, Jr. A logical framework for categorizing highway safety phenomena and activity. The Journal of Trauma. 1972;12(3):193-207.

9. Mock CN, Nugent R, Kobusingye O, Smith KR, editors. Injury Prevention and Environmental Health. Disease Control Priorities (third edition), Volume 7. Washington, DC: World Bank; 2017. doi:10.1596/978-1-4648-0522-6. 
10. Bachani AM, Peden M, Gururaj G, Norton R, Hyder AA. Road traffic injuries. In: Mock CN, Nugent R, Kobusingye O, Smith KR, editors. Injury Prevention and Environmental Health. Disease Control Priorities (third edition), Volume 7. Washington, DC: World Bank; 2017; pp 35-54. doi:10.1596/978-1-4648-0522-6.

11. Herbel SL, L. McGovern, C. Highway Safety Improvement Program Manual (FHWASA-09-029). Washington, DC: Department of Transportation Federal Highway Administration; 2010. [Available from: https://safety.fhwa.dot.gov/hsip/resources/fhwasa09029/fhwasa09029.pdf]

12. Singh S. Critical Reasons for Crashes Investigated in the National Motor Vehicle Crash Causation Survey (DOT HS 812 115). Washington, DC: National Highway Traffic Safety Administration; 2015. [Available at: https://crashstats.nhtsa.dot.gov/Api/Public/ViewPublication/812115]

13. Dingus TA, Guo F, Lee S, Antin JF, Perez M, Buchanan-King M, et al. Driver crash risk factors and prevalence evaluation using naturalistic driving data. Proceedings of the National Academy of Sciences. 2016;113(10):2636-41.

14. Organisation for Economic Cooperation and Development. "Executive Summary", in Drugs and Driving: Detection and Deterrence. Paris, France: OECD Publishing, 2010. doi: 10.1787/9789282102763-3-en.

15. Calinescu T, Adminaite D. Progress in Reducing Drink Driving in Europe. Brussels, Belgium: European Transport Safety Council; 2018. [Available from: https://etsc.eu/wp-content/uploads/report reducing drink driving final.pdf]

16. Ogden EJ, Moskowitz H. Effects of alcohol and other drugs on driver performance. Traffic Injury Prevention. 2004;5(3):185-98.

17. Jung MK, Callaci JJ, Lauing KL, Otis JS, Radek KA, Jones MK, et al. Alcohol exposure and mechanisms of tissue injury and repair. Alcoholism: Clinical and Experimental Research. 2011;35(3):392-9.

18. Stubig T, Petri M, Zeckey C, Brand S, Muller C, Otte D, et al. Alcohol intoxication in road traffic accidents leads to higher impact speed difference, higher ISS and MAIS, and higher preclinical mortality. Alcohol (Fayetteville, NY). 2012;46(7):681-6.

19. Fynbo L. Drinking and driving in a sociological perspective. [PhD thesis]. Copenhagen, Denmark: University of Copenhagen; 2013. [Available from: https://www.soc.ku.dk/Forskning/PublikationerLink/dokument/drinking-anddriving-in-a-sociological-perspective/Drinking and driving phd-afhandling.pdf] 
20. Ruud J, Gjerde H. Alkoholkonsum blant promilledømte. Tidsskrift for Den norske lægeforening. 1992;112:3216-20.

21. Gjerde H, Sakshaug J, Mørland J. Heavy drinking among Norwegian male drunken drivers: a study of gamma-glutamyltransferase. Alcoholism: Clinical and Experimental Research. 1986;10(2):209-12.

22. Skurtveit S, Christophersen AS, Beylich KM, Bjørneboe A, Mørland J. Study of rearrests for drunken driving in Norway. Forensic Science International. 1998;92(1):21-8.

23. Christophersen AS, Skurtveit S, Grung M, Mørland J. Rearrest rates among Norwegian drugged drivers compared with drunken drivers. Drug and Alcohol Dependence. 2002;66(1):85-92.

24. Norwegian Mobile Police Service. Førere med høy risikovillighet. En analyse av anmeldte fartsovertredere og rusførere [High risk drivers: speeders and drink/drug drivers]. Stavern, Norway: Norwegian Mobile Police Service; 2012.

25. Impinen A, Mäkelä P, Karjalainen K, Haukka J, Lintonen T, Lillsunde P, et al. The Association between Social Determinants and Drunken Driving: A 15-Year Register-based Study of 81,125 Suspects. Alcohol and Alcoholism. 2011;46(6):7218.

26. Karjalainen K, Karjalainen K, Lintonen T, Joukamaa M, Lillsunde P. Mental Disorders Associated with Driving under the Influence of Alcohol and/or Drugs: A Register-Based Study. European Addiction Research. 2013;19(3):113-20.

27. World Health Organization. Managing Speed. Geneva, Switzerland: World Health Organization; 2017. [Available from: https://www.who.int/publications/i/item/managing-speed]

28. Aarts L, van Schagen I. Driving speed and the risk of road crashes: A review. Accident Analysis and Prevention. 2006;38(2):215-24.

29. Elvik R, Christensen P, Amundsen A. Speed and road accidents. An evaluation of the Power Model (TØI report 740/2004). Oslo, Norway: Institute of Transport Economics; 2004. [Available from: https://www.toi.no/getfile.php?mmfileid=1007]

30. Torre FL. Forgiving roadsides design guide. Paris, France: Conference of European Directors of Roads; 2012. [Available from: 
https://www.cedr.eu/download/Publications/2013/T10 Forgiving roadsides.pdf ]

31. Yao Y, Carsten O, Hibberd D. A close examination of speed limit credibility and compliance on UK roads. IATSS Research. 2020;44(1): 17-29.

32. FIA Foundation for the Automobile and Society. Seat-belts and child restraints: a road safety manual for decision-makers and practitioners. London, UK: FIA Foundation; 2009. [Available from:

https://www.who.int/roadsafety/publications/Seat-beltsManual EN.pdf?ua=1]

33. Statens Havarikommisjon for Transport. Temarapport om sikkerhet i bil [Thematic Report Concerning Safety in Cars] (Rapport Vei 2012/01). Lillestrøm, Norway: Statens Havarikommisjon for Transport; 2012. [Available from: https://havarikommisjonen.no/Vei/Avgitte-rapporter/2012-01]

34. The National Highway Traffic Safety Administration (NHTSA). Special Crash Investigations (SCI) First Generation Frontal Air Bags - A Model for Future Corrective Action (DOT HS 811 261). Washington, DC: National Highway Traffic Safety Administration; 2010. [Available from: https://crashstats.nhtsa.dot.gov/Api/Public/ViewPublication/811261]

35. European Transport Safety Council. Seatbelt reminders on every new car seat from 2019. Brussels, Belgium: European Transport Safety Council; 2018 [Available from: https://etsc.eu/seatbelt-reminders-on-every-new-car-seat-from-2019]

36. Steptoe A, Wardle J, Fuller R, Davidsdottir S, Davou B, Justo J. Seatbelt use, attitudes, and changes in legislation: an international study. American Journal of Preventive Medicine. 2002;23(4):254-9.

37. Lie A, Krafft M, Kullgren A, Tingvall C. Intelligent seat belt reminders-do they change driver seat belt use in Europe? Traffic Injury Prevention. 2008;9(5):446-9.

38. Page Y, Hermitte T, Cuny S. How Safe is Vehicle Safety? The Contribution of Vehicle Technologies to the Reduction in Road Casualties in France from 2000 to 2010. Annals of advances in automotive medicine Association for the Advancement of Automotive Medicine Annual Scientific Conference. 2011;55:101-12.

39. Safety Research \& Strategies. A Brief History of Electronic Stability Controls and their Applications. Rehoboth, MA: Safety Research \& Strategies, Inc.; 2004 [Available from: http://www.safetyresearch.net/blog/articles/brief-historyelectronic-stability-controls-and-their-applications] 
40. van Ratingen M, Williams A, Lie A, Seeck A, Castaing P, Kolke R, et al. The European New Car Assessment Programme: A historical review. Chinese Journal of Traumatology. 2016;19(2):63-9.

41. Page Y, Cuny S, Hermitte T, Labrousse M. A comprehensive overview of the frequency and the severity of injuries sustained by car occupants and subsequent implications in terms of injury prevention. Annals of Advances in Automotive Medicine. 2012;56:165-74.

42. Rich J, Prato CG, Hels T, Lyckegaard A, Kristensen NB. Analyzing the relationship between car generation and severity of motor-vehicle crashes in Denmark. Accident; Analysis and Prevention. 2013;54:81-9.

43. World Health Organization. Global status report on road safety 2013: supporting a decade of action. Geneva, Switzerland: World Health Organization; 2013. [Available from: https://www.who.int/violence injury prevention/road safety status/2013/en/]

44. Statistics Norway. Drepte eller skadde i trafikkulykker, etter alder, trafikantgruppe og politidistrikt (F) 1999 - 2019. Kongsvinger, Norway: Statistics Norway; 2020 [Available from: https://www.ssb.no/statbank/table/09011/]

45. Elvik R. Improving road safety in Norway (TØI report 446/1999). Oslo, Norway: Institute of Transport Economics; 1999. [Available from:

https://www.toi.no/publications/improving-road-safety-in-norway-article1830629.html]

46. Boge K. Votes Count but the Number of Seats Decides. A comparative historical case study of 20th century Danish, Swedish and Norwegian road policy. Oslo, Norway: BI Norwegian School of Management; 2006. [Available from: https://biopen.bi.no/bi-xmlui/handle/11250/94346]

47. Nordli R. Trafikksikkerhetseffekt av forsterket midtoppmerking [Centerline rumble strips - effect on traffic safety] (Master thesis). Trondheim, Norway: Norwegian University of Science and Technology; 2015. [Available from: https://vegvesen.brage.unit.no/vegvesen-xmlui/handle/11250/2430842]

48. Ragnøy A. Streknings-ATK. VD Rapport nr. 1. [Automatic section speed control Evaluation Results]. Oslo: Norwegian Public Roads Administration; 2011. [Available from: https://www.vegvesen.no/ attachment/196324/binary/593960? fast title=Evaluering+av+streknings-ATK+2011.pdf] 
49. Soole DW, Watson BC, Fleiter JJ. Effects of average speed enforcement on speed compliance and crashes: a review of the literature. Accident Analysis and Prevention. 2013;54:46-56.

50. Hanrahan RB, Layde PM, Zhu S, Guse CE, Hargarten SW. The association of driver age with traffic injury severity in Wisconsin. Traffic Injury Prevention. 2009;10(4):361-7.

51. Bose D, Segui-Gomez M, Crandall JR. Vulnerability of female drivers involved in motor vehicle crashes: an analysis of US population at risk. American Journal of Public Health. 2011;101(12):2368-73.

52. New Spanish safety cameras to detect seat belt use [press release]. Brussels, Belgium: European Transport Safety Council; 2017. [Available from: https://etsc.eu/new-spanish-safety-cameras-to-detect-seat-belt-use/]

53. Alghnam S, Towhari J, Alkelya M, Binahmad A, Bell TM. The effectiveness of introducing detection cameras on compliance with mobile phone and seatbelt laws: a before-after study among drivers in Riyadh, Saudi Arabia. Injury Epidemiology. 2018;5(1):31.

54. Andenaes J. The Scandinavian experience. In: Laurence MD, Snortum JR, Zimring FE, editors. Social control of the drinking driver. Chicago, IL: The University of Chicago Press; 1988.

55. Lee H-W. Taking Deterrence Seriously: The Wide-Scope Deterrence Theory of Punishment. Criminal Justice Ethics. 2017;36(1):2-24.

56. Mørland J, Steentoft A, Simonsen KW, Ojanperä I, Vuori E, Magnusdottir K, et al. Drugs related to motor vehicle crashes in northern European countries: A study of fatally injured drivers. Accident Analysis and Prevention. 2011;43(6):1920-6.

57. Song JW, Chung KC. Observational studies: cohort and case-control studies. Plastic and Reconstructive Surgery. 2010;126(6):2234-42.

58. Gjerde H, Ramaekers JG, Mørland JG. Methodologies for establishing the relationship between alcohol/drug use and driving impairment - Differences between epidemiological, experimental, and real-case studies. Forensic Science Review. 2019;31(2):141-60.

59. Petrisor A-I. Ethical issues in epidemiological data analysis. Revista Română de Bioetică. 2010;8:211-20. 
60. Hill AB. The Environment and Disease: Association or Causation? Proceedings of the Royal Society of Medicine. 1965;58(5):295-300.

61. Gjerde H, Strand MC, Mørland J. Driving Under the Influence of Non-Alcohol Drugs-An Update Part I: Epidemiological Studies. Forensic Science Review. 2015;27(2):89-113.

62. Kelly E, Darke S, Ross J. A review of drug use and driving: epidemiology, impairment, risk factors and risk perceptions. Drug and Alcohol Review. 2004;23(3):319-44.

63. Penning R, Veldstra JL, Daamen AP, Olivier B, Verster JC. Drugs of abuse, driving and traffic safety. Current Drug Abuse Reviews. 2010;3(1):23-32.

64. Rudisill TM, Zhu MT, Kelley GA, Pilkerton C, Rudisill BR. Medication use and the risk of motor vehicle collisions among licensed drivers: A systematic review. Accident Analysis and Prevention. 2016;96:255-70.

65. Bernhoft IM, Hels T, Lyckegaard A, Houwing S, Verstraete AG. Prevalence and Risk of Injury in Europe by Driving with Alcohol, Illicit Drugs and Medicines. Procedia Social and Behavioral Sciences. 2012;48:2907-16.

66. Strand MC, Gjerde H, Mørland J. Driving under the influence of non-alcohol drugs-An update. Part II: Experimental studies. Forensic Science Review. 2016;28(2):79101.

67. Walsh JM, de Gier JJ, Christopherson AS, Verstraete AG. Drugs and driving. Traffic Injury Prevention. 2004;5(3):241-53.

68. Drummer OH. The role of drugs in road safety. Australian Prescriber. 2008;31(2).

69. Verstraete AG, Legrand SA, Vandam L, Hughes B, Griffiths B. Drug use, impaired driving, and traffic accidents, second edition. Lisbon, Portugal: European Monitoring Centre for Drugs and Drug Addiction; 2014. [Available from: http://www.emcdda.europa.eu/attachements.cfm/att 229259 EN TDXD14016EN N.pdf]

70. Hels T, Bernhoft IM, Lyckegaard A, Houwing S, Hagenzieker M, Legrand S-A, et al. Risk of injury by driving with alcohol and other drugs. Kongens Lyngby, Denmark: Technical University of Denmark; 2011. [Available from: http://hdl.handle.net/1854/LU-1988746] 
71. Martin TL, Solbeck PA, Mayers DJ, Langille RM, Buczek Y, Pelletier MR. A review of alcohol-impaired driving: the role of blood alcohol concentration and complexity of the driving task. Journal of Forensic Sciences. 2013;58(5):1238-50.

72. Borkenstein RF, Crowther RF, Shumate R. The role of the drinking driver in traffic accidents (the Grand Rapids study). Blutalkohol. 1974;11(Suppl):1-131.

73. Blomberg RD, Peck RC, Moskowitz H, Burns M, Fiorentino D. The Long Beach/Fort Lauderdale relative risk study. Journal of Safety Research. 2009;40(4):285-92.

74. Zador PL, Krawchuk SA, Voas RB. Alcohol-related relative risk of driver fatalities and driver involvement in fatal crashes in relation to driver age and gender: an update using 1996 data. Journal of Studies on Alcohol. 2000;61(3):387-95.

75. Hurst PM, Harte D, Frith WJ. The Grand Rapids dip revisited. Accident Analysis and Prevention. 1994;26(5):647-54.

76. Compton RP, Blomberg RD, Moskowitz H, Burns M, Peck RC, Fiorentino D. Crash risk of alcohol impaired driving. In: Mayhew DR, Dussault C, eds. Proceedings of the 16th International Conference on Alcohol, Drugs and Traffic Safety, Montreal, 4-9 August 2002. Montreal, Canada: Société de l'assurance automobile du Québec; 2002. pp: 39-44.

77. Schweizer TA, Vogel-Sprott M. Alcohol-impaired speed and accuracy of cognitive functions: A review of acute tolerance and recovery of cognitive performance. Experimental and Clinical Psychopharmacology. 2008;16(3):240-50.

78. Schweizer TA, Vogel-Sprott M, Danckert J, Roy EA, Skakum A, Broderick CE. Neuropsychological Profile of Acute Alcohol Intoxication during Ascending and Descending Blood Alcohol Concentrations. Neuropsychopharmacology. 2006;31(6):1301-9.

79. Hartman RL, Huestis MA. Cannabis effects on driving skills. Clinical Chemistry. 2013;59.

80. Huestis MA. Cannabis (Marijuana) - Effects on Human Performance and Behavior. Forensic Science Review. 2002;14(1-2):15-60.

81. Ramaekers JG, Berghaus G, van Laar M, Drummer OH. Dose related risk of motor vehicle crashes after cannabis use. Drug and Alcohol Dependence. 2004;73(2):10919. 
82. Desrosiers NA, Ramaekers JG, Chauchard E, Gorelick DA, Huestis MA. Smoked cannabis' psychomotor and neurocognitive effects in occasional and frequent smokers. Journal of Analytical Toxicology. 2015;39(4):251-61.

83. Ramaekers JG, Kauert G, Theunissen EL, Toennes SW, Moeller MR. Neurocognitive performance during acute THC intoxication in heavy and occasional cannabis users. Journal of Psychopharmacology (Oxford, England). 2009;23(3):266-77.

84. Gjerde H, Mørland J. Risk for involvement in road traffic crash during acute cannabis intoxication. Addiction (Abingdon, England). 2016;111(8):1492-5.

85. Hartman RL, Brown TL, Milavetz G, Spurgin A, Gorelick DA, Gaffney GR, et al. Effect of Blood Collection Time on Measured Delta(9)-Tetrahydrocannabinol Concentrations: Implications for Driving Interpretation and Drug Policy. Clinical Chemistry. 2016;62(2):367-77.

86. Karschner EL, Swortwood MJ, Hirvonen J, Goodwin RS, Bosker WM, Ramaekers JG, et al. Extended plasma cannabinoid excretion in chronic frequent cannabis smokers during sustained abstinence and correlation with psychomotor performance. Drug Testing and Analysis. 2016;8(7):682-9.

87. Odell MS, Frei MY, Gerostamoulos D, Chu M, Lubman DI. Residual cannabis levels in blood, urine and oral fluid following heavy cannabis use. Forensic Science International. 2015;249:173-80.

88. Huestis MA. Pharmacokinetics and metabolism of the plant cannabinoids, delta9tetrahydrocannabinol, cannabidiol and cannabinol. Handbook of Experimental Pharmacology. 2005(168):657-90.

89. Wood E, Brooks-Russell A, Drum P. Delays in DUI blood testing: Impact on cannabis DUI assessments. Traffic Injury Prevention. 2016;17(2):105-8.

90. Barateau L, Lopez R, Dauvilliers Y. Treatment Options for Narcolepsy. CNS Drugs. 2016;30(5):369-79.

91. Mitler MM. Evaluation of treatment with stimulants in narcolepsy. Sleep. 1994;17(8 Suppl):S103-6.

92. Castle L, Aubert RE, Verbrugge RR, Khalid M, Epstein RS. Trends in Medication Treatment for ADHD. Journal of Attention Disorders. 2007;10(4):335-42. 
93. Hodgkins $\mathrm{P}$, Shaw M, McCarthy S, Sallee FR. The pharmacology and clinical outcomes of amphetamines to treat ADHD: does composition matter? CNS Drugs. 2012;26(3):245-68.

94. United States Drug Enforcement Administration. Drug Scheduling. Springfield, VA: United States Drug Enforcement Administration; 2019. [Available from: https://www.dea.gov/drug-scheduling]

95. Addiction Center. Understanding Stimulants. Orlando, FL: Recovery Worldwide LLC; 2019 [Available from: https://www.addictioncenter.com/stimulants/]

96. Gjersing L, Bretteville-Jensen AL, Furuhaugen H, Gjerde H. Illegal substance use among 1,309 music festival attendees: An investigation using oral fluid sample drug tests, breathalysers and questionnaires. Scandinavian Journal of Public Health. 2019;47(4):400-7.

97. Miller P, Curtis A, Jenkinson R, Droste N, Bowe SJ, Pennay A. Drug use in Australian nightlife settings: estimation of prevalence and validity of self-report. Addiction (Abingdon, England). 2015;110(11):1803-10.

98. Nordfjærn T, Bretteville-Jensen AL, Edland-Gryt M, Gripenberg J. Risky substance use among young adults in the nightlife arena: An underused setting for riskreducing interventions? Scandinavian Journal of Public Health. 2016;44(7):638-45.

99. Palamar JJ, Acosta P, Ompad DC, Cleland CM. Self-Reported Ecstasy/MDMA/"Molly" Use in a Sample of Nightclub and Dance Festival Attendees in New York City. Substance Use and Misuse. 2017;52(1):82-91.

100. Baker A, Lee NK, Jenner L. Models of intervention and care for psychostimulant users, 2nd Edition, National Drug Strategy Monograph Series No. 51. Canberra, Australia: Australian Government Department of Health and Ageing; 2004. [Available from: http://nceta.flinders.edu.au/files/1814/3130/6039/Models of Intervention Monograph 51.pdf]

101. Logan BK. Methamphetamine - Effects on Human Performance and Behavior. Forensic Science Review. 2002;14(1-2):133-51.

102. Wardle MC, Kirkpatrick MG, de Wit H. 'Ecstasy' as a social drug: MDMA preferentially affects responses to emotional stimuli with social content. Social Cognitive and Affective Neuroscience. 2014;9(8):1076-81. 
103. Montoya AG, Sorrentino R, Lukas SE, Price BH. Long-term neuropsychiatric consequences of "ecstasy" (MDMA): a review. Harvard Review of Psychiatry. 2002;10(4):212-20.

104. Musshoff F, Madea B. Driving under the influence of amphetamine-like drugs. Journal of Forensic Sciences. 2012;57(2):413-9.

105. Silber BY, Papafotiou K, Croft RJ, Ogden E, Swann P, Stough C. The effects of dexamphetamine on simulated driving performance. Psychopharmacology. 2005;179(3):536-43.

106. Medhus S, Holm B, Mørland J, Bramness JG. Association Between Methamphetamine Versus Amphetamine and Acute Psychiatric Symptoms. Journal of Dual Diagnosis. 2013;9(4):292-300.

107. European Monitoring Centre for Drugs and Drug Addiction (EMCDDA). Methamphetamine drug profile. Lisbon, Portugal: European Monitoring Centre for Drugs and Drug Addiction; 2009 [Available from: https://www.emcdda.europa.eu/publications/drug-profiles/methamphetamine]

108. Gjerde H, Normann PT, Christophersen AS, Samuelsen SO, Mørland J. Alcohol, psychoactive drugs and fatal road traffic accidents in Norway: A case-control study. Accident Analysis and Prevention. 2011;43(3):1197-203.

109. Kuypers KPC, Wingen M, Samyn N, Limbert N, Ramaekers JG. Acute effects of nocturnal doses of MDMA on measures of impulsivity and psychomotor performance throughout the night. Psychopharmacology (Berl.). 2007;192(1):1119.

110. Bosker WM, Kuypers KP, Conen S, Kauert GF, Toennes SW, Skopp G, et al. MDMA (ecstasy) effects on actual driving performance before and after sleep deprivation, as function of dose and concentration in blood and oral fluid. Psychopharmacology (Berl). 2012;222(3):367-76.

111. Stoduto G, Mann RE, Ialomiteanu A, Wickens CM, Brands B. Examining the link between collision involvement and cocaine use. Drug and Alcohol Dependence. 2012;123(1-3):260-3.

112. Schwartz TL, Goradia V. Managing insomnia: an overview of insomnia and pharmacologic treatment strategies in use and on the horizon. Drugs in Context. 2013;2013:212257. 
113. Dell'osso B, Lader M. Do benzodiazepines still deserve a major role in the treatment of psychiatric disorders? A critical reappraisal. European Psychiatry. 2013;28(1):7-20.

114. Beirness D. The Effects of Psychoactive Prescription Drugs on Driving. Ottawa, Canada: Canadian Centre on Substance Abuse and Addiction; 2017. [Available from: https://www.ccsa.ca/effects-psychoactive-prescription-drugs-drivingreport]

115. Vindenes V, Jordbru D, Knapskog A-B, Kvan E, Mathisrud G, Slørdal L, et al. Impairment based legislative limits for driving under the influence of non-alcohol drugs in Norway. Forensic Science International. 2012;219(1-3):1-11.

116. Vindenes V, Aamo T, Innerdal C, Mathisrud G, Mørland J, Riedel B. Revidering av "forskrift om faste grenser for påvirkning av andre berusende eller bedøvende middel enn alkohol m.m." -- Vurdering av eksisterende faste grenser og forslag til faste grenser for flere stoffer [Revision of "regulations on fixed limits for impairment by other intoxicating or anaesthetic/sedative substances than alcohol etc." -- Assessment of existing fixed limits and proposed fixed limits for more substances]. Oslo, Norway: Ministry of Transport and Communications; 2015. [Available from:

https://www.regjeringen.no/contentassets/2b19347b73dd45d0b523f1dd19ae91 54/n-0558b-revidering-av-forskrift-om-faste-grenser.pdf]

117. Dassanayake T, Michie P, Carter G, Jones A. Effects of Benzodiazepines, Antidepressants and Opioids on Driving A Systematic Review and Meta-Analysis of Epidemiological and Experimental Evidence. Drug Safety. 2011;34(2):125-56.

118. van der Sluiszen N, Vermeeren A, Jongen S, Vinckenbosch F, Ramaekers JG. Influence of Long-Term Benzodiazepine use on Neurocognitive Skills Related to Driving Performance in Patient Populations: A Review. Pharmacopsychiatry. 2017;50(5):189-96.

119. Roth T, Eklov SD, Drake CL, Verster JC. Meta-Analysis of On-the-Road Experimental Studies of Hypnotics: Effects of Time After Intake, Dose, and Half-Life. Traffic Injury Prevention. 2014;15(5):439-45.

120. Verster JC, Mets MA. Psychoactive medication and traffic safety. International Journal of Environmental Research and Public Health. 2009;6(3):1041-54.

121. Leufkens TRM, Vermeeren A. Zopiclone's Residual Effects on Actual Driving Performance in a Standardized Test: A Pooled Analysis of Age and Sex Effects in 4 Placebo-Controlled Studies. Clinical Therapeutics. 2014;36(1):141-50. 
122. Mailis-Gagnon A, Lakha SF, Furlan A, Nicholson K, Yegneswaran B, Sabatowski R. Systematic review of the quality and generalizability of studies on the effects of opioids on driving and cognitive/psychomotor performance. The Clinical Journal of Pain. 2012;28(6):542-55.

123. Strand MC, Arnestad M, Fjeld B, Mørland J. Acute impairing effects of morphine related to driving: A systematic review of experimental studies to define blood morphine concentrations related to impairment in opioid-naive subjects. Traffic Injury Prevention. 2017;18(8):788-94.

124. Stout PR, Farrell LJ. Opioids - Effects on Human Performance and Behavior. Forensic Science Review. 2003;15(1):29-59.

125. Strand MC, Fjeld B, Arnestad M, Mørland J. Can patients receiving opioid maintenance therapy safely drive? A systematic review of epidemiological and experimental studies on driving ability with a focus on concomitant methadone or buprenorphine administration. Traffic Injury Prevention. 2013;14(1):26-38.

126. Holmgren A, Holmgren P, Kugelberg FC, Jones AW, Ahlner J. Predominance of illicit drugs and poly-drug use among drug-impaired drivers in Sweden. Traffic Injury Prevention. 2007;8(4):361-7.

127. Karjalainen KK, Lintonen TP, Impinen AO, Lillsunde PM, Ostamo AI. Poly-drug findings in drugged driving cases during 1977-2007. Journal of Substance Use. 2010;15(2):143-56.

128. Legrand SA, Gjerde H, Isalberti C, Van der Linden T, Lillsunde P, Dias MJ, et al. Prevalence of alcohol, illicit drugs and psychoactive medicines in killed drivers in four European countries. International Journal of Injury Control and Safety Promotion. 2014;21(1):17-28.

129. Legrand SA, Isalberti C, der Linden TV, Bernhoft IM, Hels T, Simonsen KW, et al. Alcohol and drugs in seriously injured drivers in six European countries. Drug Testing and Analysis. 2013;5(3):156-65.

130. Houwing S, Hagenzieker M, Mathijssen R, Bernhoft IM, Hels T, Janstrup K, et al. Prevalence of alcohol and other psychoactive substances in drivers in general traffic. Part 1: General results and part 2: Country reports. DRUID Deliverable 2.2.3. Leidschendam, The Netherlands: SWOV Institute for Road Safety Research; 2011. 
131. Gudin JA, Mogali S, Jones JD, Comer SD. Risks, management, and monitoring of combination opioid, benzodiazepines, and/or alcohol use. Postgraduate Medicine. 2013;125(4):115-30.

132. World Health Organization. Global status report on road safety 2018. Geneva, Switzerland: World Health Organization; 2018. [Available from: https://www.who.int/publications/i/item/global-status-report-on-road-safety2018]

133. European Commission. 2018 road safety statistics: what is behind the figures? Brussels, Belgium: European Commission; 2019 [Available from: https://ec.europa.eu/commission/presscorner/detail/en/MEMO 19 1990]

134. World Population Review. High Income Countries Population. Walnut, CA: World Population Review; 2019 [Available from: http://worldpopulationreview.com/countries/high-income-countries/]

135. Ahangari H, Atkinson-Palombo C, Garrick NW. Progress towards zero, an international comparison: Improvements in traffic fatality from 1990 to 2010 for different age groups in the USA and 15 of its peers. Journal of Safety Research. 2016;57:61-70.

136. The Swedish Transport Administration. Analysis of road safety trends 2017. Management by objectives for road safety work towards the 2020 interim targets. Borlänge, Sweden: Swedish Transport Administration; 2018. [Available from: https://trafikverket.ineko.se/Files/sv-SE/57185/ Ineko.Product.RelatedFiles/2019 035 analysis of road safety trends 2017 mana gement by objectives for road safety work towards the 2020 interim targets.pd f]

137. Statistics Norway. 135 drept, 656 hardt skadd [135 killed, 656 seriously injured] 2017. Kongsvinger, Norway: Statistics Norway; 2018 [Available from: https://www.ssb.no/transport-og-reiseliv/artikler-og-publikasjoner/135-drept656-hardt-skadd]

138. Brude U, Elvik R. The turning point in the number of traffic fatalities: two hypotheses about changes in underlying trends. Accident Analysis and Prevention. 2015;74:60-8.

139. Holtedahl B. Samferdsel i Norge - før og nå. Oslo, Norway: Leif Holtedahls forlag; 1979. 
140. Statistics Norway. Kongsvinger, Norway: Statistics Norway; 2018 [Available from: https://www.ssb.no/en]

141. Ministry of Transport and Communication. Ot.prp. nr. 53 (2003-2004) Om lov om endringer i lov 18. juni 1965 nr. 4 om vegtrafikk 2004. Oslo, Norway: Ministry of Transport and Communication; 2004. [Available from: https://www.regjeringen.no/no/dokumenter/otprp-nr-53-2003-2004Lid393129/sec6]

142. Elvik R. Miniscenario: Fartsgrensepolitikk - Virkninger på trafikksikkerhet av ulike fartsgrenser (TØI-rapport 1589/2017). Oslo, Norway: Institute of Transport Economics; 2017. [Available from: https://www.toi.no/getfile.php?mmfileid=46446]

143. Assum T. Reduction of the blood alcohol concentration limit in Norway--effects on knowledge, behavior and accidents. Accident Analysis and Prevention. 2010;42(6):1523-30.

144. The Norwegian Public Roads Administration. Penalty points on your driving licence. Oslo, Norway: Norwegian Public Roads Administration; 2018 [Available from: https://www.vegvesen.no/en/driving-licences/driving-licence-holders]

145. Inderhaug E. Nå dobler politiet ANPR-kapasiteten. Politiforum, September 29, 2016. [Available at: https://www.politiforum.no/nyheter/na-dobler-politiet-anprkapasiteten/132456]

146. Inderhaug E. ANPR. Politiforum, September 17, 2014. [Available from: https://www.politiforum.no/diverse-faktabokser/anpr/118766]

147. Ministry of Transport. Lov om endringar i veglova og vegtrafikkloven. Oslo, Norway: Ministry of Transport; 2012. [Available from: https://lovdata.no/dokument/LTI/lov/2012-06-22-59]

148. Hansen K. Über das Verhältnis zwischen der Alkoholkonzentration im Blute und dem Grad der Alkoholbeeinflussung [Relation between the concentration of alcohol in the blood and the degree of the alcohol influence]. Forschung zur Alkoholfrage. 1938;46(1):1-8.

149. Norwegian Ministry of Transport and Communications. Driving under the influence of non-alcohol drugs - legal limits implemented in Norway. Oslo, Norway: Ministry of Transport and Communications; 2014. [Available from: https://www.regjeringen.no/no/dokumenter/Driving-under-the-influence-ofnon-alcohol-drugs--legal-limits-implemented-in-Norway/id2351035/] 
150. Norwegian Directorate of Health. Retningslinjer for fylkesmennene ved behandling av førerkortsaker (IS-1348). Oslo, Norway: Directorate of Health; 2011.

151. Norwegian Directorate of Health. Legemidler (helsekrav til førerkort) [Drugs (health requirements for driving license)]. Oslo, Norway: Norwegian Directorate of Health; 2018. [Available from:

https://www.helsedirektoratet.no/veiledere/forerkortveilederen/midler-alkoholrusmidler-og-legemidler-som-kan-pavirke-kjoreevnen-35-37-helsekrav-tilforerkort/legemidler-helsekrav-til-forerkort]

152. Ministry of Transport and Communication. Forskrift om endring i forskrift om faste grenser for påvirkning av andre berusende eller bedøvende middel enn alkohol m.m. (forskrift om faste grenser) [Revision of Fixed Limits for Drugs in the Traffic]. Oslo, Norway: Ministry of Justice; 2016. [Available from: https://lovdata.no/dokument/LTI/forskrift/2016-01-12-19]

153. Gjerde H, Beylich KM, Mørland J. Incidence of alcohol and drugs in fatally injured car drivers in Norway. Accident Analysis and Prevention. 1993;25(4):479-83.

154. Gjerde H, Christophersen AS, Normann PT, Morland J. Toxicological investigations of drivers killed in road traffic accidents in Norway during 2006-2008. Forensic Science International. 2011;212(1-3):102-9.

155. Christophersen AS, Gjerde H. Prevalence of alcohol and drugs among car and van drivers killed in road accidents in Norway: an overview from 2001 to 2010. Traffic Injury Prevention. 2014;15(6):523-31.

156. Christophersen AS, Gjerde H. Prevalence of alcohol and drugs among motorcycle riders killed in road crashes in Norway during 2001-2010. Accident Analysis and Prevention. 2015;80:236-42.

157. Grimstad V, Engebretsen A. Dybdeanalyser av dødsulykker i vegtrafikken 2015 [InDepth Analyses of Fatal Road Accidents in the year 2015]. Oslo, Norway: Norwegian Public Roads Administration; 2016. [Available from: https://www.vegvesen.no/ attachment/1503748/binary/1128915]

158. Bedard M, Guyatt GH, Stones MJ, Hirdes JP. The independent contribution of driver, crash, and vehicle characteristics to driver fatalities. Accident Analysis and Prevention. 2002;34(6):717-27. 
159. Liu C, Huang Y, Pressley JC. Restraint use and risky driving behaviors across drug types and drug and alcohol combinations for drivers involved in a fatal motor vehicle collision on U.S. roadways. Injury Epidemiology. 2016;3(1):9.

160. Romano E, Voas RB. Drug and Alcohol Involvement in Four Types of Fatal Crashes. Journal of Studies on Alcohol and Drugs. 2011;72(4):567-76.

161. Berning A, Smither DD. Understanding the Limitations of Drug Test Information, Reporting, and Testing Practices in Fatal Crashes (DOT HS 812 072). Washington, DC: National Highway Traffic Safety Administration; 2014. [Available from: https://crashstats.nhtsa.dot.gov/Api/Public/ViewPublication/812072]

162. Bogstrand ST, Larsson M, Holtan A, Staff T, Vindenes V, Gjerde H. Associations between driving under the influence of alcohol or drugs, speeding and seatbelt use among fatally injured car drivers in Norway. Accident Analysis and Prevention. 2015;78:14-9.

163. World Medical Association. World Medical Association Declaration of Helsinki: Ethical Principles for Medical Research Involving Human SubjectsWorld Medical Association Declaration of HelsinkiSpecial Communication. JAMA. 2013;310(20):2191-4.

164. Ministry of Health and Care Services. Lov om medisinsk og helsefaglig forskning (helseforskningsloven) [Act on Medical and Health Research]. Oslo, Norway: Ministry of Health and Care Services; 2008. [Available from: https://lovdata.no/lov/2008-06-20-44]

165. Statistics.laerd.com. Descriptive and Inferential Statistics | Laerd Statistics. [online] 2019 [Available from: https://statistics.laerd.com/statistical-guides/descriptiveinferential-statistics.php]

166. Courtney K. Taylor. Descriptive vs. Inferential Statistics. New Yourk, NY: ThoughtCo; 2018 [Available from: https://www.thoughtco.com/differences-indescriptive-and-inferential-statistics-3126224]

167. McHugh ML. The chi-square test of independence. Biochem Med (Zagreb). 2013;23(2):143-9.

168. Statistics.laerd.com. Mann-Whitney U Test using SPSS Statistics. [online]: Statistics.laerd.com; 2020 [Available from: https://statistics.laerd.com/spsstutorials/mann-whitney-u-test-using-spss-statistics.php] 
169. Hidalgo B, Goodman M. Multivariate or multivariable regression? American Journal of Public Health. 2013;103(1):39-40.

170. Centers for Disease Control and Prevention. NHANES Tutorials: Module10 Logistic Regression. Atlanta, GA: Centers for Disease Control and Prevention; 2014. [Available from: https://wwwn.cdc.gov/nchs/nhanes/tutorials/Module10.aspx]

171. Ministry of Transport. Lov om vegtrafikk (vegtrafikkloven) - § 22. Ruspåvirkning av motorvognfører [the Norwegian Road Traffic Act - $\S 22$. Driving Under the Influence] 2015 [Available from: https://lovdata.no/dokument/NL/lov/1965-0618-4/KAPITTEL 4]

172. National Highway Traffic Safety Administration. Traffic safety facts 2005 : Motorcycles. Washington, DC: National Highway Traffic Safety Administration; 2007. [Available from: https://crashstats.nhtsa.dot.gov/Api/Public/ViewPublication/810620]

173. Asgarian FS, Namdari M, Soori H. Worldwide prevalence of alcohol in fatally injured motorcyclists: A meta-analysis. Traffic Injury Prevention. 2019;20(7):6859.

174. Ojaniemi KK, Lintonen TR, Impinen AO, Lillsunde PM, Ostamo AI. Trends in driving under the influence of drugs: A register-based study of DUID suspects during 1977-2007. Accident Analysis and Prevention. 2009;41(1):191-6.

175. Steentoft A, Simonsen KW, Linnet K. The frequency of drugs among Danish drivers before and after the introduction of fixed concentration limits. Traffic Injury Prevention. 2010;11(4):329-33.

176. European Monitoring Centre for Drugs and Drug Addiction. European Drug Report 2018: Trends and Developments. Luxembourg: Publications Office of the European union; 2018. [Available from:

https://www.emcdda.europa.eu/system/files/publications/8585/20181816 TDA T18001ENN PDF.pdf]

177. Simonsen KW, Linnet K, Rasmussen BS. Driving under the influence of alcohol and drugs in the eastern part of Denmark in 2015 and 2016: Abuse patterns and trends. Traffic Injury Prevention. 2018;19(5):468-75.

178. Karjalainen K, Blencowe T, Lillsunde P. Substance use and social, health and safetyrelated factors among fatally injured drivers. Accident Analysis and Prevention. 2012;45:731-6. 
179. Wiese Simonsen K, Steentoft A, Bernhoft IM, Hels T, Rasmussen BS, Linnet K. Psychoactive substances in seriously injured drivers in Denmark. Forensic Science International. 2013;224(1-3):44-50.

180. Ahlner J, Holmgren A, Jones AW. Prevalence of alcohol and other drugs and the concentrations in blood of drivers killed in road traffic crashes in Sweden. Scandinavian Journal of Public Health. 2014;42(2):177-83.

181. Kalsi J, Selander T, Tervo T. Alcohol policy and fatal alcohol-related crashes in Finland 2000-2016. Traffic Injury Prevention. 2018;19(5):476-9.

182. Gonzalez-Wilhelm L. Prevalence of alcohol and illicit drugs in blood specimens from drivers involved in traffic law offenses. Systematic review of cross-sectional studies. Traffic Injury Prevention. 2007;8(2):189-98.

183. Jones AW. Driving under the influence of drugs in Sweden with zero concentration limits in blood for controlled substances. Traffic Injury Prevention. 2005;6(4):31722.

184. Officer J. Trends in drug use of Scottish drivers arrested under Section 4 of the Road Traffic Act - A 10 year review. Science and Justice. 2009;49(4):237-41.

185. Sweedler BM. The worldwide decline in drinking and driving. In: Kloeden CN, McLean AJ, eds. Proceedings of the 13th International Conference on Alcohol, Drugs and Traffic Safety, Adelaide, 13-18 August 1995. Adelaide: University of Adelaide, Road Accident Research Unit.; 1995.

186. Skretting A, Vedøy TF, Lund KE, Bye EK. Rusmidler i Norge 2016 - Alkohol, tobakk, vanedannende legemidler, narkotika, sniffing, doping og tjenestetilbudet. Oslo, Norway: Norwegian Institute of Public Health; 2016. [Available from: https://www.fhi.no/publ/2017/rusmidler-i-norge-2016/]

187. Kvaavik E, Rossow I. Alkohol i Norge - 2018 [Alcohol in Norway - 2018]. Oslo, Norway: Norwegian Institute of Public Health; 2018. [Available from: https://fhi.brage.unit.no/fhi-xmlui/handle/11250/2579169]

188. Norstrom T, Rossow I. Population drinking and drink driving in Norway and Sweden: an analysis of historical data 1957-89. Addiction (Abingdon, England). 2013;108(6):1051-8.

189. Gjerde H, Christophersen AS, Normann PT, Mørland J. Increased population drinking is not always associated with increased number of drink driving convictions. Addiction (Abingdon, England). 2013;108(12):2221-3. 
190. Wegman F, Allsop R, Antoniou C, Bergel-Hayat R, Elvik R, Lassarre S, et al. How did the economic recession (2008-2010) influence traffic fatalities in OECD-countries? Accident Analysis and Prevention. 2017;102:51-9.

191. Tjaderborn M, Jonsson AK, Sandstrom TZ, Ahlner J, Hagg S. Non-prescribed use of psychoactive prescription drugs among drug-impaired drivers in Sweden. Drug and Alcohol Dependence. 2016;161:77-85.

192. Sakshaug S, Strøm H, Berg C, Blix HS, Litleskare I, Granum T. Drug Consumption in Norway 2012-2016. Oslo, Norway: Norwegian Institute of Public Health; 2017. [Available from: https://www.fhi.no/publ/2017/legemiddelforbruket-i-norge2012-2016/]

193. The Norwegian Institute of Public Health. The Norwegian Prescription Database (NorPD). Oslo, Norway: Norwegian Institute of Public Health; 2017 [Available from: http://www.norpd.no]

194. Christophersen AS, Karinen R, Mørland J, Gjerde H. The implementation of per-se limits for driving under the influence of benzodiazepines and related drugs: No increased risk for arrest during therapeutic use in Norway. Traffic Injury Prevention. 2020;21(2):122-6.

195. The National Criminal Investigation Service (KRIPOS). Narkotika- og Dopingstatistikk 2015 [Drug Seizure Statistics 2015]. Oslo, Norway: KRIPOS; 2016 [Available from: https://www.politi.no/vedlegg/lokale vedlegg/kripos/Vedlegg 3549.pdf]

196. The National Criminal Investigation Service (Kripos). Narkotikastatistikk 2007 [drug seizure statistics 2007]. Oslo, Norway: KRIPOS; 2007. [Available from: http://www.forebygging.no/PageFiles/4393/KRIPOS narkotikastatistikk 2007.pd f]

197. Bogstrand ST, Middelkoop G, Christophersen AS. Trends in amphetamine and benzodiazepine use among drivers arrested for drug impaired driving in Norway 2000-2009. Norsk Epidemiologi. 2011; 21(1): 61-66. doi: 10.5324/nje.v21i1.1427.

198. Bilgrei OR. Narkotikamarkedet. Oslo, Norway: Norwegian Institute of Public Health; 2018. [Available from:

https://www.fhi.no/nettpub/narkotikainorge/bruk-avnarkotika/narkotikamarkedet/] 
199. Furuhaugen H, Jamt REG, Nilsson G, Vindenes V, Gjerde H. Roadside survey of alcohol and drug use among Norwegian drivers in 2016-2017: A follow-up of the 2008-2009 survey. Traffic Injury Prevention. 2018;19(6):555-62.

200. Cascini F, Aiello C, Di Tanna G. Increasing delta-9-tetrahydrocannabinol (Delta-9THC) content in herbal cannabis over time: systematic review and meta-analysis. Current Drug Abuse Reviews. 2012;5(1):32-40.

201. Dujourdy L, Besacier F. A study of cannabis potency in France over a 25 years period (1992-2016). Forensic Science International. 2017;272:72-80.

202. ElSohly MA, Mehmedic Z, Foster S, Gon C, Chandra S, Church JC. Changes in Cannabis Potency Over the Last 2 Decades (1995-2014): Analysis of Current Data in the United States. Biological Psychiatry. 2016;79(7):613-9.

203. Havig SM, Hoiseth G, Strand MC, Karinen RA, Brochmann GW, Strand DH, et al. THC and CBD in blood samples and seizures in Norway: Does CBD affect THC-induced impairment in apprehended subjects? Forensic Science International. 2017;276:12-7.

204. Gunn RL, Skalski L, Metrik J. Expectancy of impairment attenuates marijuanainduced risk taking. Drug and Alcohol Dependence. 2017;178:39-42.

205. MacDonald S, Mann R, Chipman M, Pakula B, Erickson P, Hathaway A, et al. Driving Behavior Under the Influence of Cannabis or Cocaine. Traffic Injury Prevention. 2008;9(3):190-4.

206. Sewell RA, Poling J, Sofuoglu M. The effect of cannabis compared with alcohol on driving. American Journal of Addiction. 2009;18(3):185-93.

207. Vasshus M. Høy temperatur og mange deltakere i cannabisdebatten i mediene. Rusfag. 2014:25-7.

208. Burdzovic Andreas J, Bretteville-Jensen AL. Ready, willing, and able: the role of cannabis use opportunities in understanding adolescent cannabis use. Addiction (Abingdon, England). 2017;112(11):1973-82.

209. Christophersen AS, Mørland J, Stewart K, Gjerde H. International trends in alcohol and drug use among vehicle drivers. Forensic Science Review. 2016;28(1):37-66.

210. Robertson RD, Mainegra Hing M, Pashley CR, Brown SW, Vanlaar WGM. Prevalence and trends of drugged driving in Canada. Accident Analysis and Prevention. 2017;99(Pt A):236-41. 
211. Brady JE, Li G. Trends in alcohol and other drugs detected in fatally injured drivers in the United States, 1999-2010. American Journal of Epidemiology.

2014;179(6):692-9.

212. Hingson R, Zha W, Smyth D. Magnitude and Trends in Heavy Episodic Drinking, Alcohol-Impaired Driving, and Alcohol-Related Mortality and Overdose Hospitalizations Among Emerging Adults of College Ages 18-24 in the United States, 1998-2014. Journal of Studies on Alcohol and Drugs. 2017;78(4):540-8.

213. Azagba S, Latham K, Shan L, Qeadan F. Positive drug test trends in fatally-injured drivers in the United States from 2007 to 2017. Substance Abuse Treatment, Prevention, and Policy. 2019;14(1):43.

214. Slater ME, Castle IJP, Logan BK, Hingson RW. Differences in state drug testing and reporting by driver type in U.S. fatal traffic crashes. Accident Analysis and Prevention. 2016;92:122-9.

215. Chihuri S, Li G. Trends in Prescription Opioids Detected in Fatally Injured Drivers in 6 US States: 1995-2015. American Journal of Public Health. 2017;107(9):148792.

216. Shipton EA, Shipton EE, Shipton AJ. A Review of the Opioid Epidemic: What Do We Do About It? Pain and Therapy. 2018;7(1):23-36.

217. Pulido J, Barrio G, Lardelli P, Bravo MJ, Regidor E, de la Fuente L. Association between cannabis and cocaine use, traffic injuries and use of protective devices. European Journal of Public Health. 2011;21(6):753-5.

218. Laz TH, Shemontee MO, Rahman M, Berenson AB. Association of prescription drug misuse with risky motor vehicle behaviors among low-income young women. Substance Abuse. 2013;34(4):405-8.

219. Michael TB, Yolanda W, Linda PD, Moynahan SE, Perry IB, Catherine AM. The Sensation Seeking Trait and Substance Use: Research Findings and Clinical Implications. Current Psychiatry Reviews. 2007;3(1):3-13.

220. Thanki D, Matias J, Griffiths P, Noor A, Olszewski D, Simon R, et al. Prevalence of daily cannabis use in the European Union and Norway. Luxembourg: Publications Office of the European Union; 2012. [Available from: https://www.emcdda.europa.eu/publications/thematic-papers/prevalence-dailycannabis-use-european-union-and-norway en] 
221. Brubacher JR, Chan H, Erdelyi S, Macdonald S, Asbridge M, Mann RE, et al. Cannabis use as a risk factor for causing motor vehicle crashes: a prospective study. Addiction (Abingdon, England). 2019;114(9):1616-26.

222. Kalsi J, Tervo T, Bachour A, Partinen M. Sleep versus non-sleep-related fatal road accidents. Sleep Medicine. 2018;51:148-52.

223. Wilson FA, Stimpson JP, Tibbits MK. The role of alcohol use on recent trends in distracted driving. Accident Analysis and Prevention. 2013;60:189-92.

224. Tervo TM, Neira W, Kivioja A, Sulander P, Parkkari K, Holopainen JM. Observational failures/distraction and disease attack/incapacity as cause(s) of fatal road crashes in Finland. Traffic Injury Prevention. 2008;9(3):211-6.

225. Gjerde H, Valen A, Frost J, Pasnin L. Rusrelaterte dødsulykker i vegtrafikken 20052018. Oslo, Norway: Oslo University Hospital; 2020. [Available from: https://oslouniversitetssykehus.no/seksjon/avdeling-for-rettsmedisinskefag/Documents/OUS\%2002502 RusrelaterteD\%c3\%b8dsulykker\%202020.pdf]

226. Bjørnskau T. Risiko i veitrafikken 2013/14 [Road traffic risk in Norway 2013/14] (TØI rapport 1448/2015). Oslo, Norway: Institute of Transport Economics; 2016. [Available from: https://www.toi.no/getfile.php?mmfileid=42538]

227. Bernhoft IM, Hels T, Rendsvig TL, Orozova-Bekkevold I. Karakteristik af spiritusbilisten [Characteristic of the drunken driver]. Kongens Lyngby, Denmark: Danmarks Transportforskning; 2007. [Available from: http://www.transport.dtu.dk/-/media/Institutter/Transport/forskning/ publikationer/publikationer\%20dtf/2007/spiritusbilisten.ashx?la=da]

228. Sweedler BM, Biecheler MB, Laurell H, Kroj G, Lerner M, Mathijssen MP, et al. Worldwide trends in alcohol and drug impaired driving. Traffic Injury Prevention. 2004;5(3):175-84.

229. Sagberg F, Bjørnskau T. Fart og alder. Fartsutviklingen på veier med fartsgrense 80 $\mathrm{km} / \mathrm{t}$ [Speed and age. Changes in speed level on Norwegian roads with $80 \mathrm{~km} / \mathrm{h}$ limit] (TØI rapport 1462/2016). Oslo, Norway: Institute of Transport Economics; 2016. [Available from: https://www.toi.no/getfile.php?mmfileid=42289]

230. Jones AP, Sauerzapf V, Haynes R. The effects of mobile speed camera introduction on road traffic crashes and casualties in a rural county of England. Journal of Safety Research. 2008;39(1):101-10. 
231. Høye A. Safety effects of fixed speed cameras-An empirical Bayes evaluation. Accident Analysis and Prevention. 2015;82:263-9.

232. The Norwegian Public Roads Administration. Tilstandsundersøkelse kap. 1 - Bruk av bilbelte 2017 [Evaluation chapter 1 - Use of seatbelts 2017]. Oslo, Norway: Norwegian Public Roads Administration; 2017. [Available from: https://www.vegvesen.no/fag/fokusomrader/trafikksikkerhet/Tilstandsunderso kelser/ attachment/2167152? ts=16193d8a018\&fast title=Rapport+2017]

233. Enriquez J, Pickrell TM. Seat Belt Use in 2018-Overall Results (DOT HS 812 662). Washington, DC: National Highway Traffic Safety Administration; 2019. [Available from: https://crashstats.nhtsa.dot.gov/Api/Public/ViewPublication/812662]

234. Gicquel L, Ordonneau P, Blot E, Toillon C, Ingrand P, Romo L. Description of Various Factors Contributing to Traffic Accidents in Youth and Measures Proposed to Alleviate Recurrence. Frontiers in Psychiatry. 2017;8:94.

235. Sedgwick P. Cross sectional studies: advantages and disadvantages. BMJ 2014;348:g2276.

236. Carlson MD, Morrison RS. Study design, precision, and validity in observational studies. Journal of Palliative Medicine. 2009;12(1):77-82.

237. Tourangeau R, Yan T. Sensitive questions in surveys. Psychological Bulletin. 2007;133(5):859-83.

238. Fendrich M, Johnson TP, Wislar JS, Hubbell A, Spiehler V. The utility of drug testing in epidemiological research: results from a general population survey. Addiction (Abingdon, England). 2004;99(2):197-208.

239. Khorsan R, Crawford C. How to assess the external validity and model validity of therapeutic trials: a conceptual approach to systematic review methodology. Evidence-Based Complementary and Alternative Medicine. 2014;2014:694804.

240. Grimes DA, Schulz KF. Bias and causal associations in observational research. The Lancet. 2002;359(9302):248-52.

241. Page P. Beyond statistical significance: clinical interpretation of rehabilitation research literature. International Journal of Sports Physical Therapy. 2014;9(5):726-36.

242. Althubaiti A. Information bias in health research: definition, pitfalls, and adjustment methods. Journal of Multidisciplinary Healthcare. 2016;9:211-7. 
243. Drummer OH, Kennedy B, Bugeja L, Ibrahim JE, Ozanne-Smith J. Interpretation of postmortem forensic toxicology results for injury prevention research. Injury Prevention. 2013;19(4):284.

244. Pelissier-Alicot AL, Gaulier JM, Champsaur P, Marquet P. Mechanisms underlying postmortem redistribution of drugs: a review. Journal of Analytical Toxicology. 2003;27(8):533-44.

245. Assi S, Gulyamova N, Ibrahim K, Kneller P, Osselton D. Profile, effects, and toxicity of novel psychoactive substances: A systematic review of quantitative studies. Human Psychopharmacology. 2017;32(3).

246. Kadir MM, Qureshi AF. Validity and Reliability. In: Practical Epidemiology and Biostatistics in Research. Journal of the Pakistan Medical Association. 1994;44(6).

247. Rossow I, Makela P, Kerr W. The collectivity of changes in alcohol consumption revisited. Addiction (Abingdon, England). 2014;109(9):1447-55.

248. Longo MC, Hunter CE, Lokan RJ, White JM, White MA. The prevalence of alcohol, cannabinoids, benzodiazepines and stimulants amongst injured drivers and their role in driver culpability: Part II: The relationship between drug prevalence and drug concentration, and driver culpability. Accident Analysis and Prevention. 2000;32(5):623-32.

249. Poulsen H, Moar R, Pirie R. The culpability of drivers killed in New Zealand road crashes and their use of alcohol and other drugs. Accident Analysis and Prevention. 2014;67:119-28.

250. Christophersen AS, Hammer T, Mørland J. Fatal accident drivers with earlier arrests due to drugged driving. In: Logan BK, Isenschmid DS, Walsh JM, Beirness D, Mørland J, red. Conference Abstracts of the Joint Meeting of The International Association of Forensic Toxicologists (TIAFT), and International Council on Alcohol, Drugs and Traffic Safety (ICADTS) and featuring the 8th Ignition Interlock Symposium (IIS) T2007. Seattle, WA: TIAFT and ICADTS; 2007.

251. Kristoffersen R, Iversen JS. Samfunnsstraff - på tide med en revisjon. Tidsskrift for Strafferett. 2018; 18(3): 151-180. [Available from:

https://krus.brage.unit.no/krusxmlui/bitstream/handle/11250/2569166/Samfunnsstraff.pdf?sequence=6\&isAllo wed $=y$ ] 
252. Elvik R, Høye AK. The potential for reducing the number of killed or seriously injured road users in Norway in the period 2018-2030 [The Potential for Reducing the Number of Killed or Seriously Injured Road Users in Norway in the Period 2018-2030] (TØI report 1764/2020). Oslo, Norway: Institute of Transport Economics; 2020. [Available from:

https://www.toi.no/getfile.php?mmfileid=53054]

253. Brand S, Otte D, Mueller CW, Petri M, Haas P, Stuebig T, et al. Injury patterns of seniors in traffic accidents: A technical and medical analysis. World Journal of Orthopedics. 2012;3(9):151-5.

254. European Transport Safety Council. ETSC welcomes provisional deal on new vehicle safety standards. Brussels, Belgium: European Transport Safety Council; 2019. [Available from: https://etsc.eu/etsc-welcomes-provisional-deal-on-newvehicle-safety-standards/]

255. European Commission. New safety features in your car. Brussels, Belgium: European Commission; 2018 [Available from: https://ec.europa.eu/docsroom/documents/29343] 
8 Appendices 

I 



\title{
Toxicological findings in suspected drug-impaired drivers in Norway - Trends during 1990-2015
}

\author{
Anja Valen ${ }^{\mathrm{a}, \mathrm{b}, *}$, Stig Tore Bogstrand ${ }^{\mathrm{a}, \mathrm{c}}$, Vigdis Vindenes ${ }^{\mathrm{a}, \mathrm{b}}$, Hallvard Gjerde $^{\mathrm{a}}$ \\ a Department of Forensic Sciences, Oslo University Hospital, Oslo, Norway \\ ${ }^{\mathrm{b}}$ Institute of Clinical Medicine, University of Oslo, Oslo, Norway \\ ${ }^{\mathrm{c}}$ Lovisenberg University College, Oslo, Norway
}

\section{A R T I C L E I N F O}

\section{Article history:}

Received 4 July 2017

Received in revised form 3 September 2017

Accepted 8 September 2017

Available online 15 September 2017

\section{Keywords:}

Driving under the influence

Blood concentrations

Drugs

Prevalence

Trends

\begin{abstract}
A B S T R A C T
This study describes trends in drug use among drivers suspected of driving under the influence of drugs, apprehended by the police in Norway during 1990-2015. Chromatographically determined toxicological findings in blood samples were retrospectively investigated. Drug findings above defined cut-off concentrations were considered positive; hence making the annual prevalence comparable during the 26 years studied.

Blood samples from 112,348 drivers were included, of which $63 \%$ were positive for drugs; $43 \%$ had combined drug with alcohol or other drugs. In total, $87 \%$ of the drug-positive drivers were men, and a higher proportion of them were positive for illicit drugs compared to the women. Benzodiazepines and related drugs were found in $57 \%$ of the drug-positive drivers, stimulants in $51 \%$, cannabis (tetrahydrocannabinol, THC) in $34 \%$, and opioids in $18 \%$. The types of benzodiazepines and opioids changed over time. The age distribution also changed; the proportion of drug-positive drivers above 40 years of age increased for all drug classes. The annual number of suspected drug-impaired drivers increased by $122 \%$ from 1990 to 1999 , and by $54 \%$ from 2000 to 2015 ; the annual number of drug-positive samples increased by 260\% from 1990 to 1999, and by 60\% from 2000 to 2015. During 2000-2015, an increasing prevalence of amphetamines was found among suspected drug-impaired drivers above age 30; the highest rate of increase was observed among those at or above age 40 . In the same period, the prevalence of benzodiazepines and related drugs decreased among all age groups, whereas the prevalence of THC increased; the highest prevalence and rate of increase were among suspected drugimpaired drivers under the age of 30 . The results from this study indicate a slight change in the types of drugs used by drivers in Norway.
\end{abstract}

(C) 2017 Elsevier B.V. All rights reserved.

\section{Introduction}

Drunk driving has been regarded as one of the major contributing factors to road traffic crashes. However, driving under the influence of illicit drugs and psychoactive medications are also associated with increased risk of involvement in a road traffic crash [1-3]. Use of toxicological data from fatal road traffic crashes to study trends in hazardous drug use is limited in Norway, due to few cases per year. Data from drivers arrested under suspicion of drug-impaired driving might be used instead; the majority of those drivers have been involved in non-fatal road traffic crashes, aberrant or reckless driving, recognized by the

\footnotetext{
* Corresponding author at: Oslo University Hospital, Department of Forensic Sciences, P.O. Box 4950 Nydalen, NO-0424 Oslo, Norway.

E-mail address: anja.valen@ous-hf.no (A. Valen).
}

police as problematic drug users, or reported to the police by family, friends or other observers [4]. Toxicological data from suspected drug-impaired drivers may thus give information about trends in use of potential traffic-hazardous drugs. Other factors influencing the risk of road traffic crash when using psychoactive $\operatorname{drug}(\mathrm{s})$ are the dose taken, time between intake and driving, infrequent or habitual use, and the purpose of use (medicinal treatment or illicit use) [5].

Trends in drug use in the population might change over time with availability, price, culture etc. Monitoring drug use among suspected drug-impaired drivers may provide important data for revealing new trends in drug use among a subpopulation probably underrepresented in population surveys. Furthermore, the data might be useful in evaluation of emerging drugs' potential for association with road traffic crashes. Test results from blood samples are preferred over other materials due to high correlation 
to pharmacological effects. The data might also be useful when deciding actions to reduce the extent and impact of drug abuse.

Norway implemented a legal limit for driving under the influence (DUI) of alcohol of $0.5 \mathrm{~g} / \mathrm{kg}$ (about $0.5 \mathrm{~g} / \mathrm{L}$ ) in 1936 as the first country in the world, and a law on DUI of drugs in 1959. A study from 1980 investigated drug findings in blood samples from drivers suspected of DUI of alcohol and found that a large proportion were also positive for drugs, particularly suspected drunk drivers with blood alcohol concentration below $0.5 \mathrm{~g} / \mathrm{kg}$ [6]. This study concluded that analysis of only alcohol was insufficient in many DUI cases, and led to an increase in the proportion of samples submitted for drug analysis. An impairment based legislation was present at that time, where drug concentrations in blood, history of drug use, and a clinical examination by a physician were performed in order to assess whether the driver could be convicted of DUI.

Legal limits were implemented for 20 drugs in 2012 [7] and eight more drugs in 2016 [8], resulting in a more simple procedure for evaluating drug findings in relation to the Road Traffic Act. The drugs selected for legal limits were the most frequently found psychoactive substances detected in samples from arrested drivers, known to increase the risk of traffic accidents, in addition to some rarely observed hallucinogenic compounds for reasons of principle. The legal limits for medicinal drugs do not apply if the driver has a valid prescription for the detected $\operatorname{drug}(\mathrm{s})$ and the detected concentrations are in line with the dosage proscribed by the doctor. In such cases, individual evaluations are performed by medical experts taking possible tolerance into account. Individual evaluations may also be performed in cases of multi-drug use, if none of the drug concentrations are above the highest limit for graded sanctions corresponding to a blood alcohol concentration of $1.2 \mathrm{~g} / \mathrm{kg}$.

Compared to other European countries, few citizens of Norway drive while impaired by alcohol [9]. This might be explained by a long tradition in Norway with traffic controls for alcohol (roadside breath tests), and strict law enforcement of the legal limit of DUI of alcohol, which in 2012 was reduced to $0.2 \mathrm{~g} / \mathrm{kg}$. In contrast to alcohol, roadside screening for drug use was not implemented by the police in Norway until mid-2015 when the Mobile Police Service purchased ten Dräger DrugTest 5000 instruments.

During the last decades we have observed changes in drugs detected in blood samples from suspected DUI offenders. The aim of this study was to perform a systematic and thorough investigation of the trends in drug use among drivers suspected of driving under the influence of drugs, apprehended by the police in Norway during the years 1990-2015.

\section{Material and methods}

\subsection{Setting and toxicological methods}

In Norway, all blood samples from suspected impaired drivers are sent to one national laboratory for toxicological analyses. The laboratory has since 1996 been accredited for analysis of drugs of abuse in blood (Norwegian Accreditation, Lillestrøm, Norway; www.akkreditert.no/en). The toxicological analyses include either drugs and alcohol, or only alcohol, dependent on request from the police, based on their suspicion. During the years 19902015 there were some exceptions: Between 1990 and mid1996 some samples from suspected drug-impaired drivers were not analysed for drugs if they contained a blood alcohol concentration above the legal limit of $0.5 \mathrm{~g} / \mathrm{kg}$. Between mid1996 and 1999 samples where only alcohol use was suspected were also analysed for drugs.
The analytical methods for drugs changed somewhat during the study period. In the 1990s, blood samples were screened for cannabinoids, amphetamines, cocaine, opiates and high-dose benzodiazepines by an immunological method [10]. If other drugs or low-dose benzodiazepines were suspected by the police or from the clinical examination, those drugs were screened for by gas chromatography with electron capture detector (GC-EC) or with mass spectrometry detector (GC-MS) [11]. From the year 2001, all samples were screened for both high and low-dose benzodiazepines, z-hypnotics (zopiclone, zolpidem), methadone and carisoprodol/meprobamate by liquid chromatography-mass spectrometry (LC-MS) [12], in addition to the immunological screening. The LC-MS, GC and immunological screening methods were replaced in 2009 by a ultra-high performance LC-tandem MS (UHPLC-MS/MS) screening method for cannabinoids, amphetamines, cocaine, opioids, benzodiazepines, carisoprodol/meprobamate and z-hypnotics [13]. UHPLC-MS/MS screening for gamma-hydroxybutyrate (GHB) and pregabaline was introduced in 2010 [14]; earlier, these drugs were only analysed in cases where such use was suspected.

In the 1990s, confirmation of positive screening results was performed by GC with EC- or MS-detection [15-18]. From 2001, confirmation of amphetamines and cannabinoids continued using GC-MS, whereas other compounds were confirmed by LC-MS [12] or UHPLC-MS/MS $[19,20]$. Alcohol was analysed by an enzymatic method and by head-space gas chromatography [21,22] during the whole study period.

If the police suspected other drugs than those included in the standard analytical repertoire, analyses for more substances was performed. However, those cases are fewer and with much variation in the drugs tested, and were therefore not included in this study.

\subsection{Study design and participants}

An observational time series study was conducted, using register data from all apprehended drivers investigated for illicit drugs or psychoactive medicinal drugs in Norway between January 1st, 1990 and December 31st, 2015.

The extracted data were anonymous and therefore treated as cases and not individuals, meaning that the same person could be included more than once during the study period.

\subsection{Variables}

A research database was made containing the extracted variables age, gender, year, road traffic crash (Yes/No), and the results of all performed toxicological analyses. Drug concentrations were considered negative if lower than the legislative limits for driving under the influence of drugs of 2016 [23], or if lower than the highest analytical limit of quantification used during 1990-2015. The compounds analysed for and their respective lower concentration limits are given in Table 1. Zopiclone and zolpidem were included in the benzodiazepine group because of their pharmacodynamic similarity with benzodiazepines.

\subsection{Ethics}

Projects handling data anonymously do not need approval from the Regional Committee for Medical Research Ethics, according to the Norwegian Research Ethics Act of June 2006 and the Act on Medical and Health Research of June 2008. This study was conducted according to the data processing agreement with the Norwegian Higher Prosecuting Authority, which is the legal owner of forensic materials in Norway. In accordance with this agreement, only anonymous data were used in this study. 
Table 1

Compounds analysed for, legislative limits of 2016, lower concentration limits used (cut-offs), and frequency of findings. The cut-offs were defined as the highest analytical cut-offs used during 1990-2015, or the legislative limits from 2016 if these were higher than the analytical cut-offs, to make it possible to compare finding during the study period.

\begin{tabular}{|c|c|c|c|}
\hline Compound & Legislative limit $(\mathrm{ng} / \mathrm{mL})$ & Cut-off $(\mathrm{ng} / \mathrm{mL})$ & Finding above cut-off $\mathrm{N}(\%)$ \\
\hline Benzodiazepines and related drugs & & & $40,392(36.0)$ \\
\hline Alprazolam & 3.1 & 15 & $3800(3.4)$ \\
\hline Bromazepam & 32 & 32 & $33(0.0)$ \\
\hline Clonazepam & 1.3 & 19 & $10,923(9.7)$ \\
\hline Diazepam & 57 & 142 & $16,895(15)$ \\
\hline Phenazepam & 1.6 & 3.1 & $377(0.3)$ \\
\hline Flunitrazepam & 1.6 & 3.1 & $9473(8.4)$ \\
\hline Nordiazepam & 108 & 135 & $16,063(14.3)$ \\
\hline Nitrazepam & 17 & 84 & $1488(1.3)$ \\
\hline Oxazepam & 172 & 573 & $2259(2.0)$ \\
\hline Zolpidem & 31 & 31 & $747(0.7)$ \\
\hline Zopiclone & 12 & 19 & $2058(1.8)$ \\
\hline Stimulants & & & $36,178(32.2)$ \\
\hline Amphetamine ${ }^{\mathrm{b}}$ & 41 & 41 & $30,968(27.6)$ \\
\hline Cocaine $^{\mathrm{b}}$ & 24 & 61 & $442(0.4)$ \\
\hline 3,4-Methylenedioxymethamphetamine (MDMA) ${ }^{\mathrm{b}}$ & 97 & 97 & $1302(1.2)$ \\
\hline Methamphetamine $\mathrm{b}^{\mathrm{b}}$ & 45 & 45 & $15,039(13.4)$ \\
\hline Cannabis & & & $24,111(21.5)$ \\
\hline Delta-9-tetrahydrocannabinol (THC) ${ }^{\mathrm{b}}$ & 1.3 & 1.3 & $24,111(21.5)$ \\
\hline Opioids & & & $12,703(11.3)$ \\
\hline Buprenorphine & 0.4 & 1.2 & $1055(0.9)$ \\
\hline Codeine $^{\mathrm{c}}$ & - & 60 & $2291(2.0)$ \\
\hline Methadone & 25 & 62 & $1976(1.8)$ \\
\hline Morphine & 8.6 & 8.6 & $7781(6.9)$ \\
\hline Oxycodone & 16 & 16 & $311(0.3)$ \\
\hline Tramadol $^{\mathrm{C}}$ & - & 53 & $512(0.5)$ \\
\hline other drugs & & & 4089 (3.6) \\
\hline Carisoprodol $^{\mathrm{C}}$ & - & 1300 & $1747(1.6)$ \\
\hline Gamma-hydroxybutyric acid (GHB) ${ }^{b}$ & 10,400 & 10,400 & $980(0.9)$ \\
\hline Pregabalin $^{\mathrm{C}}$ & - & 796 & $688(0.6)$ \\
\hline Lysergic acid diethylamide (LSD) ${ }^{\mathrm{b}}$ & 1.0 & 1.0 & $2(0.0)$ \\
\hline Meprobamate $^{c}$ & - & 2180 & $2407(2.1)$ \\
\hline Alcohol & & & $44,692(39.8)$ \\
\hline Ethanol & $0.20 \mathrm{~g} / \mathrm{kg}$ & $0.20 \mathrm{~g} / \mathrm{kg}$ & $44,692(39.8)$ \\
\hline
\end{tabular}

a The percentages are calculated from the total number of samples analysed.

b Defined as illicit drug.

c Legislative limit has not been assigned.

\subsection{Measurements and statistics}

Descriptive analyses were conducted using statistical package SPSS version 23 (IBM Corporation, Armonk, NY). The significance level for all tests was set to 0.05 . Difference between two medians was compared by a Wilcoxon-Mann-Whitney test. Difference between two proportions was compared by a chi-square test of homogeneity.

Frequency distributions were used for the categorical variables. The drivers were divided into four age groups: $<20,20-29,30-39$, and $\geq 40$ years of age. The number of drug-positive drivers and frequency of individual drugs and combinations of drugs were assessed for the different age groups and gender. All measurements were studied annually to reveal trends in drug use among drug-positive drivers during 1990-2015.

Trends in drug use among suspected drug-impaired drivers were investigated by calculating proportions of the samples being positive for the different drug classes during 2000-2015, stratified by age group. This was not performed for the whole study period because some of the samples from the 1990s were not analysed for drugs, and some were analysed for drugs when only alcohol use was suspected by the police.

Drug use was defined as detection of one or more non-alcohol drugs, and multidrug use was defined as detection of two or more non-alcohol drugs. Combined findings of the following drugs and their metabolites were considered single-drug use: amphetamine and methamphetamine, carisoprodol and meprobamate, diazepam and nordiazepam. Nordiazepam is itself not marketed as a drug in Norway. Cases where oxazepam has been detected as a likely metabolite of nordiazepam have been rare in our laboratory. Therefore, findings of those two substances together were considered multidrug use.

Cases with missing data for age or gender were not included in analyses based on age or gender. However, those cases were included in descriptive analyses considering other variables.

\section{Results}

\subsection{Participants}

In total, samples from 112,348 drivers were analysed for drugs during the study period. The age distribution of these drivers were: $8 \%$ aged $<20$ years, $39 \%$ aged $20-29$ years, $28 \%$ aged $30-39$ years, and $25 \%$ aged $\geq 40$ years. Eighty-seven percent of the drivers were men, with median age 30 years; $13 \%$ were women with median age 34 years $(p<0.0005)$. The proportion of female drivers analysed for drugs increased from $10 \%$ in 1990 to $16 \%$ in 2007, followed by a decreasing trend to $13 \%$ in 2015.

Information on gender, age, and alcohol concentration was not available for 46,199 , and 134 drivers, respectively (less than $0.2 \%$ of the study population).

As illustrated in Fig. 1, the annual number of drivers suspected of alcohol- or drug-impaired driving was approximately 10,000 during the study period (average 9536, range 8257-10,647). This included cases where blood samples were analysed for drugs and/ or alcohol and evidential breath tests for alcohol (about 2000 


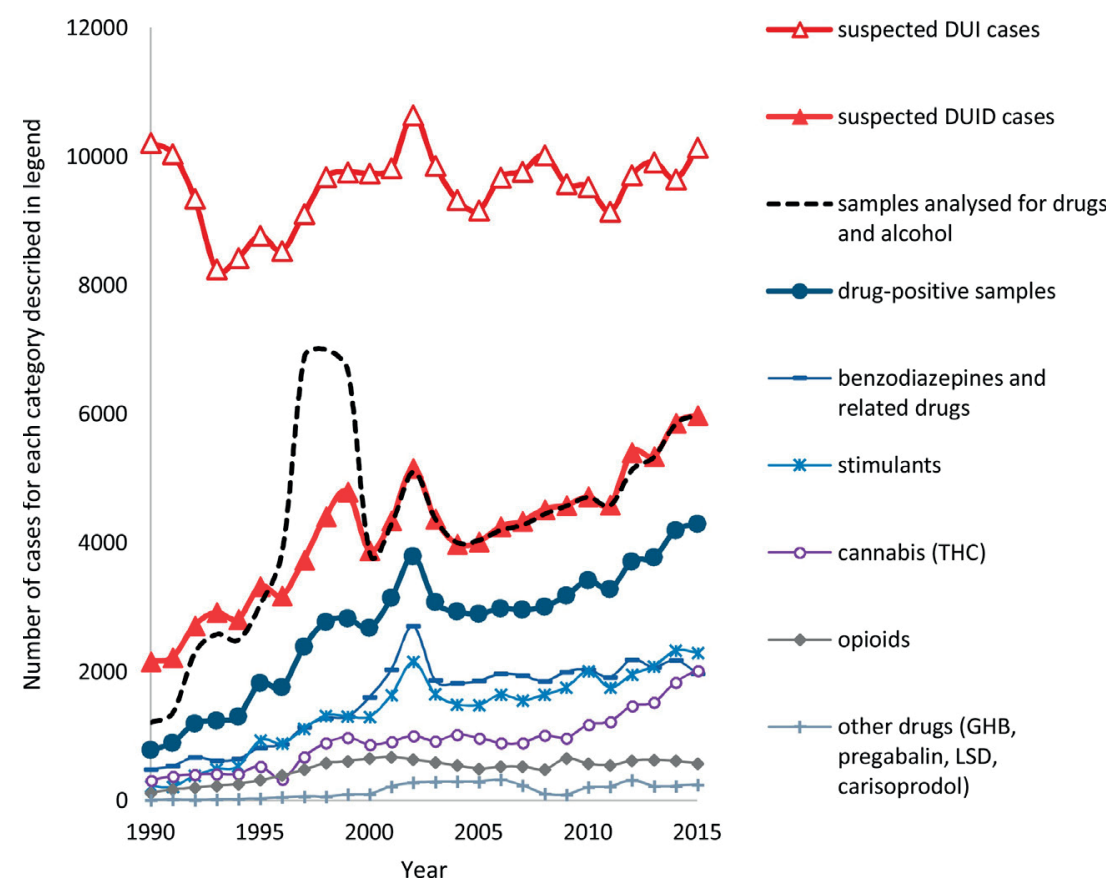

Fig. 1. Number of suspected driving under the influence (DUI) cases per year, of which the number of suspected DUI of drugs (DUID) cases are given. The number of samples analysed for drugs in addition to alcohol (dotted line) illustrates that between 1990 and mid-1996, some samples were not analysed for drugs although suspected, whereas between mid-1996 and 1999 blood samples where only alcohol was suspected were also analysed for drugs. Given in the figure are also the annual number of drug-positive samples and findings of different drug classes.

breath tests were performed every year during 1997-2015). The proportion of cases where drugs were suspected increased during the study period, from $21 \%$ of the cases in 1990 to $59 \%$ in 2015 .

\subsection{Main drug findings}

The toxicological analyses revealed findings of drugs and/or alcohol in $89 \%$ of the samples; drugs were found in $63 \%$ of the samples. The annual number of drug-positive samples increased by $260 \%$ from 1990 to 1999 , and by $60 \%$ from 2000 to 2015 . In comparison, the annual number of suspected drug-impaired drivers increased by $122 \%$ from 1990 to 1999 , and by 54\% from 2000 to 2015 (Fig. 1). Among the drug-positive, benzodiazepines and related drugs were found in $57 \%$ of the samples, stimulants in $51 \%$, tetrahydrocannabinol (THC) in $34 \%$, opioids in $18 \%$, and other drugs were found in $6 \%$ of the samples. The relative distribution of the drug classes changed only slightly during the study period (Fig. 2).

Amphetamine was the individual drug most frequently detected (found in $44 \%$ of the drug-positive drivers), followed by THC (detected in $34 \%$ of the drug-positive drivers). See Table 1 for frequency of all drugs.

\subsection{Drivers involved in a road traffic crash}

Forty-seven \% of the negative cases (no drug or alcohol found) were from drivers involved in a road traffic crash (non-fatal), while among the positive cases only $19 \%$ was involved in a crash: a statistically significant difference in proportions of $0.28, \mathrm{p}<0.0005$.

The number of suspected drug-impaired drivers involved in a road traffic crash increased from 746 in 2000 to 1305 in 2015 (75\% increase). When considering all suspected drug-impaired drivers involved in a road traffic crash during 2000-2015, the proportion that was positive for at least one drug was $56 \%$ (range $51-61 \%$ ). The proportion that was positive for drug and/or alcohol was $79 \%$, with variation within the range $72-83 \%$.

\subsection{Drug use by age}

The number of THC-findings increased among all age groups during 1990-2015. For stimulants, opioids and benzodiazepines

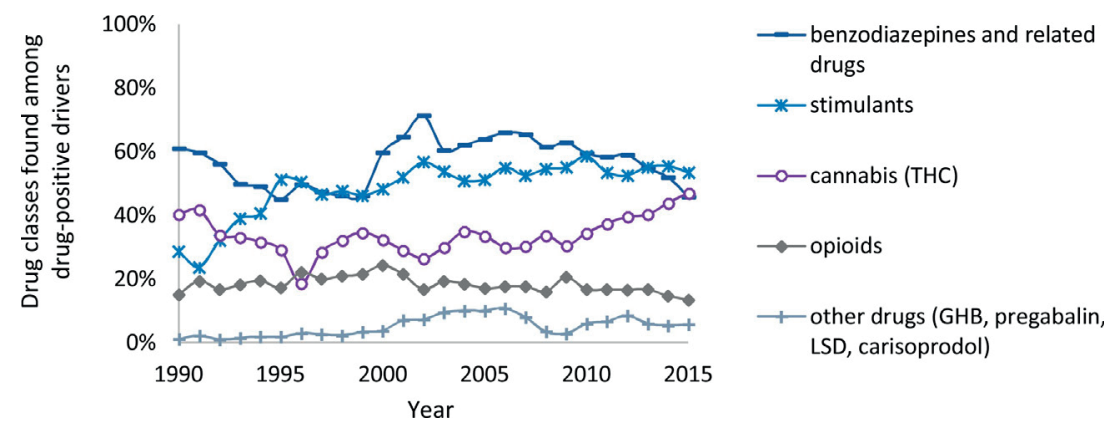

Fig. 2. Distribution of drug classes found among drug-positive drivers during the period 1990-2015. 
and related drugs, the number of positive cases increased from 1990 to 2001/2002 among all drivers aged above 20 years, thereafter the number continued to increase only for drivers aged $\geq 40$ years. For stimulants, a slight increase in the number of drivers aged 30-39 years was observed after 2008 (data not shown).

Among all drug-positive drivers during 1990-2015, 5\% were aged $<20$ years, $41 \%$ were $20-29$ years, $33 \%$ were $30-39$ years, and $22 \%$ were $\geq 40$ years. During the study period, the proportion of drivers aged $\geq 40$ years increased for all drug classes (Fig. 3 ); the largest increase was observed for the opioid-using drivers. The cannabis-using drivers were the youngest; about 10\% were aged below 20 years during the whole period.

As previously mentioned, not all samples from the 1990s were analysed for drugs, and some samples were analysed for drugs even though only alcohol use was suspected by the police. As illustrated in Fig. 1, all (and only) the cases where the police suspected drug-impaired driving were analysed for drugs during the years 2000-2015. We therefore investigated this time period in more depth.

The prevalence of stimulants decreased among the youngest suspected drug-impaired drivers during 2000-2015 whereas it increased among the oldest drivers, especially those aged $\geq 40$ years. The prevalence of THC increased among all age groups during 2000-2015, with the largest increase observed among suspected drug-impaired drivers aged below 30 years (Fig. 4).

\subsection{Drug use by gender}

The increase in prevalence of THC among suspected drugimpaired drivers aged below 30 years was observed among both genders from 2009 to 2015; the prevalence increased by $68 \%$ among male drivers and by $78 \%$ among female drivers. Between 2000 and 2009 the prevalence of THC among men was stable and among women slightly declining.
The increase in prevalence of stimulants among suspected drug-impaired drivers aged $\geq 40$ years during 2000-2015 (Fig. 4) was higher for female drivers ( $120 \%$ increase) than for male drivers (86\% increase).

Among all the drug-positive male and female drivers during 1990-2015, a higher proportion of the male drivers had used stimulants or cannabis. In drug-positive samples from male and female drivers, $52 \%$ and $46 \%$ were positive for stimulants, respectively; $37 \%$ and $18 \%$ were positive for THC, respectively. A higher proportion of the female drivers had used medicinal drugs. In drug-positive samples from female and male drivers during 1990-2015, 67\% and 56\% were positive for benzodiazepines and similar drugs, respectively; $24 \%$ and $17 \%$ were positive for opioids, respectively.

\subsection{Findings of single-drugs, multiple drugs, and alcohol}

The drug-positive drivers were found to be single-drug users in $45 \%$ of the cases (32\% if excluding those where alcohol was combined with drug). The following drugs were most prevalent among single-drug users: amphetamine/methamphetamine (found in $37 \%$ of the cases), cannabis (THC found in $29 \%$ of the cases), and diazepam/nordiazepam (found in $11 \%$ of the cases). Medicinal drugs had been used in 33\% of the single-drug cases. Alcohol was used in combination with single medicinal drug in $45 \%$ of those cases.

When considering combinations of non-alcohol drugs, two drugs were found in $33 \%$, three drugs in $16 \%$, four drugs in $5 \%$, and five or more drugs in $1 \%$ of the drug-positive drivers. These proportions changed only slightly during the study period; $48 \%$ were multidrug-users in 1990 and 51\% in 2015. Drugs were mainly combined from two or more drug classes; drugs were combined only within the same drug class in $6 \%$ of the multidrug-cases.
A

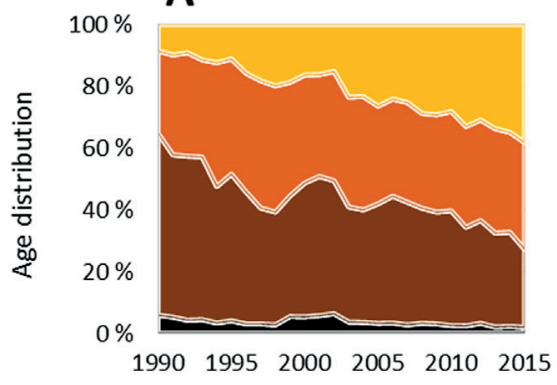

C

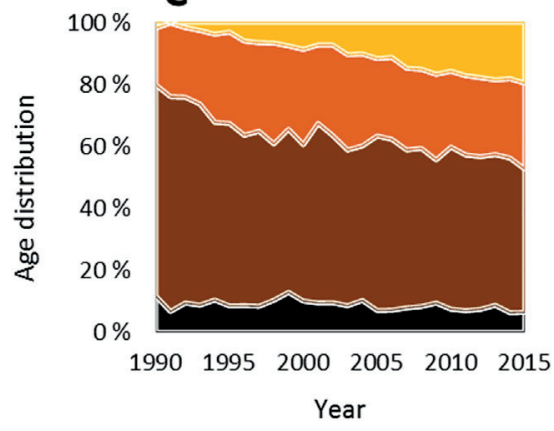

B

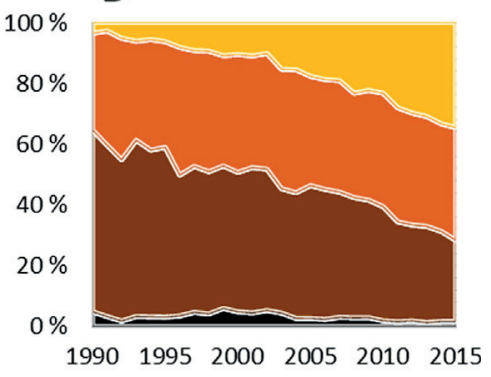

D

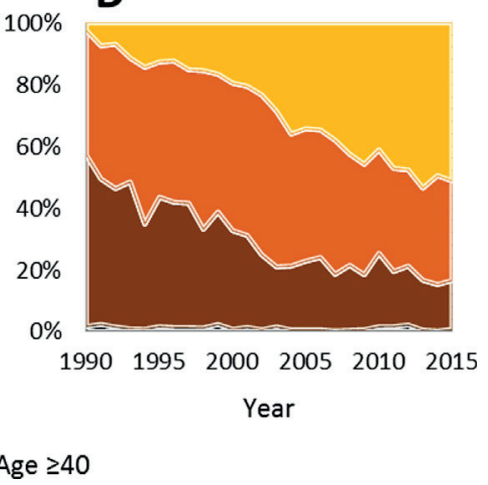

Fig. 3. Age distribution during 1990-2015 among drivers positive for A: benzodiazepines and related drugs, B: stimulants, C: THC (cannabis), and D: opioids. 

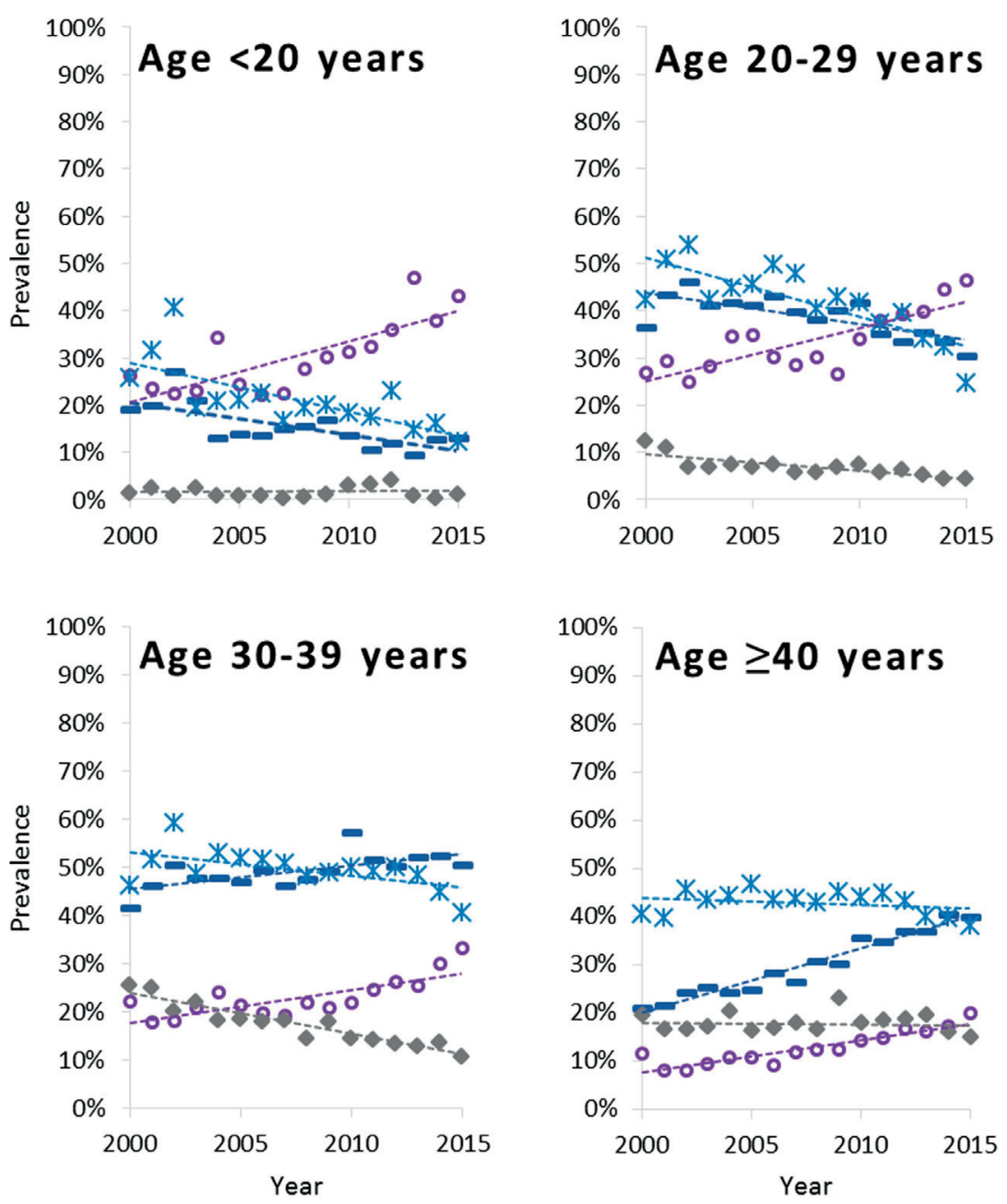

* Benzodiazepines and related drugs - Stimulants $\circ \mathrm{THC}$ (cannabis) $\diamond$ Opioids

Fig. 4. The prevalence of different drug classes among suspected drug-impaired drivers during the years 2000-2015, stratified by age group.

The annual prevalence of alcohol among the suspected drugimpaired drivers increased slightly from $34 \%$ in 2000 to $38 \%$ in 2008 , followed by a decreasing trend to $28 \%$ in 2015 . Also among the drug-positive samples, a marked decrease in annual prevalence of alcohol findings was observed from 2008 to 2015 (-11\%). In total, alcohol was present in $21 \%$ of the drug-positive cases during 1990-2015, most often combined with cannabis or benzodiazepines and related drugs.

\subsection{Details on drug classes}

\subsubsection{Benzodiazepines and related drugs}

Benzodiazepines and related drugs were found in $36 \%$ of the cases analysed; 34\% if excluding the z-hypnotics. Flunitrazepam and diazepam were the dominating benzodiazepines during the years 1990-2002 (Fig. 5). Between 2000 and 2002, the number of flunitrazepam findings increased by $134 \%$ to 1823 findings in 2002, and thereafter decreased by $62 \%$ between 2002 and 2003, and continued to decrease to six findings in 2015. During the years 2006-2015, clonazepam and diazepam were the dominating benzodiazepines detected, followed by alprazolam. Among other benzodiazepines, oxazepam and zopiclone were the most prevalent in total number of findings.

Benzodiazepines and related drugs were combined with other drug classes in $75 \%$ of the cases. The proportion of samples with only benzodiazepines or related drugs decreased during 19902015, whereas combined use with amphetamines increased.

\subsubsection{Stimulants}

The number of blood samples found positive for stimulants increased between 1990 and 2015 (Fig. 1). The proportion of stimulants found among the drug-positive drivers increased from $29 \%$ in 1990 and stabilized at an average of 52\% (range 46-59\%) during 1995-2015 (Fig. 2).

Among the stimulant-positive samples, 95\% were positive for amphetamine and/or methamphetamine; $4 \%$ were positive for MDMA and $1 \%$ for cocaine. Amphetamine and/or methamphetamine were found in $32 \%$ of the total number of cases analysed. Methamphetamine was most frequently found during 20082013 with about the same number of positive findings as for amphetamine. Before 2008 and after 2013, amphetamine dominated.

Stimulants were combined with other drug classes in $66 \%$ of the cases, mostly with benzodiazepines and related drugs (in 52\% of the stimulant-cases).

\subsubsection{Cannabis}

The number of THC-positive drivers increased during 19902015 (Fig. 1), and THC was the most frequently detected single drug in 2015. 


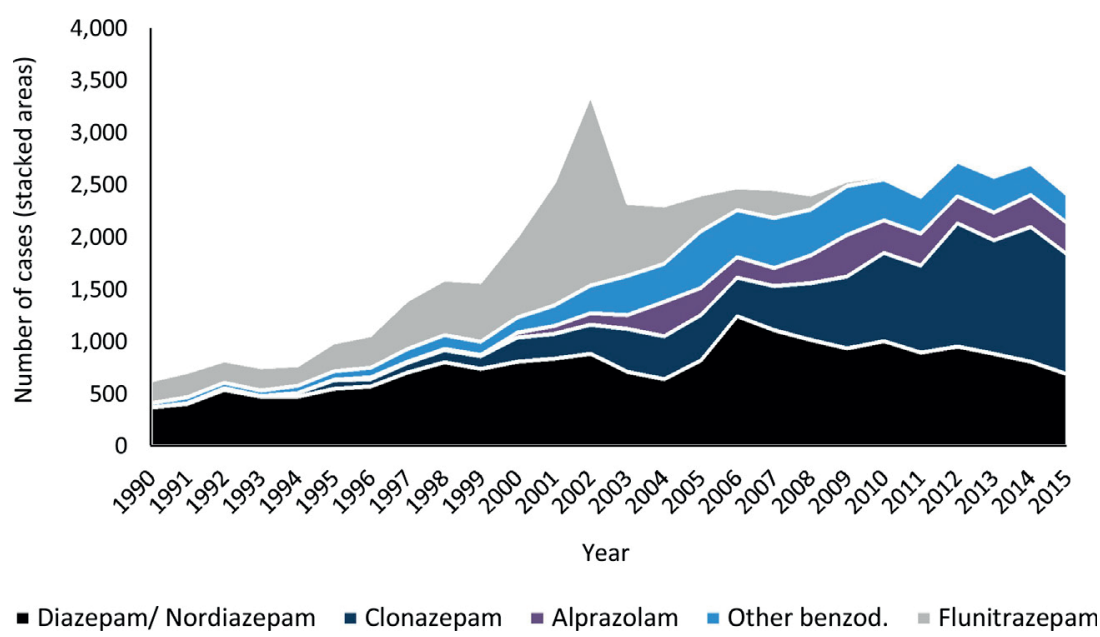

Fig. 5. Number of cases positive for benzodiazepines and related drugs, disaggregated into individual substances detected (stacked areas). Other benzodiazepines include bromazepam, phenazepam, oxazepam, and the benzodiazepine-related drugs zolpidem and zopiclone.

THC was found together with other drug classes in $62 \%$ of the cases. During the last six years, an increasing proportion of THC single-drug cases was observed. We have published a separate article with more details on the trend for THC [24].

\subsubsection{Opioids}

The annual number of drivers positive for opioids was low compared to the other drug classes (Fig. 1). The different opioids detected during the study period are given in Fig. 6. Morphine constituted the largest proportion (found in $61 \%$ of the opioidpositive cases); $17 \%$ of the drivers positive for buprenorphine or methadone were also positive for morphine. The number of samples positive for other opioids than morphine and codeine increased over time, while the number of samples positive for morphine or codeine declined after year 2000.

Opioids were combined with other drug classes in $82 \%$ of the cases, mostly with benzodiazepines and related drugs (in $70 \%$ of the opioid-cases). The two drugs without legislative limits of driving, codeine and tramadol, were found alone without alcohol or other drugs in $4 \%$ and $7 \%$ of the cases where those drugs were detected, respectively.

\subsubsection{Other drugs}

Findings of carisoprodol and/or its metabolite meprobamate increased from nine cases in 1990 to 303 cases in 2006, followed by a drop in number of cases to 11 cases in 2009. No further increase was detected during 2009-2015.

\section{Discussion}

This paper provides an overview of trends in drug use among suspected drug-impaired drivers in Norway during 26 years. Benzodiazepines and related drugs, and stimulants, were the most frequently detected drug classes, followed by cannabis. Annual prevalence of the different drug classes detected changed only slightly during the study period, and so did the prevalence of multidrug use. However, some changes in drug use were noted when disaggregating the drivers by age group. The key findings among suspected drug-impaired drivers from 2000 to 2015 were the high and increasing prevalence of THC, particularly among drivers under the age of 30, and the increase in amphetamine/ methamphetamine among drivers at or higher than age 40 .

The proportion of drug-positive drivers who were above 40 years of age increased during the study period. Our hypothesis is that at least a part of the growth in age might be explained by a cohort effect: many drugged drivers who started combining drugs with driving at young age might have continued doing so while growing older, and thereby contributed to a continuous increase in the number of drugged drivers above 40 years of age. At the same time, only the young drivers who were THC-positive increased further in numbers after about year 2002. This contributed to an elevated increased proportion aged above 40 years among drugged drivers positive for other drugs than THC.

Even though the total number of suspected impaired driving cases (including alcohol) remained stable during 1990-2015, the

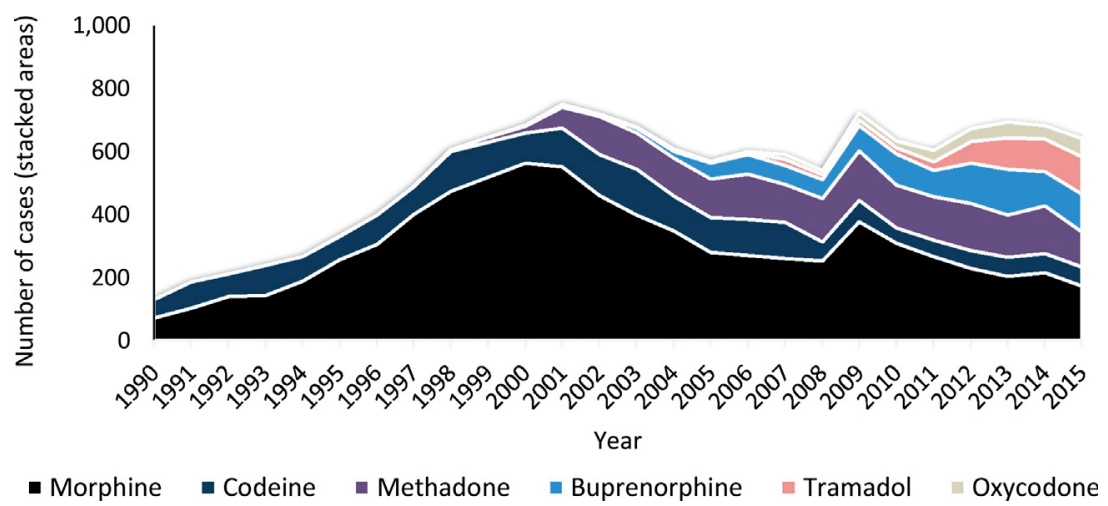

Fig. 6. Number of cases positive for opioids, disaggregated into individual substances detected (stacked areas). 
number of both suspected drug-impaired drivers and drugpositive samples increased significantly, and accordingly. The rapid increase in number of suspected drug-impaired drivers from 1990 was at least partly due to increased focus on drugs among the police, but increased drug use is also likely. During 19961999 testing of all blood samples, including those where only alcohol was suspected by the police, did not result in a substantial higher number of drug-positive findings, suggesting that the police observations were highly correlated with the toxicological results.

Performance of a Field Sobriety Test was included in the revised Road Traffic Act in 2012 to help identifying drug impaired drivers; it is likely that this causes an increase in the number of samples submitted for drug analysis. The implementation of roadside drugtests in 2015 by the Mobile Police Service has also contributed to some of the increase in number of blood samples analysed for drugs in 2015 compared to the previous years. The Mobile Police Service, which in 2014 apprehended $12 \%$ of the drivers suspected of impaired driving (from alcohol only or drugs), discovered in 2015 $18 \%$ of these drivers (according to statistics obtained from the Mobile Police Service).

There seemed to be an over-representation of drug-negative samples from drivers involved in road traffic crashes. This was likely due to police investigations to document whether or not the crash was related to violation of the Road Traffic Act, where blood sampling for alcohol and drug testing was done on a routine basis, even in cases were drug impairment was not suspected.

The results of this study have some similarities with findings from other studies in northern Europe. Suspected drug-impaired drivers in Finland during 1977-2007 had most often used benzodiazepines, followed by amphetamines, cannabis and opioids; the same order of prevalence as in Norway [25]. In our neighboring country Sweden, amphetamine was also highly prevalent among suspected drug-impaired drivers whereas only approximately $1 \%$ had used cocaine (year 2001-2004). However, benzodiazepines were less prevalent in Sweden (10\%) than in Norway [26]. In Scotland, benzodiazepines were frequently found among arrested drivers in 2008 (83\%), but unlike in Norway, opioids $(29 \%)$ and cocaine $(21 \%)$ were found more often than amphetamine (6\%) [27].

There are considerable variations in drug use between regions in Europe. A study analysing drugs in wastewater found that consumption of cocaine was highest in western and central Europe and lower in northern and eastern Europe. Consumption of amphetamines was highest in northern and eastern Europe [28]. Roadside surveys of the general driving population also found differences between different European regions. The DRUID project, which was carried out in 2008-9 in 13 European countries, found that alcohol, THC, and cocaine were more commonly used by drivers in central and southern Europe, whereas benzodiazepines were more commonly used by drivers in northern Europe. Amphetamines were most common in northern and eastern Europe [9].

During the last few years the defined daily doses (DDD) of the different benzodiazepines prescribed per inhabitant in Norway decreased; the only exception during 2012-2015 was the benzodiazepine-related drug zolpidem, which increased by $11 \%$. A slight decrease in the total DDD of opioids prescribed per inhabitant was also observed during 2012-2015, however with variations within the drug class [29]. Whether the apprehended drivers who used medicinal drugs had legal prescriptions was unknown to us, and we can therefore not evaluate whether the more restricted prescription of these drugs contributed to the decrease observed among the drivers. However, the majority of the medicinal drug users were also positive for drugs from other drug classes or alcohol, which could be an indication for problematic use. In a study performed among suspected drug-impaired drivers in Sweden during 2006-2009, the overall prevalence of nonprescribed use of psychoactive medicinal drugs was 59\%; the prevalence was highest for young offenders and multidrug users [30]. Our data show that the benzodiazepine using drivers were dominated by people aged less than 40 years, whereas the majority of benzodiazepines are prescribed to users over 60 years of age according to data from the Norwegian Prescription Database (NorPD) [31]. This was also found in a previous study [4], and suggests that a large proportion of the drivers impaired by benzodiazepines had obtained the drugs on the illicit market. Further supporting this were findings from another previous study, where individual benzodiazepines in blood samples from suspected drug-impaired drivers in Norway were compared with statistics of drug seizures, by year. The changes in prevalence of alprazolam, clonazepam, diazepam, flunitrazepam, nitrazepam and oxazepam during 2002-2009 were similar to the changes in benzodiazepines seized by the police [32]. A similar result was found in 2015, when the police reported that clonazepam constituted about $50 \%$ of the benzodiazepine seizures in Norway [33], and clonazepam was detected in more than $50 \%$ of the drivers positive for benzodiazepines and related drugs.

Zopiclone is by far the most frequently prescribed drug in Norway within the category benzodiazepines and related drugs [29]. However, there were few findings of zopiclone in the present study, although previous studies of drug use in general traffic have revealed frequent use of this drug. Both in roadside studies performed in several regions of Norway in 2008-2009, and in the northern part of Norway in 2014-2015, zopiclone was the most frequently detected drug together with THC $[34,35]$. This might indicate that zopiclone users are seldom suspected of drugimpaired driving, perhaps because of lower abuse potential than for benzodiazepines, or few impairing effects of the drug. It should, however, be mentioned that oral fluid was used in the roadside studies, and a median concentration ratio of 3.8 [36] and 2.4 [37] have previously been found between oral fluid and blood; thus, zopiclone may be detected in oral fluid for longer time after use than in blood. Zopiclone is also unstable during storage [38], so it is expected that there was some under-estimation of its prevalence in our study.

Use of amphetamines, benzodiazepines, z-hypnotics, cannabis, cocaine and opioids have been found to significantly increase the risk of fatal-, injury-, and/or property damage related road traffic crashes $[2,39,40]$. This highlights the importance of reducing drugged driving. Limiting the availability of drugs with abuse potential and impairing effects is likely to have the largest impact. Carisoprodol findings among arrested drivers decreased rapidly between 2006 and 2009, as a consequence of the change to a more restricted prescription category in 2007 , and complete withdrawal from the Norwegian market in 2008. Only a limited proportion of the previous carisoprodol-using patients switched to other prescribed drugs with abuse potential after the withdrawal [41]. The reduction in flunitrazepam findings among the arrested drivers after 2002 was due to a successful termination of the diversion of Rohypnol ${ }^{\circledR}$ from a licit manufacturer in eastern Europe to the illegal drug-market. At the same time, prescription of flunitrazepam was restricted, which might have contributing to further decrease in use of this drug [42]. However, there are indications that clonazepam replaced flunitrazepam as the benzodiazepine of choice among problematic drug users after 2002 [42].

Various alcohol policy strategies have shown effect in reducing consumption of alcohol, drunk driving and alcohol-related traffic accidents. Examples are high taxes on alcoholic beverages [43] and high minimum legal age for drinking or buying alcohol [44], low legal blood alcohol concentration for drivers and related sanctions $[45,46]$, information campaigns about negative consequences for 
health and safety [47] and frequent traffic controls with breath test for alcohol [48]. Similar strategies could be used for other psychoactive drugs. Mass media information about risks for health and safety when using drugs has been very limited in Norway, and should be performed. Further restrictions on prescription of drugs in Norway were initiated in 2016 [49]. However, most of the drugged drivers have obtained their drugs from the illegal market, which makes preventing use more challenging. Use of oral fluid tests for drug screening during roadside tests have been taken into use in many police districts in Norway in 2016; this will probably have a preventive effect in addition to help evaluate which drivers should not be allowed to drive further due to enhanced risk of causing a road traffic crash.

\subsection{Limitations}

This study reports drug findings in blood samples submitted by the police from suspected drug-impaired drivers in Norway. During the study period, the focus on impairment from drugs has increased, both because of increasing awareness about drugimpaired driving and the implementation of legal limits for 20 drugs in 2012 [7]. Therefore, the selection bias might have changed over time; thus, the increase in drugs found among drivers suspected of impaired driving cannot be generalized to drivers in general.

Drug findings during 1990-1995 could be biased because drug analysis was often not performed if a high alcohol concentration was detected first. In the 1990s, some drugs were only analysed for if suspected by the police, or if impairment was suspected from the clinical examination but no drugs were detected by the first screening method. During the whole study period, the total prevalence of drugs found might have been under-reported because a limited number of drugs were included when analysing blood samples, and because some drugs might have degraded between the time of arrest and the time of blood testing. Analysis of other psychoactive substances like antihistamines, antipsychotics, antidepressants, and new psychoactive substances (NPS) were not systematically performed, and not included in this study. Driving under the influence of impairing drugs other than those analysed for in this study, might have increased in prevalence without our knowledge.

\section{Conclusions}

The annual number of drug-positive blood samples increased by more than five times from 1990 to 2015 . This may be caused by a combination of increased drug use among drivers and increased focus on drugged driving by the police. The median age of the drivers also increased, due to a large increase in the proportion of those aged above 40 years. The prevalence of different drug classes detected changed only slightly during the study period. However, the increase during the last few years in use of cannabis among the youngest and amphetamines among the oldest suspected drugimpaired drivers might indicate emerging new trends in drug use among drivers in Norway.

\section{Funding}

This research did not receive any specific grant from funding agencies in the public, commercial, or not-for-profit sectors.

\section{Acknowledgements}

The authors wish to thank Paul Koksæter and Terje Hammer for retrieving relevant data from the toxicological database.

\section{References}

[1] A. Hetland, D.B. Carr, Medications and impaired driving, Ann. Pharmacother. 48 (2014) 494-506.

[2] H. Gjerde, M.C. Strand, J. Mørland, Driving under the influence of non-alcohol drugs-an update part I: epidemiological studies, Forensic Sci. Rev. 27 (2015) 89-113.

[3] T. Dassanayake, P. Michie, G. Carter, A. Jones, Effects of benzodiazepines, antidepressants and opioids on driving: a systematic review and meta-analysis of epidemiological and experimental evidence, Drug Saf. 34 (2011) 125-156.

[4] A.S. Christophersen, J. Mørland, Frequent detection of benzodiazepines in drugged drivers in Norway, Traffic Inj. Prev. 9 (2008) 98-104.

[5] H. Moskowitz, Commentary on variability among epidemiological studies of drugs and driving, Drugs and Traffic: A Symposium, Transportation Research Circular E-C096, Woods Hole, MA, 2005 http://onlinepubs.trb.org/onlinepubs/ circulars/ec096.pdf. (Accessed 29 June 2017).

[6] A.S. Christophersen, H. Gjerde, A. Bjørneboe, J. Sakshaug J. Mørland, Screening for drug use among Norwegian drivers suspected of driving under influence of alcohol or drugs, Forensic Sci. Int. 45 (1990) 5-14.

[7] V. Vindenes, D. Jordbru, A.-B. Knapskog, E. Kvan, G. Mathisrud, L. Slordal, J. Mørland, Impairment based legislative limits for driving under the influence of non-alcohol drugs in Norway, Forensic Sci. Int. 219 (2012) 1-11.

[8] V. Vindenes, T. Aamo, C. Innerdal, G. Mathisrud, J. Mørland, B. Riedel, Revidering av forskrift om faste grenser for påvirkning av andre berusende eller bedøvende middel enn alkohol m.m. - Vurdering av eksisterende faste grenser og forslag til faste grenser for flere stoffer [Revision of Regulations on Fixed Limits for Impairment by Other Intoxicating or Anaesthetic/Sedative Substances than Alcohol etc. - Assessment of Existing Fixed Limits and Proposed Fixed Limits for More Substances], Ministry of Transport and Communications, Oslo, Norway, 2015 https://www.regjeringen.no/contentassets/21dac5b787734d7b80f45d30c88e8632/hbrev2304rapport.pdf. (Accessed 29 August 2017).

[9] I.M. Bernhoft, T. Hels, A. Lyckegaard, S. Houwing, A.G. Verstraete, Prevalence and risk of injury in Europe by driving with alcohol, illicit drugs and medicines, Procedia Soc. Behav. Sci. 48 (2012) 2907-2916.

[10] H. Gjerde, A.S. Christophersen, B. Skuterud, K. Klemetsen, J. Mørland, Screening for drugs in forensic blood samples using EMIT urine assays, Forensic Sci. Int. 44 (1990) 179-185.

[11] A.S. Christophersen, J. Mørland, Drugged driving, a review based on the experience in Norway, Drug Alcohol Depend. 47 (1997) 125-135.

[12] A.S. Christophersen, M. Gulliksen, I. Hasvold, U. Johansen, R. Karinen, Å. Ripel, M. Krogh, Screening, confirmation and quantification of drugs of abuse in whole blood by LC-MS (ESI), Abstracts of The 39th Meeting of The International Association of Forensic Toxicologists (TIAFT), Prague, Czech Republic, 2001 www.tiaft.org/past-meetings/tiaft2001/posters/p85.doc. (Accessed 29 June 2017).

[13] E.L. Øiestad, U. Johansen, A.M. Øiestad, A.S. Christophersen, Drug screening of whole blood by ultra-performance liquid chromatography-tandem mass spectrometry, J. Anal. Toxicol. 35 (2011) 280-293.

[14] S.R. Dahl, K.M. Olsen, D.H. Strand, Determination of gamma-hydroxybutyrate (GHB) beta-hydroxybutyrate (BHB), pregabalin, 1,4-butane-diol (1,4BD) and gamma-butyrolactone (GBL) in whole blood and urine samples by UPLCMSMS, J. Chromatogr. B Anal. Technol. Biomed. Life Sci. 885-886 (2012) 37-42.

[15] H. Gjerde, I. Hasvold, G. Pettersen, A.S. Christophersen, Determination of amphetamine and methamphetamine in blood by derivatization with perfluorooctanoyl chloride and gas chromatography/mass spectrometry, J. Anal. Toxicol. 17 (1993) 65-68.

[16] H. Gjerde, E. Dahlin, A.S. Christophersen, Simultaneous determination of common benzodiazepines in blood using capillary gas chromatography, J. Pharm. Biomed. Anal. 10 (1992) 317-322.

[17] H. Gjerde, U. Fongen, H. Gundersen, A.S. Christophersen, Evaluation of a method for simultaneous quantification of codeine, ethylmorphine and morphine in blood, Forensic Sci. Int. 51 (1991) 105-110.

[18] A.S. Christophersen, Tetrahydrocannabinol stability in whole blood: plastic versus glass containers, J. Anal. Toxicol. 10 (1986) 129-131.

[19] E.N. Sauve, M. Langødegård, D. Ekeberg, A.M. Øiestad, Determination of benzodiazepines in ante-mortem and post-mortem whole blood by solidsupported liquid-liquid extraction and UPLC-MS/MS, J. Chromatogr. B Anal. Technol. Biomed. Life Sci. 883-884 (2012) 177-188.

[20] E. Eliassen, L. Kristoffersen, Quantitative determination of zopiclone and zolpidem in whole blood by liquid-liquid extraction and UHPLC-MS/MS, J. Chromatogr. B Anal. Technol. Biomed. Life Sci. 971 (2014) 72-80.

[21] L. Kristoffersen, A. Smith-Kielland, An automated alcohol dehydrogenase method for ethanol quantification in urine and whole blood, J. Anal. Toxicol. 29 (2005) 387-389.

[22] L. Kristoffersen, L.E. Stormyhr, A. Smith-Kielland, Headspace gas chromatographic determination of ethanol: the use of factorial design to study effects of blood storage and headspace conditions on ethanol stability and acetaldehyde formation in whole blood and plasma, Forensic Sci. Int. 161 (2006) 151-157.

[23] Ministry of Justice, Forskrift om endring i forskrift om faste grenser for påvirkning av andre berusende eller bedøvende middel enn alkohol m.m. (forskrift om faste grenser) [Revision of Fixed Limits for Drugs in the Traffic], Ministry of Justice, 2016 https://lovdata.no/dokument/LTI/forskrift/2016-01 12-19. (Accessed 22 February 2017). 
[24] A. Valen, S.T. Bogstrand, V. Vindenes, H. Gjerde, Increasing use of cannabis among arrested drivers in Norway, Traffic Inj. Prev. (2017), doi:http://dx.doi. org/10.1080/15389588.2017.1321114 [Epub ahead of print].

[25] K.K. Ojaniemi, T.R. Lintonen, A.O. Impinen, P.M. Lillsunde, A.I. Ostamo, Trends in driving under the influence of drugs: a register-based study of DUID suspects during 1977-2007, Accid. Anal. Prev. 41 (2009) 191-196.

[26] A. Holmgren, P. Holmgren, F.C. Kugelberg, A.W. Jones, J. Ahlner, Predominance of illicit drugs and poly-drug use among drug-impaired drivers in Sweden, Traffic Inj. Prev. 8 (2007) 361-367.

[27] J. Officer, Trends in drug use of Scottish drivers arrested under Section 4 of the Road Traffic Act - a 10 year review, Sci. Justice 49 (2009) 237-241.

[28] K.V. Thomas, L. Bijlsma, S. Castiglioni, A. Covaci, E. Emke, R. Grabic, F. Hernández, S. Karolak, B. Kasprzyk-Hordern, R.H. Lindberg, M. López de Alda, A. Meierjohann, C. Ort, Y. Pico, J.B. Quintana, M. Reid, J. Rieckermann, S. Terzic, A.L. van Nuijs, P. de Voogt, Comparing illicit drug use in 19 European cities through sewage analysis, Sci. Total Environ. 432 (2012) 432-439.

[29] S. Sakshaug, H. Strøm, C. Berg, H.S. Blix, I. Litleskare, T. Granum, Drug Consumption in Norway 2012-2016, Norwegian Institute of Public Health Oslo, Norway, 2017 https://www.fhi.no/en/publ/2017/drug-consumption2012-2016. (Accessed 21 June 2017).

[30] M. Tjäderborn, A.K. Jönsson, T.Z. Sandström, J. Ahlner, S. Hägg, Non-prescribed use of psychoactive prescription drugs among drug-impaired drivers in Sweden, Drug Alcohol Depend. 161 (2016) 77-85.

[31] The Norwegian Institute of Public Health, The Norwegian Prescription Database (NorPD), The Norwegian Institute of Public Health, 2017 http:// www.norpd.no. (Accessed 21 May 2017).

[32] S.T. Bogstrand, G. Middelkoop, A.S. Christophersen, Trends in amphetamine and benzodiazepine use among drivers arrested for drug impaired driving in Norway 2000-2009, Nor. Epidemiol. 21 (2011) 61-66.

[33] The National Criminal Investigation Service (KRIPOS), Narkotika- og Dopingstatistikk 2015 [Drug Seizure Statistics 2015], KRIPOS, Norway, 2016 https:/ www.politi.no/globalassets/dokumenter/01-rapporter-statistikk-og-analyse/ narkotikastatistikk/narkotika?og-dopingstatistikk-2015.pdf. (Accessed 15 December 2016).

[34] R.E.G. Jamt, H. Gjerde, P.T. Normann, S.T. Bogstrand, Roadside survey on alcoho and drug use among drivers in the arctic county of Finnmark (Norway), Traffic Inj. Prev. 18 (2017) 681-687.

[35] H. Gjerde, A.S. Christophersen, P.T. Normann, T. Assum, E.L. Øiestad, J. Mørland, Norwegian roadside survey of alcohol and drug use by drivers (2008-2009), Traffic Inj. Prev. 14 (2013) 443-452.

[36] H. Gjerde, J. Mordal, A.S. Christophersen, J.G. Bramness, J. Mørland, Comparison of drug concentrations in blood and oral fluid collected with the intercept sampling device, J. Anal. Toxicol. 34 (2010) 204-209.
[37] K. Langel, H. Gjerde, D. Favretto, P. Lillsunde, E.L. Øiestad, S.D. Ferrara, A.G. Verstraete, Comparison of drug concentrations between whole blood and oral fluid, Drug Test. Anal. 6 (2014) 461-471.

[38] D.C. Mata, Stability of 26 sedative hypnotics in six toxicological matrices at different storage conditions, J. Anal. Toxicol. 40 (2016) 663-668.

[39] R. Elvik, Risk of road accident associated with the use of drugs: a systematic review and meta-analysis of evidence from epidemiological studies, Accid. Anal. Prev. 60 (2013) 254-267.

[40] T.M. Rudisill, M.T. Zhu, G.A. Kelley, C. Pilkerton, B.R. Rudisill, Medication use and the risk of motor vehicle collisions among licensed drivers: a systematic review, Accid. Anal. Prev. 96 (2016) 255-270.

[41] J.G. Bramness, K. Furu, S. Skurtveit, A. Engeland, Effect of the market withdrawal of carisoprodol on use of other prescribed drugs with abuse potential, Clin. Pharmacol. Ther. 91 (2012) 438-441.

[42] G. Høiseth, G. Middelkoop, J. Mørland, H. Gjerde, Has previous abuse of flunitrazepam been replaced by clonazepam? Eur. Addict. Res. 21 (2015) $217-$ 221.

[43] A.C. Wagenaar, M.J. Salois, K.A. Komro, Effects of beverage alcohol price and tax levels on drinking: a meta-analysis of 1003 estimates from 112 studies, Addiction 104 (2009) 179-190.

[44] A.C. Wagenaar, T.L. Toomey, Effects of minimum drinking age laws: review and analyses of the literaturefrom 1960 to 2000, J. Stud. Alcohol. Suppl. (2002) 206-225.

[45] E. Desapriya, S. Shimizu, I. Pike, S. Subzwari, G. Scime, Impact of lowering the legal blood alcohol concentration limit to 0.03 on male, female and teenage drivers involved alcohol-related crashes in Japan, Int. J. Inj. Contr. Saf. Promot. 14 (2007) 181-187.

[46] J.C. Fell, R.B. Voas, The effectiveness of reducing illegal blood alcoho concentration (BAC) limits for driving: evidence for lowering the limit to .05 BAC, J. Saf. Res. 37 (2006) 233-243.

[47] R.W. Elder, R.A. Shults, D.A. Sleet, J.L. Nichols, R.S. Thompson, W. Rajab Effectiveness of mass media campaigns for reducing drinking and driving and alcohol-involved crashes: a systematic review, Am. J. Prev. Med. 27 (2004) 5765.

[48] C. Peek-Asa, The effect of random alcohol screening in reducing motor vehicle crash injuries, Am. J. Prev. Med. 16 (1999) 57-67.

[49] The Norwegian Directorate for Health, Førerkort-veileder til helsekrav [Driver Lisence - Guide to Health Requirements], The Norwegian Directorate for Health, Norway, 2016 https://helsedirektoratet.no/Retningslinjer/F ørerkortveilederen.pdf. (Accessed 27 June 2017). 


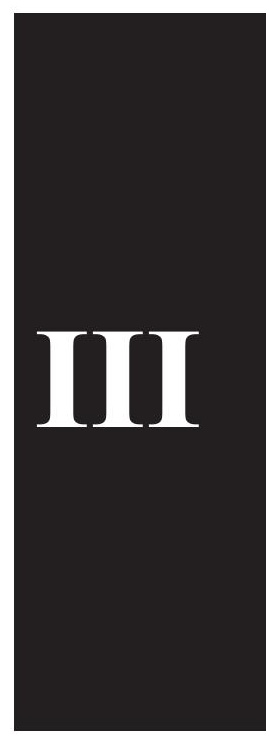





\title{
Driver-related risk factors of fatal road traffic crashes associated with alcohol or drug impairment
}

\author{
Anja Valen ${ }^{\mathrm{a}, \mathrm{b}, *}$, Stig Tore Bogstrand ${ }^{\mathrm{a}, \mathrm{c}}$, Vigdis Vindenes ${ }^{\mathrm{a}, \mathrm{b}}$, Joachim Frost ${ }^{\mathrm{d}}$, Magnus Larsson ${ }^{\mathrm{e}, \mathrm{f}}$, \\ Anders Holtan ${ }^{g}$, Hallvard Gjerde ${ }^{\mathrm{a}}$ \\ ${ }^{a}$ Oslo University Hospital, Department of Forensic Sciences, P.O. Box 4950 Nydalen, NO-0424 Oslo, Norway \\ ${ }^{\mathrm{b}}$ University of Oslo, Faculty of Medicine, Institute of Clinical Medicine, P.O box 1171 Blindern, NO-0318 Oslo, Norway \\ ${ }^{\mathrm{c}}$ University of Oslo, Faculty of Medicine, Institute of Health and Society, Department of Nursing Science, P.O. Box 1130 Blindern, NO-0318 Oslo, Norway \\ ${ }^{\mathrm{d}}$ St. Olav University Hospital, Department of Clinical Pharmacology, NO-7006 Trondheim, Norway \\ e The Norwegian Public Roads Administration, Planning and Engineering Services Department, Traffic Technic and Analysis, P.O box 1010 Nordre Ål, NO-2605 \\ Lillehammer, Norway \\ ${ }^{\mathrm{f}}$ Swedish National Road and Transport Research Institute, Traffic Safety department, VTI, Olaus Magnus väg 35, SE-581 95 Linköping, Sweden \\ ${ }^{\mathrm{g}}$ Oslo University Hospital, Division of Emergencies and Critical Care, Department of Anesthesiology \& Oslo University Hospital, Division of Emergencies and Critical Care, \\ Department of Traumatology, P.O box 4956 Nydalen, NO-0424 Oslo, Norway
}

\section{A R T I C L E I N F O}

\section{Keywords:}

Driving under the influence

Traffic accidents

Logistic model

Forensic toxicology

Drugs

Alcohol

\begin{abstract}
A B S T R A C T
Fatal road traffic crashes are often related to speeding, non-use of a seatbelt, and alcohol/drug-impaired driving. The aim of this study was to examine associations between driving under the influence of drugs and/or alcohol and driver-related risk factors that have been reported as significantly contributing causes of fatal road traffic crashes. The data were extracted from Norwegian road traffic crash registries and forensic toxicology databases. Drug/alcohol investigated car and van drivers and motorcycle riders fatally injured in road traffic crashes in Norway during 2005-2015 were included in this study $(n=772)$. Drug and alcohol concentrations corresponding to $0.5 \mathrm{~g} / \mathrm{kg}$ alcohol in blood were used as the lower limits for categorising drivers/riders as impaired; $0.2 \mathrm{~g} / \mathrm{kg}$ was the upper limit for being categorised as sober. Associations between driver-related risk factors and impairment from specific substance groups were calculated using multivariable logistic regression, adjusted for other substance groups, age, and sex, and were reported when the confidence intervals did not contain the value 1 or lower. Substances found in concentrations above the impairment limits were mainly alcohol (20\%), medicinal drugs (10\%: benzodiazepines, opioids, z-hypnotics), stimulants (5\%: amphetamines, methylphenidate, and cocaine), and cannabis (4\%: THC). The drug/alcohol-impaired drivers had compared to the sober drivers more often been speeding ( $68 \%$ versus $32 \%$ ), not used a seatbelt ( $69 \%$ versus $30 \%$ ), and been driving without a valid driver license (26\% versus 1\%). Logistic regression analysis showed that impairment from alcohol or stimulants (mainly amphetamines) was associated with all three risk factors, medicinal drugs with all except speeding, and impairment from cannabis (THC) with not having a valid driver license. Among motorcycle riders, drug/alcohol impairment was associated with not having a valid driver license and non-use of a helmet. At least one of the risk factors speeding, non-use of a seatbelt/helmet, and driving without a valid license were present among the vast majority of the drug/alcohol-impaired fatally injured drivers and riders, and also among more than half of the fatally injured sober drivers.
\end{abstract}

\section{Introduction}

Driver-related risk factors such as speeding, non-use of a seatbelt, distracted driving, drowsy driving, and drug/alcohol-impaired driving are often reported as contributing causes of fatal road traffic crashes (Pietrasik, 2018). Some risk factors of crashes or fatalities in a crash might be related, either through causal pathways or via personality traits, age, or health of the driver. A recent driving simulation experiment revealed that alcohol increased driver risk-taking and reduced the driver's ability to control the vehicle (Laude and Fillmore, 2015). Among several risk factors tested in a case-control study of motorcycle crashes in France, loss of control of the motorcycle was the most strongly associated with driving under the influence of alcohol (Wu et al., 2018). The adverse effect of alcohol on driving performance

\footnotetext{
* Corresponding author at: Oslo University Hospital, Department of Forensic Sciences, P.O. Box 4950 Nydalen, NO-0424 Oslo, Norway.

E-mail address: anja.valen@ous-hf.no (A. Valen).
} 
is well documented in the literature (Martin et al., 2013). Use of psychoactive drugs may also influence driver performance (Verstraete et al., 2014; Gjerde et al., 2015; Strand et al., 2016; Busardo et al., 2018).

Associations between impairment from drugs and unsafe driving behaviours have been previously investigated, basically in studies using data from the comprehensive US Fatality Analysis Reporting System (FARS) database (Bedard et al., 2007; Liu et al., 2016; Romano and Voas, 2011). These studies have found associations between drugs detected and inappropriate speeding, non-use of a seatbelt, passing violations, etc. among drivers involved in fatal crashes. Drawbacks with previous studies are that often a limited number of drugs have been included in analytical testing or limited data have been recorded in the databases used, and no distinction has been made between acute drug intoxication and earlier drug use, which limits the interpretation of the results from studies based on e.g. the FARS database (Berning and Smither, 2014; Compton and Berning, 2015; Romano et al., 2017). An example of insufficient distinction between acute intoxication and earlier drug use is use of detected cannabinoids, which both in the blood and urine may include both inactive and psychoactive substances, hence diluting the results. Use of delta-9-tetrahydrocannabinol (THC) detected in the urine is also likely to dilute the results as THC might be detected in the urine days after the driver was impaired by the drug (Compton, 2017; Hartman and Huestis, 2013). More studies distinguishing between acute drug intoxication and earlier drug use are therefore needed to supplement the existing literature on the associations between drug use and unsafe driving behaviours or road traffic crashes.

Since 2005, all fatal road traffic crashes in Norway have been analysed in-depth by multidisciplinary crash investigation teams. Information about each incidence is registered in a database. Using this information, the Norwegian Public Roads Administration revealed that in the period $2005-2015,40 \%$ of fatal road traffic crashes in Norway were related to speeding, and at least $21 \%$ of the crashes were related to alcohol or drug use; $41 \%$ of car occupants killed had not used a seatbelt, and $19 \%$ of motorcycle riders killed had not used a helmet (Grimstad and Engebretsen, 2016). When considering only car/van drivers killed, 33.5\% had not used a seatbelt during 2005-2015 (Valen et al., 2019).

A preliminary Norwegian study found that drug/alcohol impairment was associated with speeding or non-use of a seatbelt among car and van drivers (Bogstrand et al., 2015). That study was based on the high-quality Norwegian forensic toxicology database, which contains test results for alcohol and commonly abused drugs quantified in blood samples by accredited methods. Few study years and limited information from the crash investigation teams were however included in the preliminary study. The aim of the present study was to perform a more thorough investigation of the association between impairment from different psychoactive substances and driver-related risk factors reported to have significantly contributed to fatal road traffic crashes, including both car/van drivers and motorcycle/moped riders in the period 2005-2015.

\section{Methods}

\subsection{Study design, setting, and selection of participants}

This is a retrospective register-based study of car and van drivers and motorcycle (including moped) riders who were fatally injured in road traffic crashes in Norway between 2005 and 2015. Drivers and riders investigated for the use of drugs and/or alcohol were included, except if there was more than $24 \mathrm{~h}$ ' time lag from the incidence to death without a blood sample being collected within $24 \mathrm{~h}$ after the incidence.

\subsection{Data sources}

\subsubsection{Crash investigation team database}

The police activate local crash investigators on call from the national road authorities in all fatal crashes, and in all other severe crashes where the police request technical support for their investigation. The local crash investigators go to the crash site to secure timesensitive information, take pictures, estimate possible hazard scenarios, talk to other rescue personnel at the scene, etc. Technical documentation of the vehicle continues during the following days. In all cases where the driver died immediately or within 30 days from the injuries he/she suffered in the road traffic crash, documentation from the early investigation was further evaluated in multidisciplinary meetings where the significance of different risk factors related to the vehicle, driver, and road were evaluated. The purpose is to reveal the causes of the crashes and the causes of the fatal outcome of the crashes to suggest actions to prevent future fatal incidences. Included in the final reports are both technical information and risk factors evaluated by the multidisciplinary team to be of significant importance for the occurrence of the fatal road traffic crash. Assessments of likely undocumented factors, such as inattention and drowsy driving, are also made based on the available information. Data and conclusions from the reports are recorded in a database operated by the Norwegian Public Roads Administration. More information about these investigations and the data were recently published by Sagberg (2018).

\subsubsection{Forensic toxicology databases}

The police request alcohol and drug testing in approximately $70 \%$ of fatal road traffic crashes. The analyses are performed at two locations in Norway: the Forensic Toxicology Laboratory in Oslo, which is now a part of Oslo University Hospital, and the Department of Clinical Pharmacology at St. Olav University Hospital in Trondheim. Both forensic laboratories are accredited by Norwegian Accreditation (Lillestrøm, Norway; www.akkreditert.no/en). The analytical testing includes frequently used psychoactive drugs such as amphetamines, cocaine, cannabis, benzodiazepines, and opioids, in addition to alcohol and some other drugs with abuse potential. Immunological methods and/or high-performance gas or liquid chromatography with mass spectrometry detection (GC-MS or LC-MS) is used for drug screening; quantification is performed by accredited GC-MS or LC-MS methods.

\subsubsection{The road traffic accident registry of Statistics Norway}

The police report all serious road traffic crashes to the Road Traffic Accident Registry, which is operated by Statistics Norway and is the basis for national statistics on road traffic crashes. Suicide cases are excluded from the reported statistics, which is in accordance with international standards on reporting road traffic deaths (Adminaite et al., 2018).

\subsubsection{Coupling of data sources}

An overview of drivers and riders fatally injured in road traffic crashes, their age and sex and the date and time of the road traffic crash and results from alcohol and drug testing were obtained by combining data from the Road Traffic Accident Registry of Statistics Norway and the Forensic Toxicology Laboratory in Oslo. The coupling was performed based on the Norwegian national identity numbers. Toxicological results from cases investigated at St. Olav University Hospital were coupled based on crash site, date, time, age, and sex. Thereafter, relevant information from the Crash Investigation Team Database was added.

\subsection{Variables}

A research database was created containing data on age, sex, time period of the crash (day/night and weekday/weekend, where night was defined from $10 \mathrm{p} . \mathrm{m}$. to $4 \mathrm{a}$.m. and weekend from Friday $10 \mathrm{p} . \mathrm{m}$. to Monday 4 a.m.), single-vehicle crash (yes/no), vehicles older than 10 years (yes/no), the toxicological results (substances tested for are listed in Table 1), as well as the following recorded dichotomous data: valid driver license, speeding, use of a seatbelt/motorcycle helmet, incorrect 
Table 1

Compounds included in the study, per se limits corresponding to BAC of $0.2 \mathrm{~g} / \mathrm{kg}$, and impairment limits corresponding to BAC of $0.5 \mathrm{~g} / \mathrm{kg}$.

\begin{tabular}{|c|c|c|c|c|}
\hline \multirow[t]{2}{*}{ Compound } & \multirow[t]{2}{*}{$\begin{array}{l}\text { Per se limit } \\
(\mathrm{ng} / \mathrm{mL})\end{array}$} & \multirow[t]{2}{*}{$\begin{array}{l}\text { Impairment limit } \\
(\mathrm{ng} / \mathrm{mL})\end{array}$} & \multicolumn{2}{|c|}{$\begin{array}{l}\text { Findings at or above impairment limit } \\
\mathrm{n}(\%)^{\mathrm{b}}\end{array}$} \\
\hline & & & $\begin{array}{l}\text { Car or van drivers } \\
(\mathrm{n}=602)\end{array}$ & $\begin{array}{l}\text { Motorcycle riders } \\
(\mathrm{n}=170)\end{array}$ \\
\hline Benzodiazepines & & & $60(10.0)$ & $7(4.1)$ \\
\hline Alprazolam & 3.1 & 6.2 & $6(1.0)$ & $0(0)$ \\
\hline Bromazepam & 32 & 79 & $0(0)$ & $0(0)$ \\
\hline Clonazepam & 1.3 & 3.2 & $18(3.0)$ & $3(1.8)$ \\
\hline Diazepam & 57 & 142 & $18(3.0)$ & $3(1.8)$ \\
\hline Phenazepam & 1.6 & 4.7 & $0(0)$ & $0(0)$ \\
\hline Flunitrazepam & 1.6 & 3.1 & $2(0.3)$ & $1(0.6)$ \\
\hline Nordiazepam & 108 & 271 & $12(2.0)$ & $2(1.2)$ \\
\hline Nitrazepam & 17 & 42 & $3(0.5)$ & $0(0)$ \\
\hline Oxazepam & 172 & 430 & $6(1.0)$ & $0(0)$ \\
\hline Z-hypnotics & & & $16(2.7)$ & $O(0)$ \\
\hline Zolpidem & 31 & 77 & $4(0.7)$ & $0(0)$ \\
\hline Zopiclone & 12 & 23 & $12(2.0)$ & $0(0)$ \\
\hline Stimulants & & & $32(5.3)$ & $9(5.3)$ \\
\hline Amphetamine & 41 & $205^{\mathrm{a}}$ & $20(3.3)$ & $4(2.4)$ \\
\hline Cocaine & 24 & $120^{\mathrm{a}}$ & $0(0)$ & $0(0)$ \\
\hline MDMA & 97 & $485^{\mathrm{a}}$ & $1(0.2)$ & $1(0.6)$ \\
\hline Methamphetamine & 45 & $225^{\mathrm{a}}$ & $18(3.0)$ & $7(4.1)$ \\
\hline Methylphenidate & 3.5 & $18^{\mathrm{a}}$ & $1(0.2)$ & $0(0)$ \\
\hline Cannabis & & & $23(3.8)$ & $10(5.9)$ \\
\hline Delta-9-tetrahydrocannabinol (THC) & 1.3 & 3.1 & $23(3.8)$ & $10(5.9)$ \\
\hline Opioids & & & $6(1.0)$ & $3(1.8)$ \\
\hline Buprenorphine & 0.4 & 0.9 & $1(0.2)$ & $1(0.6)$ \\
\hline Methadone & 25 & 62 & $3(0.5)$ & $1(0.6)$ \\
\hline Morphine & 8.6 & 23 & $1(0.2)$ & $1(0.6)$ \\
\hline Oxycodone & 16 & 38 & $1(0.2)$ & $0(0)$ \\
\hline Other drugs & & & $O(0)$ & $O(0)$ \\
\hline Lysergic acid diethylamide (LSD) & 1.0 & $5.0^{\mathrm{a}}$ & $0(0)$ & $0(0)$ \\
\hline Alcohol & & & $122(20.3)$ & $19(11.2)$ \\
\hline Ethanol & $0.20 \mathrm{~g} / \mathrm{kg}$ & $0.50 \mathrm{~g} / \mathrm{kg}$ & $122(20.3)$ & $19(11.2)$ \\
\hline
\end{tabular}

Abbreviation: $\mathrm{BAC}=$ Blood alcohol concentration; MDMA = 3,4-Methylenedioxymethamphetamine (Ecstasy).

${ }^{a}$ Limits are not defined in the Road Traffic Act. Five times the per se limits were used as impairment limits for these compounds.

b Percent of all samples analysed for drugs and/or alcohol, stratified by vehicle (car/van and motorcycle).

position on the road, incorrect driving decisions, technical driving errors, lack of driving or vehicle experience, inattention while driving, and fatigue/drowsy driving. Speeding was reported when the driver had been driving inappropriately fast according to the road/driving conditions, above the speed limit, or involved in hazardous driving. Other, more rarely recorded driver-related risk factors that to some degree were based on best judgement were disregarded, such as driving while stressed, driver overestimating his/her driving skills, partying atmosphere, and suspicion of suicide (not confirmed by the police). Variables considering illness or mental stability were disregarded as the evaluation and inclusion in the database was inconsistent during the study period; health personnel were included in the crash investigation teams in 2010. Age was categorised into four groups: $<25,25-34$, $35-44$, and $\geq 45$ years. The rationale was to separate drivers/riders at different stages in their lives; the young people, often without family responsibility ( $<25$ years); those in establishment phase, often with responsibility for children (25-44 years); those tending to get more spare time again and better economy ( $\geq 45$ years). The group $25-44$ years was divided in two to make results more comparable with other published studies. Older age groups were not made because the highest age observed among impaired riders was 53 years, and only $3 \%$ of the impaired drivers were aged above 65 years, meaning that adjusting for more age groups above age 45 most likely would have reduced the statistical power without resulting in significantly more accurate results.

\subsubsection{Data processing based on the toxicological results}

The drivers/riders were categorised as sober or impaired based on the toxicological results. The per se limits corresponding to a blood alcohol concentration of $0.2 \mathrm{~g} / \mathrm{kg}$ and the graded sanction limits corresponding to a blood alcohol concentration of $0.5 \mathrm{~g} / \mathrm{kg}$ in the Norwegian Road Traffic Act (Ministry of Transport and Communications, 2016) were used in this process. The drivers/riders were categorised as sober if analysed for both drugs and alcohol, with negative results or concentrations below the per se limits. Drivers/riders with drug or alcohol concentrations equal to or above the graded sanction limits were categorised as impaired. Drivers/riders with drug or alcohol concentrations above the per se limits but below the graded sanction limits were excluded from the study.

Limits for graded sanction have not been defined for amphetamine, methamphetamine, MDMA, cocaine, LSD, and methylphenidate; for those drugs, we considered drug concentrations five times the per se limits as indications of possible impairment. Those concentrations correspond to the peak concentrations observed after taking commonly used recreational drug doses (Vindenes et al., 2012); for amphetamine and methamphetamine those concentrations are higher than those observed after therapeutic use (Schulz et al., 2012; Schweitzer and Holcomb, 2002). For amphetamine and methamphetamine, the sum of their concentrations (if both were present) were required to be five times the per se limit for amphetamine.

Findings of diazepam and/or morphine resulting from documented or likely medical treatment after the crash were disregarded during the formation of the impairment group.

Findings of alcohol were disregarded if the analysis of ethyl glucuronide (EtG) and ethyl sulphate (EtS) was performed with negative results.

The drivers categorised as impaired were grouped according to their drug/alcohol use as impaired by alcohol, stimulants (amphetamines, 
methylphenidate, and cocaine), cannabis, or medicinal drugs. The medicinal drug group included benzodiazepines, z-hypnotics, and opioids (Table 1 ).

Drivers/riders categorised as sober were excluded from the study if there were findings of tramadol and/or pregabalin (psychoactive compounds that are not included in the Norwegian Road Traffic Act) that may cause impairment. This was evaluated individually, and findings of tramadol above $263 \mathrm{ng} / \mathrm{mL}(1 \mu \mathrm{M})$ (Baselt, 2011; Strand et al., 2011) and findings of pregabalin above $1590 \mathrm{ng} / \mathrm{mL}(10 \mu \mathrm{M}$; the lowest value in the estimated range of therapeutic effect) (The Pharmacology Portal, 2018) were used as lower limits for the exclusion of drivers/riders.

\subsection{Statistical methods}

Data analyses were conducted using statistical package SPSS version 23 (IBM Corporation, Armonk, NY, USA). A significance level of 5\% (generated p-value less than 0.05 ) was together with the confidence intervals used for the interpretation of the results.

Bivariate analyses using Pearson's chi-square statistics were used to compare recorded driver-related risk factors among sober and impaired drivers by assessing the crude odds ratios and p-values. Fisher's exact test was used to generate p-values in cases with an expected count less than five. None of the risk factors were excluded from further testing based on the crude odds ratios or p-values, as adjustment for confounding variables by logistic regression potentially can adjust a nonsignificant result to significant. Adjusted odds ratios for the associations between driver-related risk factors and impairment were generated in multivariable logistic regression models adjusted for age group and sex (Model 1) and for age group, sex, and the co-variables time of crash, single-vehicle crash, vehicle 10 years or older (Model 2). The models used were non-hierarchical; both the dependent variable (impairment) and all of the independent variables were included in one run. Two models of the adjusted odds ratios were made for each unsafe driver action/condition tested, because adjustment for several co-variables (Model 2) potentially could result in a more correct result for the association between impairment and unsafe driver action/condition, but on the other hand could result in a saturated model with less statistical power, potentially camouflaging a true association. The purpose of Model 2 was to test whether the associations found in Model 1 would be influenced when additionally correcting for possible differences in crash characteristics between the impaired and sober drivers.

Driver-related risk factors significantly and positively associated with being impaired from drugs and/or alcohol were included in the further analyses where the associations were tested across different substance groups compared to sober drivers. This was performed by including all individual substance groups and paired interaction terms in the same non-hierarchical multivariable logistic regression model for each individual driver action/condition tested. The interaction terms were excluded from the analyses if they resulted in empty cells. All of the analyses were adjusted for age group and sex by including those variables in the models.

The data set for motorcycle riders was smaller, and thus had less statistical power. The results from the multivariable analyses were therefore verified by an additional test, where impairment from the substance groups were tested one-by-one against sober riders, separately for each unsafe driver action/condition as a dependent variable, with age groups and sex as independent variables.

\subsection{Ethical approval}

Ethical approval was granted by the Regional Committee for Medical and Health Research Ethics, approval no. 2010/2191. Permission to include drivers killed in road traffic crashes was granted by the Higher Prosecution Authority of Norway and the Council for Confidentiality and Research of the Norwegian Ministry of Justice. The Norwegian Registry of Withdrawal from Biological Research Consent and the Registry of Autopsy Material Research Refusal were searched to reveal if any of the drivers/riders killed had not allowed the use of their data for research purposes.

\section{Results}

\subsection{Participants}

From 2005-2015, 602 (63\%) of the 950 fatally injured drivers of cars or vans and $170(63 \%)$ of the 270 fatally injured riders of motorcycles were investigated for drugs and/or alcohol and included in our research database. Among the investigated drivers, 31\% $(n=186)$ were categorised as impaired by drugs and/or alcohol, and $56 \%$ ( $\mathrm{n}=338$ ) were categorised as sober. Among the investigated riders, $20 \%(\mathrm{n}=34)$ were categorised as impaired by drugs and/or alcohol, and $69 \%(\mathrm{n}=118)$ were categorised as sober. The individual substances used by the investigated drivers and riders are given in Table 1 . Characteristics of the investigated drivers and riders are shown in Table 2.

Table 2

Characteristics of crashes and fatally injured drivers and riders.

\begin{tabular}{|c|c|c|c|c|c|}
\hline & \multirow{2}{*}{$\begin{array}{l}\text { Included in the database } \\
(\mathrm{n}=772)^{\mathrm{c}}\end{array}$} & \multicolumn{2}{|c|}{ Car and van drivers $(n=602)$} & \multicolumn{2}{|c|}{ Motorcycle riders $(\mathrm{n}=170)$} \\
\hline & & $\begin{array}{l}\text { Sober } \\
(\mathrm{n}=338)\end{array}$ & $\begin{array}{l}\text { Impaired } \\
(\mathrm{n}=186)\end{array}$ & $\begin{array}{l}\text { Sober } \\
(\mathrm{n}=118)\end{array}$ & $\begin{array}{l}\text { Impaired } \\
(\mathrm{n}=34)\end{array}$ \\
\hline Vehicle 10 years or older & $446(58 \%)$ & $199(59 \%)$ & $143(77 \%)$ & $42(36 \%)$ & $12(35 \%)$ \\
\hline Single-vehicle crashes & $303(39 \%)$ & $79(23 \%)$ & $135(73 \%)$ & $40(34 \%)$ & $24(71 \%)$ \\
\hline \multicolumn{6}{|l|}{ Time of $\operatorname{crash}^{\mathrm{a}}$} \\
\hline Weekday & $465(60 \%)$ & $251(74 \%)$ & $65(35 \%)$ & 75 (64\%) & $11(32 \%)$ \\
\hline Weekend day & $170(22 \%)$ & $63(19 \%)$ & $46(25 \%)$ & $28(24 \%)$ & $10(29 \%)$ \\
\hline Weeknight & $41(5 \%)$ & $9(3 \%)$ & $20(11 \%)$ & $6(5 \%)$ & $2(6 \%)$ \\
\hline Weekend night & $96(12 \%)$ & $15(4 \%)$ & $55(30 \%)$ & $9(8 \%)$ & $11(32 \%)$ \\
\hline \multicolumn{6}{|l|}{ Sex } \\
\hline Male drivers & $633(82 \%)$ & $250(74 \%)$ & $165(89 \%)$ & $108(92 \%)$ & $34(100 \%)$ \\
\hline \multicolumn{6}{|l|}{ Age groups } \\
\hline$<25$ & $206(27 \%)$ & $82(24 \%)$ & $60(32 \%)$ & $29(25 \%)$ & $10(29 \%)$ \\
\hline $25-34$ & $157(20 \%)$ & $58(17 \%)$ & $51(27 \%)$ & $24(20 \%)$ & $10(29 \%)$ \\
\hline $35-44$ & $130(17 \%)$ & $45(13 \%)$ & $41(22 \%)$ & $27(23 \%)$ & $8(24 \%)$ \\
\hline$\geq 45$ & $279(36 \%)$ & $153(45 \%)$ & $34(18 \%)$ & $38(32 \%)$ & $6(18 \%)$ \\
\hline
\end{tabular}

a Day was defined from 4 a.m. to 10 p.m.; night from 10 p.m. to 4 a.m. Weekend was defined as Friday at 10 p.m. to Monday at 4 a.m.

b Information about sex missing for one sober motorcycle rider.

c Among the included drivers and riders, 96 were categorised as neither sober nor impaired. 
The age distributions of impaired versus sober drivers and riders were different (Table 2) as impairment was more common among the youngest age groups. The age distributions varied across different substance groups: the proportions of drivers aged below 25 years were $9 \%$ among those impaired by stimulants, $18 \%$ among those impaired by medicinal drugs, $42 \%$ among those impaired by alcohol, and $43 \%$ among those impaired by cannabis. For motorcycle riders, these numbers were $22 \%, 25 \%, 26 \%$, and $30 \%$, respectively. Impairment was rare among the oldest drivers and riders killed: $19 \%$ of the sober drivers were aged at or above 65 years compared to $3 \%$ of the impaired drivers; $3 \%$ of the sober riders were aged at or above 65 years compared to none of the impaired riders (the highest age observed among the impaired riders was 53 years).

A significantly higher proportion of the impaired than the sober drivers and riders were killed at night: $33 \%$ difference for drivers ( $\mathrm{p}<0.0005) ; 26 \%$ difference for riders $(\mathrm{p}=0.001)$. A significantly higher proportion of the impaired than the sober drivers and riders were fatally injured in single-vehicle crashes: $49 \%$ difference for drivers ( $\mathrm{p}<0.0005$ ); 37\% difference for riders ( $\mathrm{p}<0.0005$ ). Use of older cars, hence cars with less likelihood of having safety installations such as airbags, electronic stability control, and anti-lock braking systems, were more prevalent among the impaired than among the sober drivers (18\% difference, $\mathrm{p}<0.0005)$. No difference in the age of the motorcycle was observed between the sober and impaired riders (Table 2).

\subsection{Prevalence of drugs and alcohol above graded sanction limits}

A total of $92 \%(n=555)$ of the drivers were investigated for both drugs and alcohol; 8\% $(n=47)$ were investigated only for alcohol, of which $23 \%(\mathrm{n}=11)$ had a blood alcohol concentration above $0.5 \mathrm{~g} / \mathrm{kg}$ and were regarded as impaired by alcohol.

Among the drivers investigated for both drugs and alcohol, the prevalence of alcohol impairment was $20 \%(\mathrm{n}=111)$ compared to $16 \%$ ( $n=89$ ) for drugs. Impairment from medicinal drugs was found in $11 \%$ $(n=61)$ of the drivers, impairment from stimulants in $6 \%(n=32)$, and impairment from cannabis in $4 \%(n=23)$. Some of these drivers had combined substances from different substance groups; those exclusively impaired by alcohol or by substances within the drug groups medicinal drugs, stimulants, or cannabis constituted $15 \%(n=86), 4 \%$ $(n=23), 2 \%(n=11)$, and $1 \%(n=7)$ of the drivers, respectively; the prevalence of impairment from only alcohol (15\%) was significantly higher than the prevalence of impairment from only one drug group (7\%), $(\chi 2=15,945, \mathrm{p}<0.0005)$.

A total of $96 \%(n=164)$ of the riders were investigated for both drugs and alcohol; $4 \%(n=6)$ were investigated only for alcohol. Of the latter group, one rider was regarded as impaired by alcohol.

Among the riders investigated for both drugs and alcohol, the prevalence of alcohol impairment was $11 \%(n=18)$ as was the prevalence of impairment from drugs $(11 \%, \mathrm{n}=18)$. Impairment from medicinal drugs was found in $5 \%(n=8)$ of the riders, impairment from stimulants in $5 \%(n=9)$, and impairment from cannabis in $6 \%(n=10)$. Those exclusively impaired by alcohol or by substances within the drug groups medicinal drugs, stimulants, or cannabis constituted $9 \%$ $(n=15), 0.6 \%(n=1), 1 \%(n=2)$, and $2 \%(n=4)$ of the riders, respectively.

\subsection{Driver-related risk factors associated with drug/alcohol impairment}

The frequency of recorded driver-related risk factors evaluated by the multidisciplinary crash investigation teams to have been significant causes of the road traffic crashes or the fatal outcome of the crashes are reported in Table 3. Non-use of a seatbelt and lack of a valid driver license were reported in all cases when present, not only when evaluated by the crash investigation teams to be of significance.

For car and van drivers, not having a valid driver license, speeding, and non-use of a seatbelt were significantly associated with being impaired by drugs and/or alcohol.

If studying only drivers fatally injured in single-vehicle crashes $(n=214), 79$ were categorized as sober and 118 as impaired. The proportions not having a valid driver license among sober and impaired drivers were $4 \%$ and $27 \%$, respectively; these proportions are slightly larger than among the total sample of killed drivers. Similarly, the proportions not using a seatbelt were $44 \%$ and $76 \%$, and speeding $44 \%$ and $76 \%$, among sober and impaired drivers, respectively. Due to lower statistical power, we did not investigate single-vehicle fatalities further.

For motorcycle riders, not having a valid license and non-use of a helmet were significantly associated with being impaired from drugs and/or alcohol, except for non-use of a helmet when adjusting for all of the co-variables listed in Table 2.

\subsection{Prevalence of risk factors across substance groups}

Car/van drivers impaired by drugs only had less often been speeding or not used a seatbelt compared to those impaired by alcohol only, but were more often driving without a valid driver license (Table 4). Cannabis-impaired drivers had most often not a valid driver license.

Not having a valid driver license was more prevalent among all of the substance groups among the motorcycle riders than among the car/ van drivers. Driving without a helmet, however, was less prevalent than driving without a seatbelt (Table 4). Speeding was frequently reported both among impaired and sober riders (prevalence $65 \%$ and $53 \%$, respectively), whereas speeding was half as prevalent among sober (32\%) compared to impaired drivers (prevalence 68\%).

\subsection{Associations between driver-related risk factors and impairment across substance groups}

Among the car/van drivers, not having a valid driver license was significantly associated with impaired driving from all of the substance groups (Table 5). Speeding prior to the crash was significantly associated with impaired driving from alcohol and stimulants, whereas nonuse of a seatbelt was significantly associated with impairment from all of the substance groups except cannabis. Motorcycle riders impaired by alcohol were significantly associated with both not having a valid driver license and non-use of a helmet (Table 5). Riders impaired by stimulants were significantly associated with not having a valid driver license. No other substance groups were significantly associated with the risk factors tested.

As the sample size was not sufficiently large to include interaction terms in the regression model for motorcycle riders, the substance groups were additionally tested one-by-one against sober riders, separately for each recorded unsafe driver action/condition as a dependent variable, with age groups and sex as independent variables. The results obtained for motorcycle riders impaired by alcohol only (excluding other drugs) were similar as those reported in Table 5; impairment from alcohol only was significantly associated with both not having a valid driver license (OR 6.37, 95\% CI 1.68-24.2, p = 0.006) and non-use of a helmet (OR 11.2, 95\% CI 3.12-40.3, p < 0.0005) compared to sober riders. Having a valid driver license among those impaired by stimulants only was however not applicable to testing by this procedure.

\section{Discussion}

The most prevalent substance found among impaired drivers was alcohol. The prevalence of psychoactive drugs was lower and dominated by benzodiazepines, followed by amphetamines and THC. This finding corresponds to the results of European and US studies (Bernhoft et al., 2012; Brady et al., 2014), except that cocaine was not found in this report, and opioids were rare compared to among fatally injured drivers in the US.

We found strong and significant associations between impairment 
Table 3

Frequency of risk factors among car/van drivers and among motorcycle riders, reported separately for sober and impaired drivers/riders. Odds ratios (OR) report associations between impairment from drugs and/or alcohol (as dependent variable) and the individual risk factors.

\begin{tabular}{|c|c|c|c|c|c|c|c|c|}
\hline Risk factors & Sober & Impaired & Crude OR $(95 \% \mathrm{CI})$ & p-value & $\begin{array}{l}\text { Model } 1 \\
\text { Adjusted OR (95\% CI) }\end{array}$ & $\mathrm{p}$-value & $\begin{array}{l}\text { Model } 2 \\
\text { Adjusted OR (95\% CI) }\end{array}$ & $\mathrm{p}$-value \\
\hline Car and van drivers & $\mathrm{n}=\mathbf{3 3 8}$ & $\mathrm{n}=186$ & & & & & & \\
\hline No valid driver license & $4(1 \%)$ & $49(26 \%)$ & $29.9(10.6-84.4)$ & $<0.0005$ & $23.1(8.05-66.0)$ & $<0.0005$ & $18.5(6.03-57.0)$ & $<0.0005$ \\
\hline Non-use of a seatbelt & $103(30 \%)$ & $129(69 \%)$ & $5.16(3.50-7.61)$ & $<0.0005$ & $4.27(2.85-6.41)$ & $<0.0005$ & $2.61(1.64-4.17)$ & $<0.0005$ \\
\hline Speeding & $107(32 \%)$ & $127(68 \%)$ & $4.65(3.16-6.83)$ & $<0.0005$ & $3.97(2.58-6.11)$ & $<0.0005$ & $2.51(1.52-4.12)$ & $<0.0005$ \\
\hline Wrong or missing signal lights & $2(1 \%)$ & $0(0 \%)$ & $\mathrm{n} / \mathrm{a}$ & 0.541 & $\mathrm{n} / \mathrm{a}$ & $\mathrm{n} / \mathrm{a}$ & $\mathrm{n} / \mathrm{a}$ & $\mathrm{n} / \mathrm{a}$ \\
\hline Incorrect position on road ${ }^{\mathrm{a}}$ & $25(7 \%)$ & $4(2 \%)$ & $0.275(0.094-0.803)$ & 0.012 & $0.236(0.079-0.707)$ & 0.010 & $0.289(0.085-0.987)$ & 0.048 \\
\hline Incorrect decisions $\mathrm{s}^{\mathrm{b}}$ & $26(8 \%)$ & $4(2 \%)$ & $0.264(0.091-0.768)$ & 0.009 & $0.248(0.082-0.745)$ & 0.013 & $0.412(0.127-1.33)$ & 0.139 \\
\hline Technical driving errors ${ }^{\mathrm{c}}$ & $17(5 \%)$ & $12(6 \%)$ & $1.30(0.608-2.79)$ & 0.496 & $1.45(0.641-3.28)$ & 0.372 & $0.847(0.302-2.37)$ & 0.751 \\
\hline Inattention $^{\mathrm{d}}$ & $48(14 \%)$ & $17(9 \%)$ & $0.608(0.339-1.09)$ & 0.093 & $0.631(0.341-1.17)$ & 0.141 & $0.910(0.440-1.88)$ & 0.800 \\
\hline Fatigue /drowsy driving & $68(20 \%)$ & $22(12 \%)$ & $0.533(0.317-0.894)$ & 0.016 & $0.654(0.378-1.13)$ & 0.128 & $0.611(0.322-1.16)$ & 0.132 \\
\hline Lack of driving /vehicle experience & $33(10 \%)$ & $17(9 \%)$ & $0.930(0.503-1.72)$ & 0.816 & $0.613(0.315-1.19)$ & 0.149 & $0.478(0.218-1.05)$ & 0.065 \\
\hline Motorcycle riders & $\mathrm{n}=\mathbf{1 1 8}$ & $\mathrm{n}=34$ & & & & & & \\
\hline No valid driver license & $12(10 \%)$ & $21(62 \%)$ & $14.3(5.72-35.6)$ & $<0.0005$ & $17.4(6.05-49.9)$ & $<0.0005$ & $15.2(4.54-50.7)$ & $<0.0005$ \\
\hline Non-use of a helmet & $15(13 \%)$ & $12(35 \%)$ & $3.75(1.54-9.10)$ & 0.002 & $3.67(1.45-9.26)$ & 0.006 & $2.76(0.945-8.07)$ & 0.063 \\
\hline Speeding & $62(53 \%)$ & $22(65 \%)$ & $1.66(0.751-3.65)$ & 0.209 & $1.28(0.544-3.02)$ & 0.570 & $1.07(0.409-2.81)$ & 0.888 \\
\hline Wrong or missing signal lights & $0(0 \%)$ & $0(0 \%)$ & $\mathrm{n} / \mathrm{a}$ & $\mathrm{n} / \mathrm{a}$ & $\mathrm{n} / \mathrm{a}$ & $\mathrm{n} / \mathrm{a}$ & $\mathrm{n} / \mathrm{a}$ & $\mathrm{n} / \mathrm{a}$ \\
\hline Incorrect position on road ${ }^{\mathrm{a}}$ & $12(10 \%)$ & $1(3 \%)$ & $0.268(0.034-2.14)$ & 0.299 & $0.274(0.033-2.29)$ & 0.232 & $0.155(0.016-1.54)$ & 0.111 \\
\hline Incorrect decisions $\mathrm{s}^{\mathrm{b}}$ & $15(13 \%)$ & $3(9 \%)$ & $0.665(0.181-2.45)$ & 0.765 & $0.661(0.172-2.54)$ & 0.547 & $1.01(0.231-4.38)$ & 0.994 \\
\hline Technical driving errors ${ }^{c}$ & $18(15 \%)$ & $5(15 \%)$ & $0.958(0.327-2.80)$ & 0.937 & $0.894(0.297-2.68)$ & 0.841 & $1.02(0.307-3.40)$ & 0.973 \\
\hline Inattention ${ }^{\mathrm{d}}$ & $21(18 \%)$ & $0(0 \%)$ & $\mathrm{n} / \mathrm{a}$ & 0.004 & $\mathrm{n} / \mathrm{a}$ & $\mathrm{n} / \mathrm{a}$ & $\mathrm{n} / \mathrm{a}$ & $\mathrm{n} / \mathrm{a}$ \\
\hline Fatigue /drowsy driving & $2(2 \%)$ & $1(3 \%)$ & $1.76(0.155-20.0)$ & 0.535 & $1.32(0.113-15.3)$ & 0.825 & $0.379(0.027-5.38)$ & 0.474 \\
\hline Lack of driving /vehicle experience & $20(17 \%)$ & $7(21 \%)$ & $1.27(0.486-3.32)$ & 0.625 & $1.33(0.478-3.69)$ & 0.587 & $0.889(0.273-2.89)$ & 0.845 \\
\hline
\end{tabular}

Model 1: Adjusted by age group and sex.

Model 2: Adjusted by age group, sex, time of crash, single-vehicle crashes, and vehicle 10 years or older.

${ }^{a}$ Wrong lane, too close to the vehicle in front, incorrect position for leaving the road, etc.

b The driver adjusted without taking into consideration the consequences of other road users, for example, when trying to pass the front car when there is no clear sight.

c Wrong automatic response, for example, speeding instead of stopping, wrong gear, etc.

${ }^{\mathrm{d}}$ Inattention included failing to gather/see important and easily observable traffic information, use of a mobile phone, or adjusting the media player or radio.

from drugs and/or alcohol and not having a valid driver license, speeding, and non-use of a seatbelt. When divided into substance groups, both alcohol and stimulants were significantly associated with all three risk factors, medicinal drugs with all except speeding, and cannabis was associated with not having a valid driver license. Among the fatally injured motorcycle riders, alcohol impairment was significantly associated with not having a valid driver license and non-use of a helmet.

\subsection{Car/van drivers}

Alcohol impairment was significantly more prevalent than drug impairment, which is in accordance with the findings of other studies. In a study of fatal crashes using the FARS database, Bedard et al. (2007) found a clear relationship between increasing blood alcohol concentration and risky driving behaviour. Also our findings of associations between alcohol or drug impairment and speeding and non-use of a seatbelt comply with findings in other studies. Liu et al. (2016) found

Table 4

Driver-related risk factors associated with impaired driving among fatally injured car and van drivers and motorcycle riders investigated for drug/alcohol use. Impairment is disaggregated into substance groups.

\begin{tabular}{|c|c|c|c|c|}
\hline & No valid driver license & Speeding & Non-use of a seatbelt & Speeding and/or non-use of a seatbelt \\
\hline \multicolumn{5}{|l|}{ Car and van drivers } \\
\hline Sober $(n=338)$ & $4(1 \%)$ & $107(32 \%)$ & $103(30 \%)$ & $176(52 \%)$ \\
\hline Impaired $(n=186)$ & $49(26 \%)$ & $127(68 \%)$ & $129(69 \%)$ & $171(92 \%)$ \\
\hline \multicolumn{5}{|l|}{ Impaired by } \\
\hline Alcohol only $(n=97)$ & $18(19 \%)$ & $77(79 \%)$ & $74(76 \%)$ & $94(97 \%)$ \\
\hline Drugs only $(n=64)$ & $21(33 \%)$ & $31(48 \%)$ & $38(59 \%)$ & $53(83 \%)$ \\
\hline Alcohol $(\mathrm{n}=122)^{\mathrm{a}}$ & $28(23 \%)$ & $96(79 \%)$ & $91(75 \%)$ & $118(97 \%)$ \\
\hline Stimulants $(\mathrm{n}=32)^{\mathrm{a}}$ & $14(44 \%)$ & $19(59 \%)$ & $20(63 \%)$ & $28(88 \%)$ \\
\hline Cannabis $(\mathrm{n}=23)^{\mathrm{a}}$ & $13(57 \%)$ & $17(74 \%)$ & $14(61 \%)$ & $21(91 \%)$ \\
\hline Medicinal drugs $(\mathrm{n}=61)^{\mathrm{a}}$ & $20(33 \%)$ & $28(46 \%)$ & $37(61 \%)$ & $51(84 \%)$ \\
\hline \multicolumn{5}{|l|}{ Motorcycle riders } \\
\hline Sober $(n=118)$ & $12(10 \%)$ & $62(53 \%)$ & $15(13 \%)$ & $69(59 \%)$ \\
\hline Impaired $(n=34)$ & $21(62 \%)$ & $22(65 \%)$ & $12(35 \%)$ & $28(82 \%)$ \\
\hline \multicolumn{5}{|l|}{ Impaired by } \\
\hline Alcohol only $(n=16)$ & $6(38 \%)$ & $9(56 \%)$ & $9(56 \%)$ & $14(88 \%)$ \\
\hline Drugs only $(\mathrm{n}=15)$ & $12(80 \%)$ & $10(67 \%)$ & $2(13 \%)$ & $11(73 \%)$ \\
\hline Alcohol $(\mathrm{n}=19)^{\mathrm{a}}$ & $9(47 \%)$ & $12(63 \%)$ & $10(53 \%)$ & $17(89 \%)$ \\
\hline Stimulants $(\mathrm{n}=9)^{\mathrm{a}}$ & $8(89 \%)$ & $5(56 \%)$ & $2(22 \%)$ & $6(67 \%)$ \\
\hline Cannabis $(\mathrm{n}=10)^{\mathrm{a}}$ & $7(70 \%)$ & $7(70 \%)$ & $1(10 \%)$ & $7(70 \%)$ \\
\hline Medicinal drugs $(\mathrm{n}=8)^{\mathrm{a}}$ & $8(100 \%)$ & $5(63 \%)$ & $1(13 \%)$ & $6(75 \%)$ \\
\hline
\end{tabular}

\footnotetext{
a Including combinations with other drugs and/or alcohol.
} 
Table 5

Associations between driver-related risk factors and impairment from different substance categories compared to sober car/van drivers and motorcycle riders. The associations are presented as odds ratios (OR) adjusted for age, sex, and use of other substance groups. ${ }^{\text {a }}$

\begin{tabular}{|c|c|c|c|c|c|c|}
\hline & \multicolumn{2}{|l|}{ No valid driver license } & \multicolumn{2}{|l|}{ Speeding } & \multicolumn{2}{|l|}{ Non-use of a seatbelt } \\
\hline & Adjusted OR (95\% CI) & $\mathrm{p}$-value & Adjusted OR (95\% CI) & $\mathrm{p}$-value & Adjusted OR (95\% CI) & $\mathrm{p}$-value \\
\hline \multicolumn{7}{|l|}{ Car and van drivers } \\
\hline \multicolumn{7}{|l|}{ Impaired by } \\
\hline Alcohol & $10.4(3.66-29.5)$ & $<0.0005$ & $6.61(3.65-12.0)$ & $<0.0005$ & $5.33(3.14-9.07)$ & $<0.0005$ \\
\hline Stimulants & $15.7(2.54-96.7)$ & 0.003 & $20.0(3.69-108)$ & 0.001 & $4.31(1.20-15.6)$ & 0.026 \\
\hline Cannabis & $37.8(7.08-202)$ & $<0.0005$ & $1.21(0.250-5.83)$ & 0.815 & $0.978(0.220-4.35)$ & 0.977 \\
\hline Medicinal drugs & $9.47(1.93-46.5)$ & 0.006 & $1.32(0.491-3.53)$ & 0.584 & $3.74(1.59-8.81)$ & 0.002 \\
\hline \multicolumn{7}{|l|}{ Interaction terms } \\
\hline Alcohol by cannabis & & 0.037 & & 0.807 & & 0.932 \\
\hline Alcohol by stimulants & & 0.987 & & 0.140 & & 0.555 \\
\hline Alcohol by medicinal drugs & & 0.140 & & 0.283 & & 0.028 \\
\hline Stimulants by cannabis & & - & & 0.437 & & - \\
\hline Cannabis by medicinal drugs & & 0.278 & & 0.180 & & 0.999 \\
\hline Stimulants by medicinal drugs & & 0.482 & & 0.005 & & 0.027 \\
\hline \multicolumn{7}{|l|}{ Motorcycle riders } \\
\hline \multicolumn{7}{|l|}{ Impaired by } \\
\hline Alcohol & $7.01(1.88-26.2)$ & 0.004 & $0.895(0.304-2.64)$ & 0.841 & $12.6(3.63-43.6)$ & $<0.0005$ \\
\hline Stimulants & $15.1(1.08-212)$ & 0.044 & $0.466(0.070-3.12)$ & 0.431 & $7.26(0.646-81.6)$ & 0.108 \\
\hline Cannabis & $5.84(0.843-40.4)$ & 0.074 & $2.47(0.518-11.8)$ & 0.256 & $0.196(0.018-2.14)$ & 0.181 \\
\hline Medicinal drugs & $\mathrm{n} / \mathrm{a}$ & $\mathrm{n} / \mathrm{a}$ & $1.81(0.235-14.0)$ & 0.569 & $0.216(0.013-3.71)$ & 0.291 \\
\hline
\end{tabular}

$\mathrm{n} / \mathrm{a}=$ no resulting values obtained, but the variable remains included in the analysis.

"_" = not included in the analysis.

a Analysis was conducted separately for each recorded unsafe driver action/condition as a dependent variable using the substance groups, age groups, and sex as independent variables. As interaction terms, two-drug combinations were included in the analyses if not resulting in empty cells. For motorcycle riders, no interaction terms were used due to limited statistical power.

that speeding violations were significantly higher for drivers who tested positive for stimulants, alcohol, and/or cannabinoids compared to drivers with no drug or alcohol detected; speeding violations among those testing positive for medicinal drugs were not significantly different from the sober drivers. Romano and Voas (2011) used a similar multivariable regression model as the one presented in our study and found that speeding was associated with the same substance classes as in our study: stimulants and alcohol. In a study of drivers killed in road traffic crashes in Finland during 2006-2008, a higher frequency of crashes related to speed over $120 \mathrm{~km} / \mathrm{h}$ was reported among drivers testing positive for alcohol $(31 \%)$ or drugs $(23 \%)$ than among sober drivers (10\%) (Karjalainen et al., 2012). In our study, the same tendency was observed, although with a much higher prevalence, as we reported speeding as driving above the speed limit or inappropriately according the road/driving conditions. Bedard et al. (2007) also found that drivers who tested positive for cannabis had more often been speeding, and been erratic, reckless, careless or negligent while operating the vehicle. We did not find a similar association for use of cannabis in our study.

Liu et al. (2016) found increased odds ratios of non-use of a seatbelt among those testing positive for alcohol, stimulants, and medicinal drugs, which were within the confidence intervals of our odds ratios for the same associations. Romano and Voas (2011) reported that non-use of a seatbelt was associated with cannabinoids in addition to the substance classes found in our study. Also Beasley et al. (2011) found in a Canadian study that the use of a seatbelt was significantly lower in crashes where the driver tested positive for drugs. This was also the case in a US roadside survey, where the prevalence of drugs was significantly higher in drivers who did not wear a seatbelt (Lacey et al., 2009).

Lack of a driving license does not directly affect the outcome of a crash, but might indicate that the driver is unskilled or not motivated to drive safely. An investigation of fatalities and traffic offences in Western Australia found that those driving/riding without a valid license were approximately 3.5 times more likely to test positive for an illicit substance (Palamara et al., 2014). In our study, lack of a valid driver license was associated with impaired driving within all of the substance groups tested. This extensive association between lack of a driver license and impaired driving could possibly be explained by a high recidivism rate among drugged and drunk drivers, even after their driver license has been suspended (Christophersen et al., 2002; National Mobile Police Service, 2009).

In contrast to cannabis and stimulants, the psychoactive medicinal drugs included in this study are per definition legal in use among drivers if used according to prescription doses administered by general practitioners and if no driving restriction has been given. The concentrations found in this study indicate, however, that higher doses than those prescribed were used. The drivers might also have obtained the medicinal drugs from other illegal sources; that $62 \%$ had combined medicinal drugs with illegal drugs or alcohol further support this theory. Lack of compliance with other safety rules among those drivers might be more common than among drivers using the same drugs according to prescriptions. The medicinal drugs most frequently detected were clonazepam, diazepam, and zopiclone, which are drugs that might reduce alertness. The associations found among fatally injured drivers between impairment from medicinal drugs and not having a valid driver license and non-use of a seatbelt might therefore be confounded by high-risk personality traits, not necessarily indicating that the medicinal drugs caused risk-taking behaviour.

In our study, $91 \%$ of the cannabis-impaired drivers had been speeding and/or not used a seatbelt prior to the crash. However, cannabis impairment was not significantly associated with risky driving actions such as speeding or non-use of a seatbelt when adjusting for age, sex, and the use of other drug groups. The explanation might be that young age was a confounder associated with both cannabis use and risk-taking behaviour. From previous studies, we know that the majority of the arrested cannabis-using drivers in Norway are of young age (Valen et al., 2017a,b), which in itself is likely associated with speeding and non-use of a seatbelt due to higher risk-taking behaviour among young adults (Steinberg, 2010), especially when driving with peers (Scott-Parker and Weston, 2017). Adjustment for age and sex in this study resulted in a more accurate assessment of the effect of cannabis impairment on risky driver actions. However, a high prevalence of speeding and non-use of a seatbelt combined with a reduced reaction time due to impairment from cannabis among young drivers may be a 
problem for traffic safety, regardless of the age of these drivers and the lack of a direct association between cannabis and unsafe driving behaviours.

\subsection{Motorcycle riders}

Lack of a significant association between risk factors and impairment from drugs other than alcohol among motorcycle riders in this study might be due to the low sample size. However, the association found in this study between alcohol impairment and non-use of a helmet or not having a valid motorcycle driving license was in accordance with results reported in other countries. Among fatally injured motorcycle riders in the US, increased odds of not wearing a helmet were individually associated with use of alcohol, cannabis, or other drugs (Rossheim et al., 2014). Brown et al. (2011) found that a higher blood alcohol level was associated with a decreasing incidence of wearing a helmet among injured motorcycle riders sent to trauma centres in Texas.

Not having a valid license to operate a motorcycle was previously found to be more prevalent among crash-involved motorcycle riders than among non-crash-involved riders (Kraus et al., 1991) and was associated with being fully or partly responsible for a road traffic crash (Moskal et al., 2012). Riding under the influence of alcohol was also associated with being responsible for a road traffic crash, but the association between alcohol impairment and not having a valid license was not tested (Lardelli-Claret et al., 2005; Moskal et al., 2012). No association between not having a valid license and testing positive for alcohol or drugs was found among fatally injured riders in Ohio (Connor, 2014), contradicting our results.

When comparing fatally injured motorcycle riders with car/van drivers, our results showed that a higher proportion of the investigated fatally injured car/van drivers were categorised as impaired (31\%) compared to the investigated motorcycle riders (20\%). Furthermore, a higher proportion of both sober and impaired drivers had not used seatbelt or were tired compared to the proportion of riders without a helmet or who were tired. This difference between drivers and riders might be explained by the higher risk of injuries for motorcycle riders when involved in a crash than for car drivers. More mistakes might be necessary for a car driver to be fatally injured in a crash and hence included in this study. However, a higher proportion of both sober and impaired riders had no valid driver license, and a substantially higher proportion of the sober riders had been speeding prior to the crash compared to the sober drivers. Riding a motorcycle when impaired from drugs and/or alcohol was in our study not significantly associated with speeding, as speeding was approximately equally frequently recorded among the fatally injured sober riders.

\subsection{Strengths and limitations}

This study has some important strengths but also some limitations. The main strengths are that fatally injured drivers who were investigated for use of drugs were analysed for the same types of substances using accredited sensitive and specific analytical methods, only drug findings in blood samples were used, the same cutoff concentrations were systematically used, and there was no limitation in the number of substances reported. For those reasons, our toxicological test results are better suitable for this type of study than those using data from fatality databases with poorer quality of toxicology data.

A possible limitation of this study is that only approximately $70 \%$ of the fatally injured drivers and riders were investigated for drugs. Results from the Department of Clinical Pharmacology in Trondheim were available only for 2011-2015, and in this period represented $11 \%$ of the total number of investigated drivers and riders.

The associations between impairment from drugs and/or alcohol and unsafe driving behaviours observed in this study cannot necessarily be generalised to drivers in general, as only fatally injured drivers were included.

We cannot exclude that a few drivers/riders might have used substances not tested for in this study that may have affected their ability to drive safely.

In post-mortem samples, drug and alcohol concentrations might not necessary reflect concentrations at the time of incidence due to postmortem changes, such as redistribution, metabolism, degradation, and formation, among others (Pelissier-Alicot et al., 2003; Drummer, 2004).

Accurate information regarding driver-related risk factors in fatal crashes might be difficult to obtain, especially variables such as inattention and fatigue/drowsy driving. Some data recorded in the Crash Investigation Team Database were therefore based on best judgement if obtaining accurate documentation was impossible.

Data on potentially significant confounders, such as risk-taking behaviour or impulsivity, were not available for this study.

Conclusions from the crash investigation teams regarding crash culpability were not available for multiple vehicle crashes. If including only culpable drivers, it is likely that less marked differences between impaired and sober drivers may have been observed for some risk factors. Culpable drivers have been investigated in several previous studies, with the advantage that probably more equal groups of drivers were compared; hence, better isolating the effect of drugs/alcohol on driving behaviour. Our results do, however, better represent the differences between the whole population of sober and impaired drivers who get fatally injured in road traffic crashes.

With a higher number of studied drivers and riders, more detailed information about the association between individual substance types and risky driving behaviour may be obtained.

\section{Conclusions}

Drug/alcohol impairment among car/van drivers was significantly associated with not having a valid driver license, speeding, and non-use of a seatbelt; among motorcycle/moped riders, significant associations were found for not having a valid driver license and non-use of a helmet. At least one of these risk factors was also reported in a substantial proportion of the sober drivers and riders. Actions to reduce the impact of speeding on road traffic safety may therefore also reduce the number of fatal crashes related to alcohol or drug impairment, and use of seatbelt alarms may reduce the injury severity among crash-involved drivers. Also, better enforcement of speed limits and legislation regarding use of protective devices may reduce the number of road traffic crashes. Further investigation is needed to understand the contribution of risk-taking personality on both drug/alcohol-impaired driving and other risky driving behaviours.

\section{Funding}

This study was supported by Oslo University Hospital and St. Olav University Hospital. This study did not receive external funding.

\section{Acknowledgements}

Thanks to Terje Hammer for extracting data from the Forensic Toxicology Database at Oslo University Hospital, thanks to the Department of Clinical Pharmacology at St. Olav University Hospital for providing toxicology data from the middle region of Norway, and thanks to Arild Engebretsen, who is responsible for the Crash Investigation Team Database operated by the Norwegian Public Roads Administration.

\section{References}

Adminaite, D., Jost, G., Stipdonk, H., Ward, H., 2018. An Overview of Road Death Data Collection in the EU - PIN Flash Report 35. European Transport Safety Council, Brussels, Belgium. Available at: https://etsc.eu/an-overview-of-road-death-data- 
collection-in-the-eu-pin-flash-35/. (Accessed 10 March 2019).

Baselt, R.C., 2011. Disposition of Toxic Drugs and Chemicals in Man, 9th ed. Biomedical Publications, Seal Beach, CA.

Beasley, E.E., Beirness, D.J., Porath-Waller, A.J., 2011. A Comparison of Drug and Alcohol Involved Motor Vehicle Driver Fatalities. Canadian Centre on Substance Abuse, Ottawa, Ontario, Canada. Available at: https://ccsa.ca/comparison-drug-andalcohol-involved-motor-vehicle-driver-fatalities. (Accessed 17 June 2019).

Bedard, M., Dubois, S., Weaver, B., 2007. The impact of cannabis on driving. Can. J. Public Health 98 (1), 6-11.

Bernhoft, I.M., Hels, T., Lyckegaard, A., Houwing, S., Verstraete, A.G., 2012. Prevalence and risk of injury in Europe by driving with alcohol, illicit drugs and medicines. Proc - Soc. Behav. Sci. 48, 2907-2916.

Berning, A., Smither, D.D., 2014. Understanding the Limitations of Drug Test Information, Reporting, and Testing Practices in Fatal Crashes (Research Note DOT HS 812 072). National Highway Traffic Safety Administration, Washington, DC (Accessed 9 April 2019). https://crashstats.nhtsa.dot.gov/Api/Public/ViewPublication/812072.

Bogstrand, S.T., Larsson, M., Holtan, A., Staff, T., Vindenes, V., Gjerde, H., 2015. Associations between driving under the influence of alcohol or drugs, speeding and seatbelt use among fatally injured car drivers in Norway. Accid. Anal. Prev. 78 14-19.

Brady, J.E., Li, G., 2014. Trends in alcohol and other drugs detected in fatally injured drivers in the United States, 1999-2010. Am. J. Epidemiol. 179 (6), 692-699.

Brown, C.V., Hejl, K., Bui, E., Tips, G., Coopwood, B., 2011. Risk factors for riding and crashing a motorcycle unhelmeted. J. Emerg. Med. 41 (4), 441-446.

Busardo, F.P., Pichini, S., Pellegrini, M., Montana, A., Lo Faro, A.F., Zaami, S., Graziano, S., 2018. Correlation between blood and oral fluid psychoactive drug concentrations and cognitive impairment in driving under the influence of drugs. Curr. Neuropharmacol. 16 (1), 84-96.

Christophersen, A.S., Skurtveit, S., Grung, M., Mørland, J., 2002. Rearrest rates among Norwegian drunken drugged drivers compared with drivers. J. Alcohol. Drug Depend. 66 (1), 85-92.

Compton, R., 2017. Marijuana-Impaired Driving - a Report to Congress. (DOT HS 812 440). National Highway Traffic Safety Administration, Washington, DC (Accessed 30 April 2019). https://www.nhtsa.gov/sites/nhtsa.dot.gov/files/documents/812440marijuana-impaired-driving-report-to-congress.pdf.

Compton, R.P., Berning, A., 2015. Drug and Alcohol Crash Risk (Research Note DOT HS 812 117). National Highway Safety Administration, Washington, DC (Accessed 9 April 2019). http://www.nhtsa.gov/staticfiles/nti/pdf/812117-Drug_and_Alcohol Crash_Risk.pdf.

Connor, S.M., 2014. Involvement of unendorsed motorcycle operators in fatal crashes in Cuyahoga county, Ohio, 2005-2011. Traffic Inj. Prev. 15 (5), 508-512.

Drummer, O.H., 2004. Postmortem toxicology of drugs of abuse. Forensic Sci. Int. 142 (2-3), 101-113.

Gjerde, H., Strand, M.C., Mørland, J., 2015. Driving under the influence of non-alcohol drugs-an update part i: epidemiological studies. Forensic Sci. Rev. 27 (2), 89-113.

Grimstad, V., Engebretsen, A., 2016. Dybdeanalyser av dødsulykker i vegtrafikken 2015 [In-Depth Analyses of Fatal Road Accidents in The Year 2015]. Norwegian Public Roads Administration, Oslo, Norway.

Hartman, R.L., Huestis, M.A., 2013. Cannabis effects on driving skills. Clin. Chem. 59 (3), 478-492.

Karjalainen, K., Blencowe, T., Lillsunde, P., 2012. Substance use and social, health and safety-related factors among fatally injured drivers. Accid. Anal. Prev. 45, 731-736.

Kraus, J.F., Anderson, C., Zador, P., Williams, A., Arzemanian, S., Li, W.C., Salatka, M., 1991. Motorcycle licensure, ownership, and injury crash involvement. Am. J. Public Health 81 (2), 172-176.

Lacey, J.H., Kelley-Baker, T., Furr-Holden, D., Voas, R.B., Romano, E., Ramirez, A., Brainard, K., Moore, C., Torres, P., Berning, A., 2009. 2007 National Roadside Survey of Alcohol and Drug Use by Drivers - Drug Results (DOT HS 811 249). National Highway Safety Administration, Washington, DC. Available at: www.nhtsa.gov/ DOT/NHTSA/Traffic\%20Injury\%20Control/Articles/Associated\%20Files/811249. pdf, (Accessed 17 June 2019).

Lardelli-Claret, P., Jimenez-Moleon, J.J., De Dios Luna-Del-Castillo, J., Garcia-Martin, M., Bueno-Cavanillas, A., Galvez-Vargas, R., 2005. Driver dependent factors and the risk of causing a collision for two wheeled motor vehicles. Inj. Prev. 11 (4), 225-231.

Laude, J.R., Fillmore, M.T., 2015. Simulated driving performance under alcohol: effects on driver-risk versus driver-skill. Drug Alcohol Depend. 154, 271-277.

Liu, C., Huang, Y., Pressley, J.C., 2016. Restraint use and risky driving behaviors across drug types and drug and alcohol combinations for drivers involved in a fatal motor vehicle collision on U.S. Roadways. Inj. Epidemiol. 3 (1), 9.

Martin, T.L., Solbeck, P.A., Mayers, D.J., Langille, R.M., Buczek, Y., Pelletier, M.R., 2013. A review of alcohol-impaired driving: the role of blood alcohol concentration and complexity of the driving task. J. Forensic Sci. 58 (5), 1238-1250.

Ministry of Transport and Communications, 2016. Forskrift om endring i forskrift om faste grenser for påvirkning av andre berusende eller bedøvende middel enn alkohol m.m. (forskrift om faste grenser) [Revision of Fixed Limits for Drugs in The Traffic]. Ministry of Transport and Communications, Oslo, Norway (Accessed 30 April 2019). https://lovdata.no/dokument/LTI/forskrift/2016-01-12-19.

Moskal, A., Martin, J.-L., Laumon, B., 2012. Risk factors for injury accidents among moped and motorcycle riders. Accid. Anal. Prev. 49, 5-11.

National Mobile Police Service, 2009. Hvem fortjener politiets oppmerksomhet? En studie av dødsulykkene i trafikken i 2004 og 2005 [Who Deserves Police Attention? A Study of Fatal Road Traffic Accidents in 2004 and 2005]. National Mobile Police Service, Stavern, Norway.

Palamara, P., Broughton, M., Chambers, F., 2014. Illicit Drugs and Driving: An Investigation of Fatalities and Traffic Offences in Western Australia, Report No. R 13-001. Curtin-Monash Accident Research Centre, Bentley, Australia (Accessed 30 April 2019). http://c-marc.curtin.edu.au/local/docs/final-drugs-and-drivingnovember-2014_upload.pdf.

Pelissier-Alicot, A.L., Gaulier, J.M., Champsaur, P., Marquet, P., 2003. Mechanisms underlying postmortem redistribution of drugs: a review. J. Anal. Toxicol. 27 (8), 533-544.

Pietrasik, T., 2018. Road Traffic Injuries. World Health Organization, Geneva Switzerland (Accessed 30 April 2019). https://www.who.int/news-room/fact-sheets/detail/ road-traffic-injuries.

Romano, E., Torres-Saavedra, P., Voas, R.B., Lacey, J.H., 2017. Marijuana and the risk of fatal car crashes: what can we learn from FARS and NRS data? J. Prim. Prev. 38, 315-328.

Romano, E., Voas, R.B., 2011. Drug and alcohol involvement in four types of fatal crashes. J. Stud. Alcohol Drugs 72 (4), 567-576.

Rossheim, M.E., Wilson, F., Suzuki, S., Rodriguez, M., Walters, S., Thombs, D.L., 2014. Associations between drug use and motorcycle helmet use in fatal crashes. Traffic Inj. Prev. 15 (7), 678-684.

Sagberg, F., 2018. Characteristics of fatal road crashes involving unlicensed drivers or riders: implications for countermeasures. Accid. Anal. Prev. 117, 270-275.

Schulz, M., Iwersen-Bergmann, S., Andresen, H., Schmoldt, A., 2012. Therapeutic and toxic blood concentrations of nearly 1,000 drugs and other xenobiotics. Crit. Care 16 (4), R136.

Schweitzer, J.B., Holcomb, H.H., 2002. Drugs under investigation for attention-deficit hyperactivity disorder. Curr. Opin. Invest. Drugs 3 (8), 1207-1211.

Scott-Parker, B., Weston, L., 2017. Sensitivity to reward and risky driving, risky decision making, and risky health behaviour: a literature review. Transp. Res. Part F Traffic Psychol. Behav. 49, 93-109.

Steinberg, L., 2010. A dual systems model of adolescent risk-taking. Dev. Psychobiol. 52 (3), 216-224

Strand, M.C., Fjeld, B., Arnestad, M., Mørland, J., 2011. Psychomotor Relevant Performance: 1. After Single Dose Administration of Opioids, Narcoanalgesics and Hallucinogens to Drug Naïve Subjects 2. In Patients Treated Chronically with Morphine or methadone/buprenorphine. Norwegian Institute of Public Health, Oslo, Norway (Accessed 30 April 2019). https://www.bast.de/Druid/EN/deliverales-list/ downloads/Deliverable 1 1 _ 2 C.pdf.

Strand, M.C., Gjerde, H., Mørland, J., 2016. Driving under the influence of non-alcohol drugs-an update. Part ii: experimental studies. Forensic Sci. Rev. 28 (2), 79-101.

The Pharmacology Portal, 2018. Farmakologiportalen - norsk portal for legemiddel- og rusmiddelanalyser [The Pharmacology Portal - Norwegian Portal for Drug Analyses]. The Norwegian Association of Clinical Pharmacology, Oslo, Norway (Accessed 30 April 2019). http://www.farmakologiportalen.no/content/3729/Information-inEnglish.

Valen, A., Bogstrand, S.T., Vindenes, V., Gjerde, H., 2017a. Increasing use of cannabis among arrested drivers in Norway. Traffic Inj. Prev. 18 (8), 801-806.

Valen, A., Bogstrand, S.T., Vindenes, V., Gjerde, H., 2017b. Toxicological findings in suspected drug-impaired drivers in Norway - trends during 1990-2015. Forensic Sci. Int. $280,15-24$.

Valen, A., Bogstrand, S.T., Vindenes, V., Frost, J., Larsson, M., Holtan, A., Gjerde, H., 2019. Fatally injured drivers in Norway $2005-2015$ - trends in substance use and crash characteristics. Traffic Inj. Prev. 20 (5), 460-466. https://doi.org/10.1080/ 15389588.2019.1616700.

Verstraete, A.G., Legrand, S.A., Vandam, L., Hughes, B., Griffiths, B., 2014. Drug Use, Impaired Driving, and Traffic Accidents, Second edition. Publications Office of the European Union, Luxembourg (Accessed 30 April 2019). http://www.emcdda. europa.eu/publications/insights/2014/drugs-and-driving.

Vindenes, V., Jordbru, D., Knapskog, A.B., Kvan, E., Mathisrud, G., Slørdal, L., Mørland, J., 2012. Impairment based legislative limits for driving under the influence of nonalcohol drugs in Norway. Forensic Sci. Int. 219 (1-3), 1-11.

Wu, D., Hours, M., Martin, J.L., 2018. Risk factors for motorcycle loss-of-control crashes. Traffic Inj. Prev. 19 (4), 433-439. 




\section{Errata}

The cut-off concentration for alcohol presented in Table 1 in Paper I and in Table 1 in Paper II is incorrect; the used cut-off was $0.04 \mathrm{~g} / \mathrm{kg}$. In Paper II a sentence under the heading "Variables" should have been more precise: "Findings of drugs were considered ..." should have been written instead of "Findings were considered ...".

Paper III: The heading of the third column of Table 4 should read "Non-use of a seatbelt/helmet"; the heading of the forth column should read "Speeding and/or nonuse of a seatbelt/helmet". The heading of the fifth column of Table 5 should read " Non-use of a seatbelt/helmet"

Paper III: The number of investigated drivers fatally injured in single-vehicle crashes were 214 if only considering the sober and impaired drivers, but if including those with low substance concentrations the number is 235.235 should preferably have been used in chapter 3.3, third section, as a description of the total number. The number of impaired drivers given in the same section should have been 135 and not 118 . 